Naval Surface Warfare Center

Carderock Division

West Bethesda, MD 20817-5700

NSWCCD-80-2014/030

August 2014

Naval Architecture and Engineering Department

Technical Report

\title{
Unmanned Three-Environment Vehicle (U3V)
}

by

Mark Lewis and Matthew Pickering

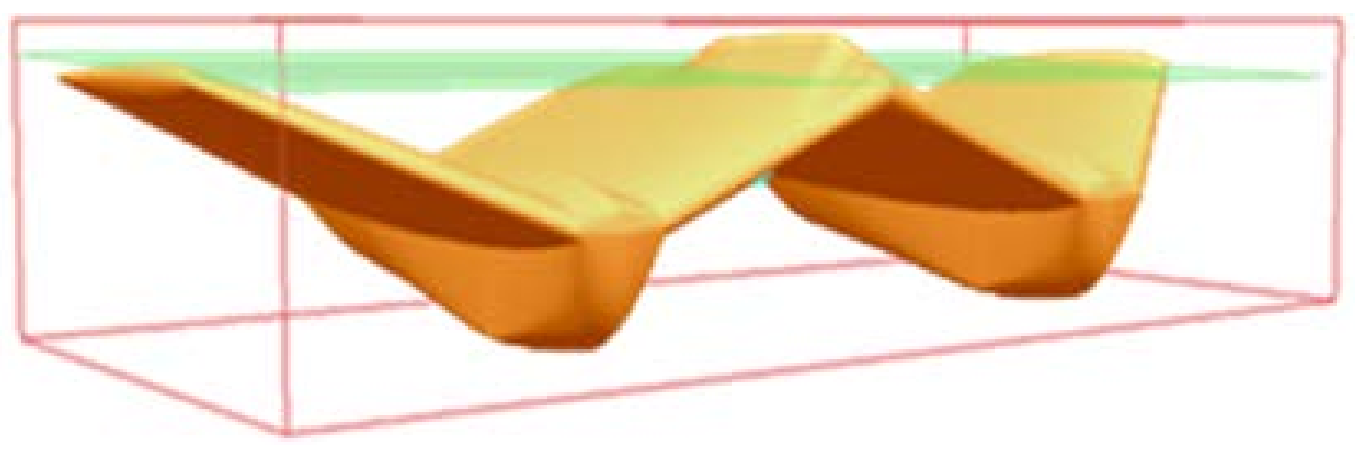





\begin{tabular}{|c|c|c|c|c|c|}
\hline \multicolumn{5}{|c|}{ REPORT DOCUMENTATION PAGE } & $\begin{array}{c}\text { Form Approved } \\
\text { OMB No. 0704-0188 }\end{array}$ \\
\hline \multicolumn{6}{|c|}{ 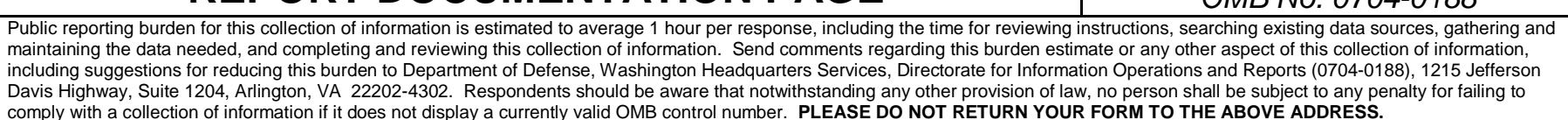 } \\
\hline \multicolumn{2}{|c|}{$\begin{array}{l}\text { 1. REPORT DATE (DD-MM-YYYY) } \\
\text { 29-Aug-2014 }\end{array}$} & \multicolumn{3}{|c|}{$\begin{array}{l}\text { play a currently valid OMB control number. PLEASE DO NOT RETURN YOUR F } \\
\text { 2. REPORT TYPE } \\
\text { Final }\end{array}$} & $\begin{array}{l}\text { 3. DATES COVERED (From - To) } \\
\text { 1-Jan-2012 - 30-Aug-12 }\end{array}$ \\
\hline \multirow{3}{*}{\multicolumn{5}{|c|}{$\begin{array}{l}\text { 4. TITLE AND SUBTITLE } \\
\text { Unmanned Three-Environment Vehicle (U3V) }\end{array}$}} & 5a. CONTRACT NUMBER \\
\hline & & & & & 5b. GRANT NUMBER \\
\hline & & & & & \begin{tabular}{|l|} 
5c. PROGRAM ELEMENT NUMBER \\
\end{tabular} \\
\hline \multirow{3}{*}{\multicolumn{5}{|c|}{$\begin{array}{l}\text { 6. AUTHOR(S) } \\
\text { Mark Lewis and Matthew Pickering }\end{array}$}} & 5d. PROJECT NUMBER \\
\hline & & & & & 5e. TASK NUMBER \\
\hline & & & & & 5f. WORK UNIT NUMBER \\
\hline \multicolumn{5}{|c|}{$\begin{array}{l}\text { 7. PERFORMING ORGANIZATION NAME(S) AND ADDRESS(ES) AND ADDRESS(ES) } \\
\text { NAVAL SURFACE WARFARE CENTER } \\
\text { CARDEROCK DIVISION } \\
\text { CARDEROCK DIVISION (CODE 8202) } \\
\text { 9500 MACARTHUR BOULEVARD } \\
\text { WEST BETHESDA, MD 20817-5700 }\end{array}$} & NSWCCD-80-2014/030 \\
\hline \multirow{2}{*}{\multicolumn{5}{|c|}{$\begin{array}{l}\text { 9. SPONSORING I MONITORING AGENCY NAME(S) AND ADDRI } \\
\text { CHIEF OF NAVAL RESEARCH } \\
\text { ONE LIBERTY CENTER } \\
\text { 875 NORTH RANDOLPH STREET, SUITE } 1425 \\
\text { ARLINGTON, VA 22203-1995 }\end{array}$}} & 10. SPONSOR/MONITOR'S ACRONYM(S) \\
\hline & & & & & $\begin{array}{l}\text { 11. SPONSOR/MONITOR'S REPORT } \\
\text { NUMBER(S) }\end{array}$ \\
\hline \multicolumn{6}{|c|}{$\begin{array}{l}\text { 12. DISTRIBUTION / AVAILABILITY STATEMENT } \\
\text { Approved for public release; distribution is unlimited. }\end{array}$} \\
\hline \multicolumn{6}{|c|}{ 13. SUPPLEMENTARY NOTES } \\
\hline \multicolumn{6}{|c|}{$\begin{array}{l}\text { 14. ABSTRACT } \\
\text { Design of an unmanned autonomous vehicle capable of operating in air, on the surface, and underwater was } \\
\text { explored to assess technical and technological issues required by such a vehicle. A goal of the vehicle was } \\
\text { a footprint comparable to an } 11 \mathrm{~m} \text { Rigid Hull Inflatable Boat (RHIB) to facilitate shipboard compatibility. } \\
\text { Characteristics of the design are gross weight less than } 8 \text { tonne, wing span of } 11 \mathrm{~m} \text {, length of } 5 \mathrm{~m} \text {, and height } \\
\text { of } 2.4 \mathrm{~m} \text {. Airborne cruise speed is estimated to be over } 100 \text { knots. Maximum submergence depth is } 50 \mathrm{~m} \text {. } \\
\text { A major objective of the project was to explore the complex design issues associated with a vehicle that } \\
\text { operates in the three fluid domains and document the design process used. }\end{array}$} \\
\hline \multicolumn{6}{|l|}{ 15. SUBJECT TERMS } \\
\hline \multicolumn{3}{|c|}{ 16. SECURITY CLASSIFICATION OF: } & \multirow{2}{*}{$\begin{array}{l}\text { 17. LIMITATION } \\
\text { OF ABSTRACT } \\
\text { SAR }\end{array}$} & \multirow{2}{*}{$\begin{array}{l}\text { 18. NO. OF } \\
\text { PAGES } \\
\quad 98\end{array}$} & $\begin{array}{l}\text { 19a. RESPONSIBLE PERSON } \\
\text { Colen Kennell }\end{array}$ \\
\hline $\begin{array}{l}\text { a. REPORT } \\
\text { UNCLASSIFIED }\end{array}$ & $\begin{array}{l}\text { b. ABSTRACT } \\
\text { UNCLASSIFIED }\end{array}$ & $\begin{array}{l}\text { c. THIS PAGE } \\
\text { UNCLASSIFIED }\end{array}$ & & & $\begin{array}{l}\text { 19b. TELEPHONE NUMBER } \\
\text { 301-227-5468 }\end{array}$ \\
\hline
\end{tabular}


14. ABSTRACT (continued) 


\section{Contents}

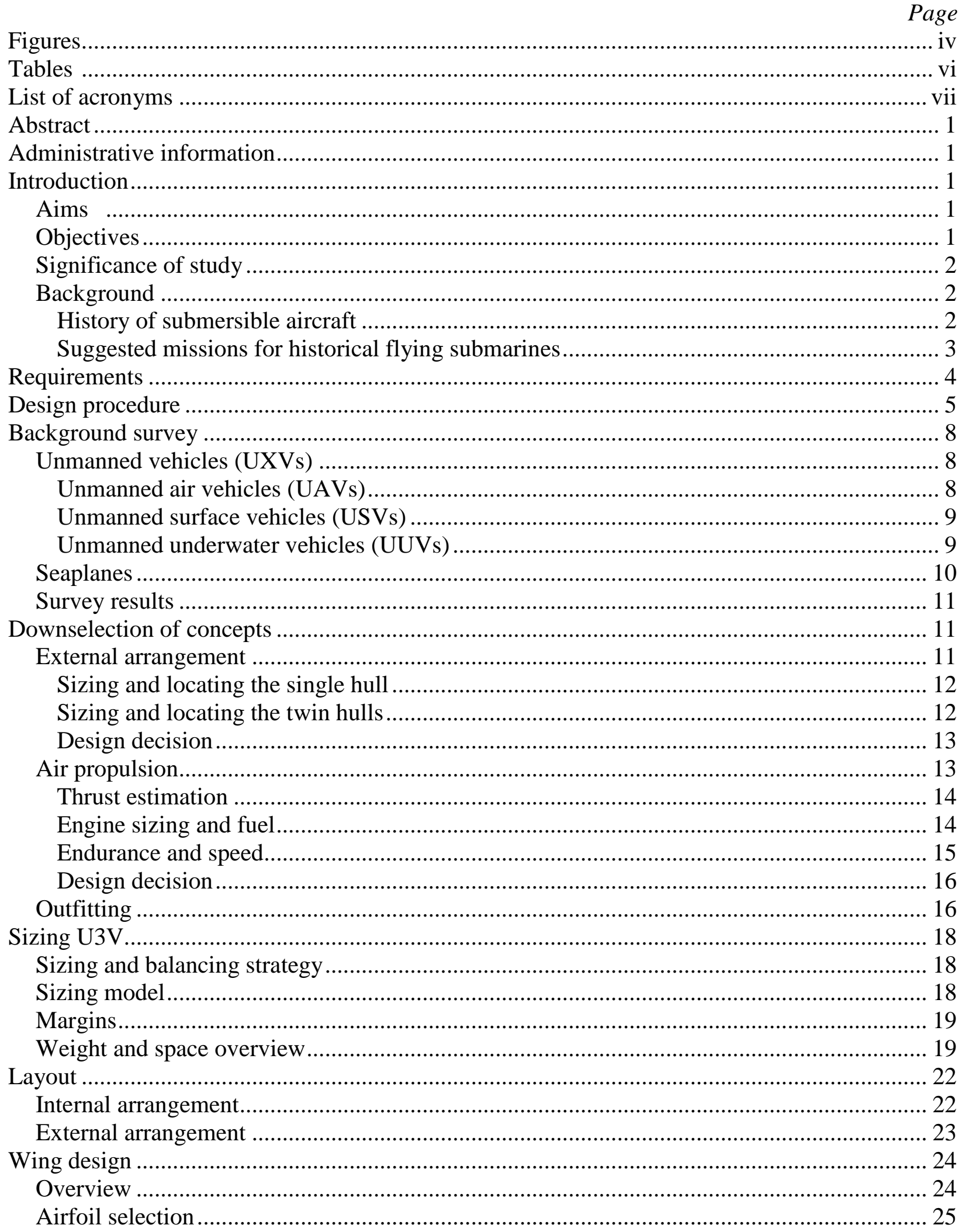




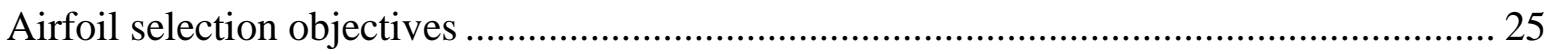

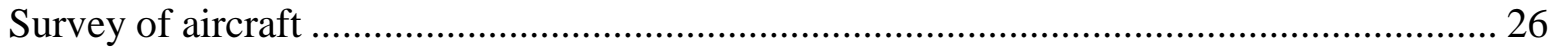

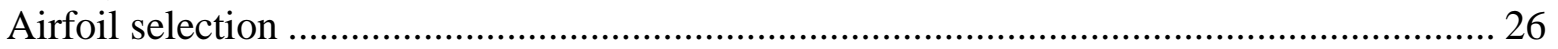

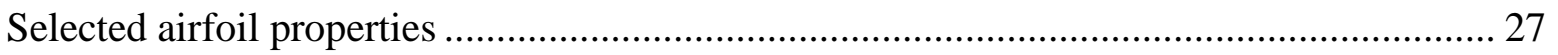

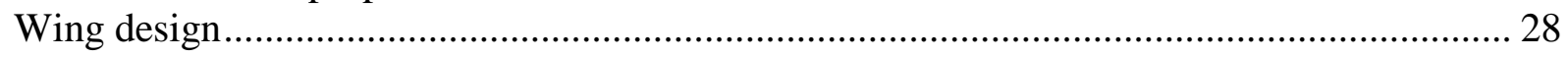

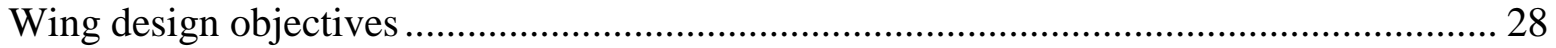

Wing design tool - TORNADO ................................................................................. 28

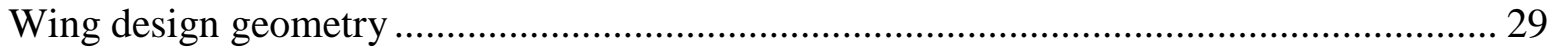

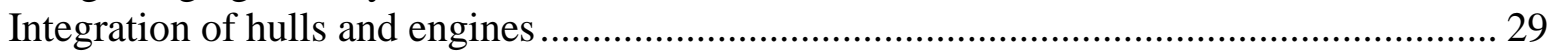

Relative partition size ……………………………………............................................ 31

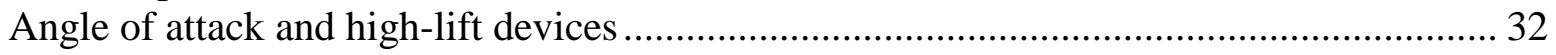

Wing geometry summary .................................................................................................. 32

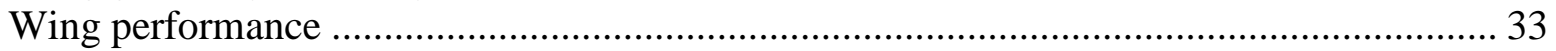

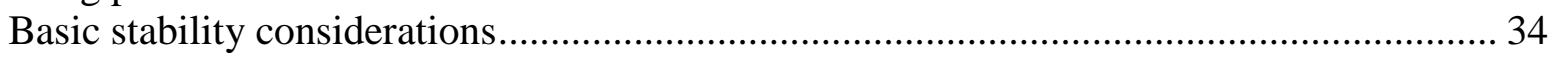

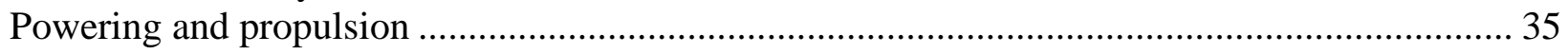

Air power and propulsion................................................................................................. 35

Submerged power and propulsion..................................................................................... 36

Submerged resistance..................................................................................................... 36

Submerged shaft power requirement ...................................................................................... 37

Hotel load requirement .................................................................................................. 38

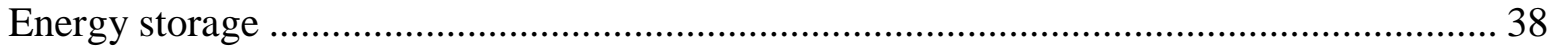

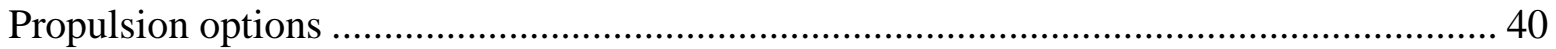

Motor and propulsion selection ................................................................................. 42

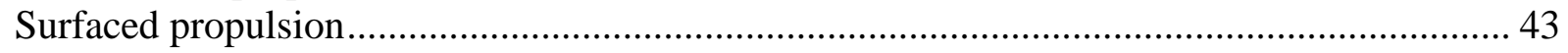

Maneuvering and control ...................................................................................................... 43

Air maneuvering and control.............................................................................................. 43

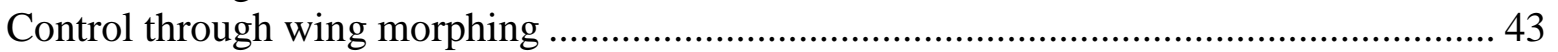

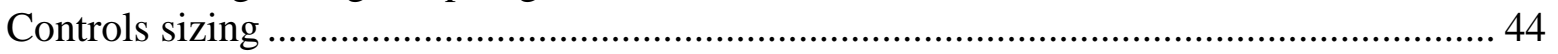

Surfaced maneuvering and control.................................................................................... 45

Submerged maneuvering and control............................................................................... 46

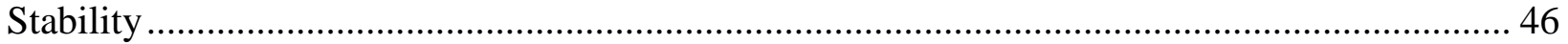

Load conditions and hydrostatics ....................................................................................... 47

Surface and transitional stability .................................................................................... 47

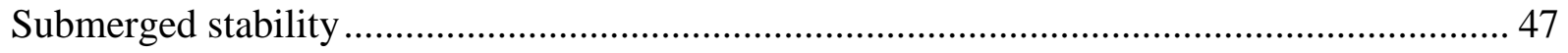

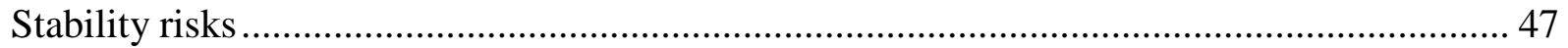

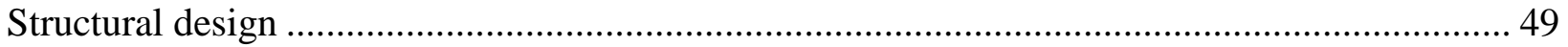

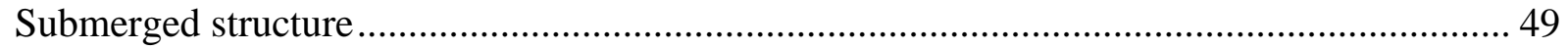

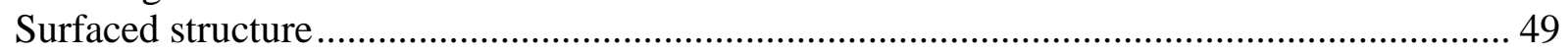

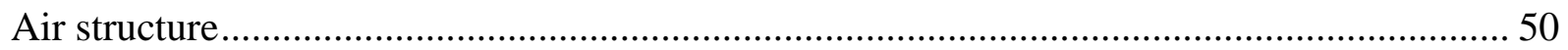

Proposal for structural optimization ................................................................................ 50

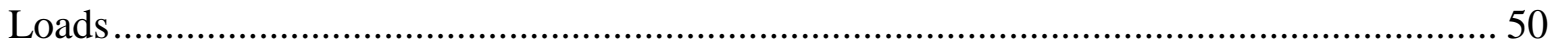

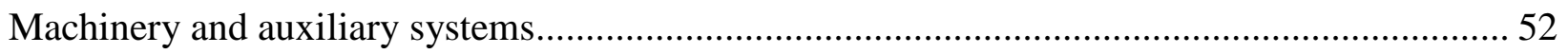

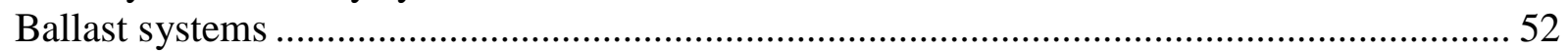

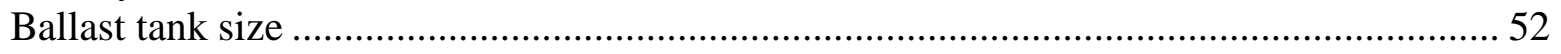

High-pressure air system............................................................................................... 52

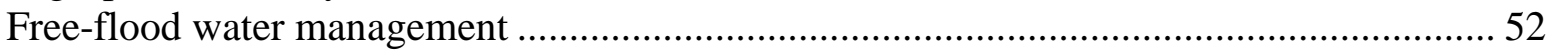




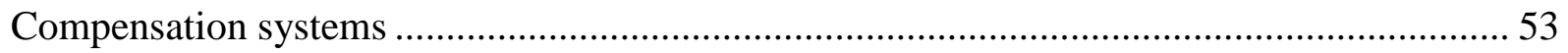

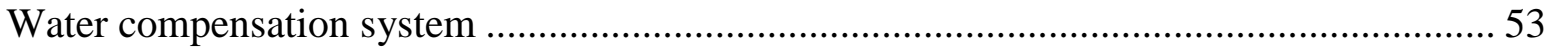

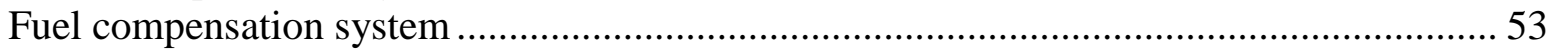

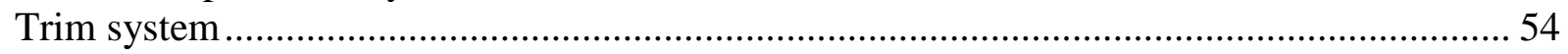

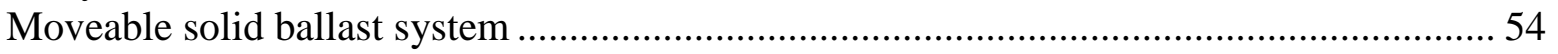

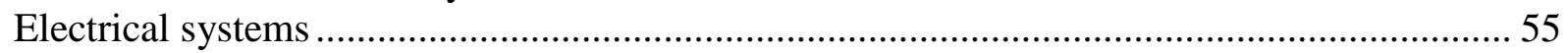

Jet engine pressure hull sealing mechanism........................................................... 56

Background to sealing mechanisms ....................................................................... 56

Modified sealing mechanism design for U3V ...................................................... 57

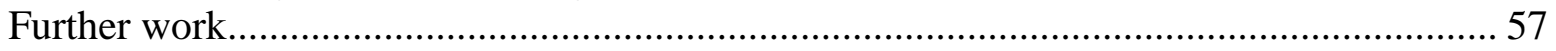

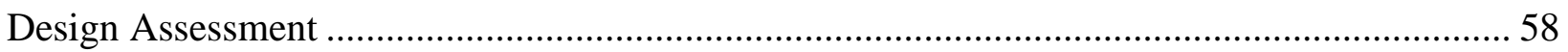

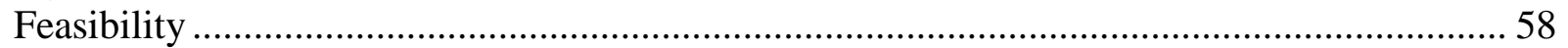

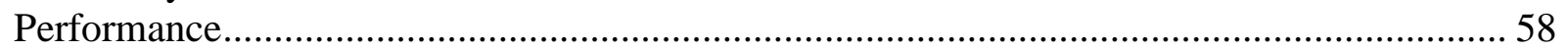

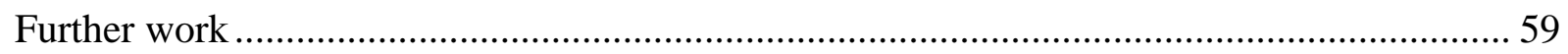

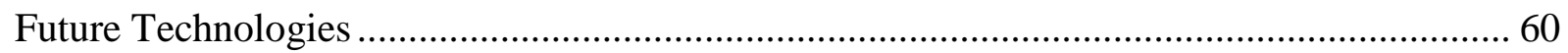

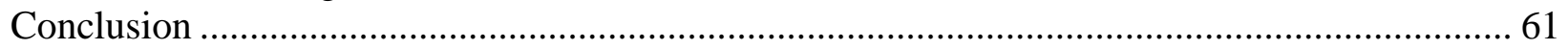

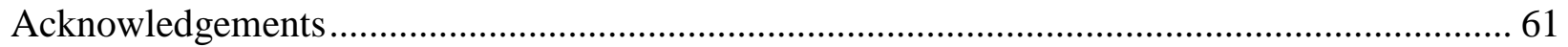

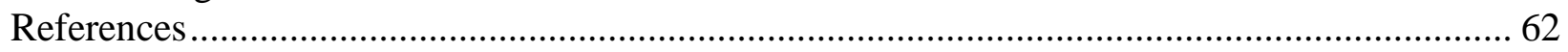

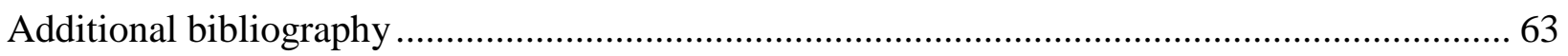

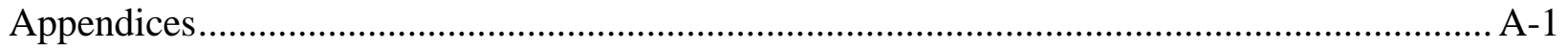

Appendix A: Background UAV survey plots............................................................... A-1

Appendix B: Aircraft sizing from a conceptual sketch .................................................. B-1

Appendix C: Submerged power and propulsion ........................................................... C-1

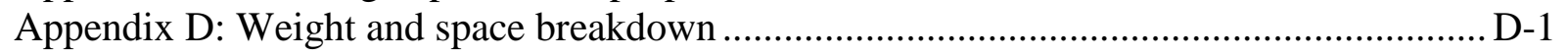

Appendix E: External form - developing and refining in RHINO …................................... E-1

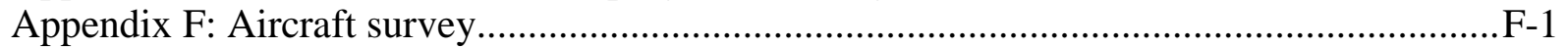

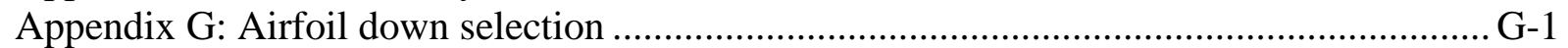

Appendix H: Air propulsion drag - hump resistance .................................................... H-1

Appendix I: Turbojet pressure hull sealing mechanism ..................................................

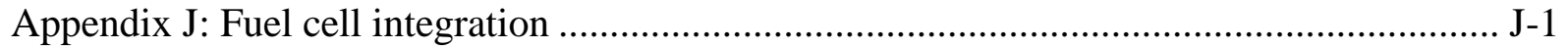

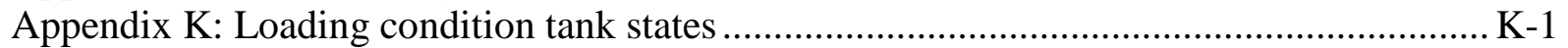

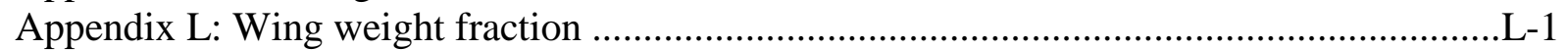

Appendix M: Water compensation system ................................................................. M-1

Appendix N: Aircraft fuel compensation system ...................................................... N-1

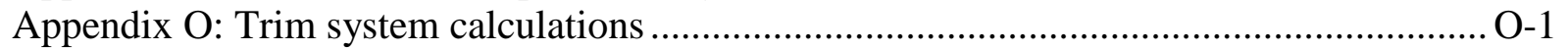




\section{Figures}

Figre 1-Ushakov (loge

Figure 1 - Ushakov (left) and Reid flying submarines (right)........................................................ 2

Figure 2 - Convair ‘subplane’ (left) and Sea Dart (right) ............................................................. 3

Figure 3 - Steps in the U3V design process ……….................................................................. 7

Figure 4 - UAV length-wingspan ratio for various craft weights ............................................. 8

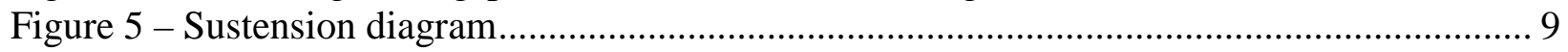

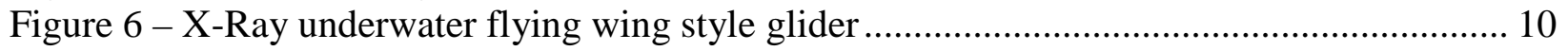

Figure 7 - External arrangement options ................................................................................. 12

Figure 8 - Estimating transverse metacentric height for a twin hull seaplane ............................... 13

Figure 9 - Flying boat and twin-hull seaplane configurations ..................................................... 13

Figure 10 - Sensitivity of propulsion weight to speed and endurance ........................................... 16

Figure 11 - Submerged mass breakdown .................................................................................... 20

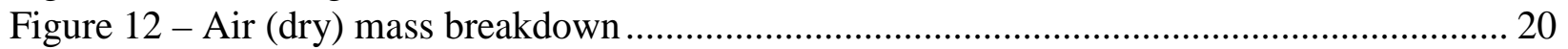

Figure 13 - Internal volume breakdown of main sensory PVs....................................................... 20

Figure 14 - Internal volume breakdown of electric motor PVs..................................................... 21

Figure 15 - Internal volume breakdown of turbojet PVs ........................................................... 21

Figure 16 - External volume breakdown ................................................................................ 21

Figure 17 - Internal layout of the main sensory PV ……….......................................................... 23

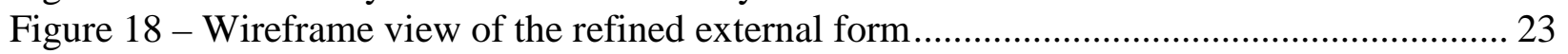

Figure 19 - External arrangement of the wing …………........................................................... 24

Figure 20 - Overview of the wing design process....................................................................... 25

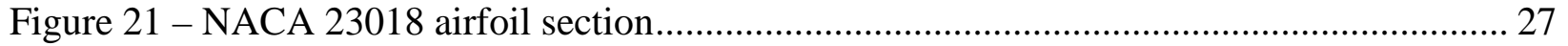

Figure 22 - Properties of NACA 23018 ..................................................................................... 28

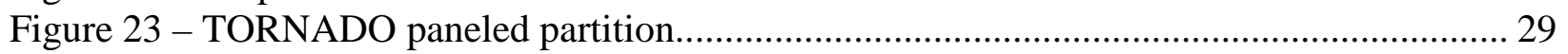

Figure 24 - Simplified wing geometry variables (frontal view).................................................. 30

Figure 25 - Sponsoned versus integrated engines ......................................................................... 30

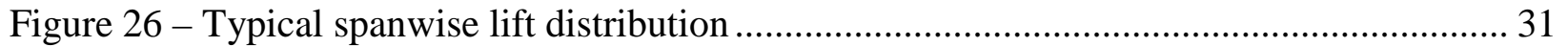

Figure 27 - The effect of relative partition size on wing performance ……………….................. 32

Figure 28 - Illustration of static longitudinal stability..................................................................... 35

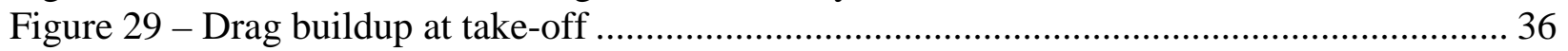

Figure 30 - Effective power against speed for a range of torpedo shaped UUVs......................... 37

Figure 31 - Power against speed for maximum hotel load.............................................................. 39

Figure 32 - Endurance against speed for maximum hotel load......................................................... 39

Figure 33 - Power against speed for lean hotel load ................................................................... 40

Figure 34 - Endurance against speed for lean hotel load ................................................................ 40

Figure 35 - Extendable bow thruster with moving keel piece........................................................... 41

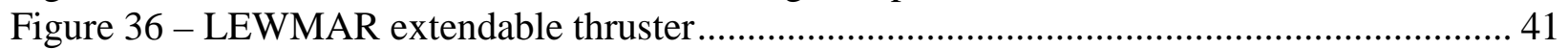

Figure 37 - Pump jet integrated with a ship's hull .......................................................................... 41

Figure 38 - Retracted and extended thruster locations for air and sea operations respectively ... 42

Figure 39 - Overall dimensions for the extendable thruster ............................................................. 43

Figure 40 - Trailing edge section of AFTI/F-111 mission adaptive wing .................................... 44

Figure 41 - Folded inner skins.................................................................................................... 44

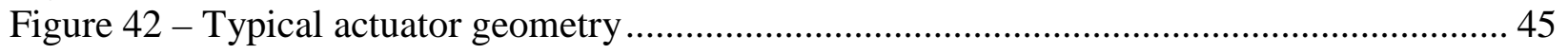

Figure 43 - Yaw control surface further work design ............................................................... 45

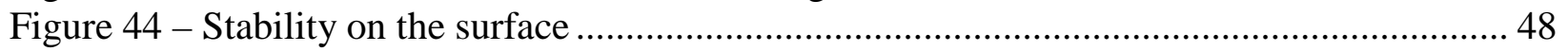


Figure 45 - Loads and moments (no pressures) on the Hypermesh model ............................... 51

Figure 46 - Illustration of freeboard requirement for U3V .................................................. 53

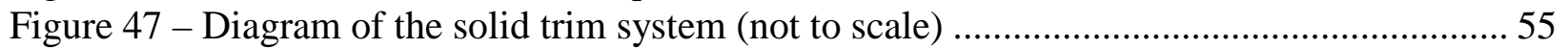

Figure 48 - Simplified electrical system schematic ...................................................... 56

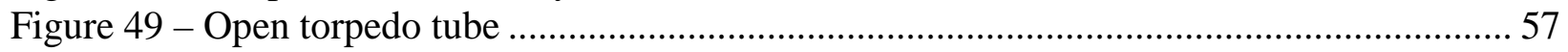

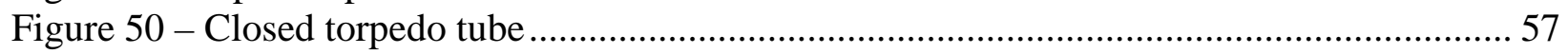

Figure 51 - Sealing mechanism for the pressure hull door ................................................ 57

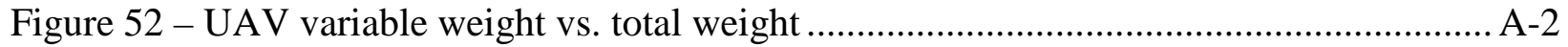

Figure 53 - UAV payload weight vs. total weight ..................................................... A-2

Figure 54 - Seaplane MTOW vs. wing area ................................................................ A-3

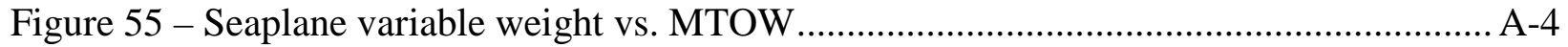

Figure 56 - Seaplane power loading vs. maximum speed................................................ A-5

Figure 57 - Seaplane cruise thrust vs. MTOW …........................................................... A-5

Figure 58 - Example mission profile ........................................................................... B-1

Figure 59 - Trade-off between payload, additional weight and range ................................. B-3

Figure 60 - Variation of weight and range with specific fuel consumption........................... B-4

Figure 61 - Drag coefficient against Reynolds number for bluff bodies ............................... C-1

Figure 62 - Power against speed for a range of torpedo shaped UUVs ................................ C-2

Figure 63 - Assumed relationship between motor efficiency and vehicle speed ...................... C-4

Figure 64 - Pump jet process sketches ...........................................................................

Figure 65 - The Northrop N-1M (left) and Akaflieg SB13 (right) ..........................................1

Figure 66 - Typical XFOIL alpha sweep output .............................................................

Figure 67 - Streamlining of the body using the sealing mechanism ........................................

Figure 68 - Motor speed against torque for the selected step motor ......................................... I-2

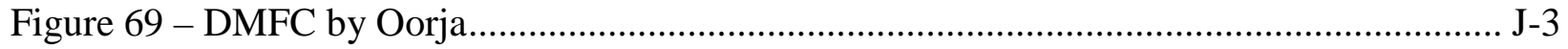

Figure 70 - Material handler powered by an Oorja DMFC .................................................... J-3

Figure 71 - Schematic diagram of the wing group and its notation ...........................................

Figure 72 - Calculation of restoring forces and moments at take-off .................................. O-1 


\section{Tables}

Tabe $1-1$ Page

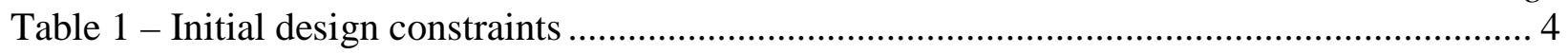

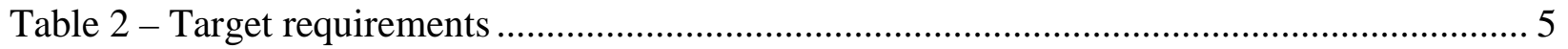

Table 3 - Propulsion sizing methodologies ..................................................................................... 15

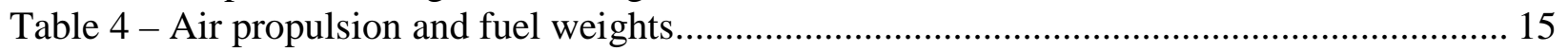

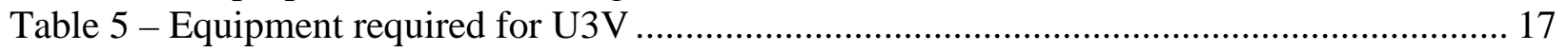

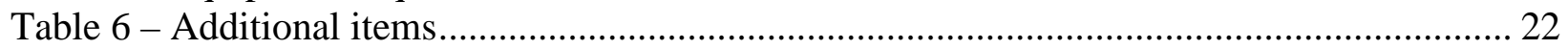

Table 7 - Airfoil figure of merit ............................................................................................. 27

Table 8 - The incremental effect of dihedral and integration of appendages on lift.................... 31

Table 9 - The effect of four wing-flap combinations on lift ........................................................... 32

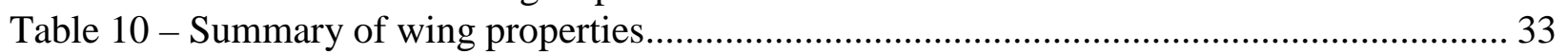

Table 11 - Wing performance in three states ............................................................................... 34

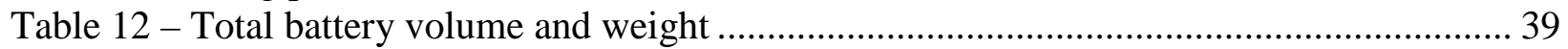

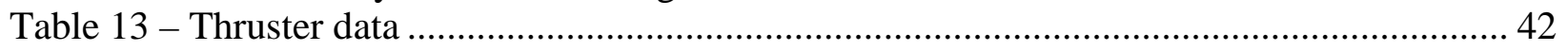

Table 14 - Trim systems for each condition................................................................................ 54

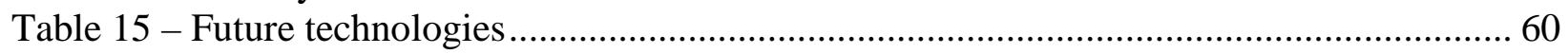

Table 16 - RQ-170 Sentinel principal characteristics .......................................................... A-1

Table 17 - Example inputs to the aircraft initial sizing ........................................................... B-1

Table 18 - Example mission segment weight calculations …………................................ B-2

Table 19 - Example of total weight iteration...................................................................... B-2

Table 20 - Battery sizing data ............................................................................................. C-3

Table 21 - Energy density and specific weight for a range of batteries ...................................... C-4

Table 22 - Group 1 Structure mass and volume breakdown ...................................................... D-1

Table 23 - Group 2 Propulsion mass and volume breakdown ................................................... D-1

Table 24 - Group 3 Electrical mass and volume breakdown .................................................... D-2

Table 25 - Group 4 Control \& Communication mass and volume breakdown............................ D-2

Table 26 - Group 5 Auxiliary systems mass and volume breakdown........................................ D-2

Table 27 - Group 6 Outfit \& Furnishings mass and volume breakdown ................................... D-3

Table 28 - Group 7 Ballast mass and volume breakdown............................................................ D-3

Table 29 - Group 8 Loads mass and volume breakdown............................................................ D-3

Table 30 - Group 1 Structure center of gravity location .......................................................... D-4

Table 31 - Group 2 Propulsion center of gravity location.......................................................... D-4

Table 32 - Group 3 Electrical center of gravity location............................................................. D-4

Table 33 - Group 4 Control \& Communications center of gravity location ............................... D-5

Table 34 - Group 5 Auxiliary Systems center of gravity location ............................................ D-5

Table 35 - Group 6 Outfit \& Furnishings center of gravity location ........................................ D-5

Table 36 - Group 7 Ballast center of gravity location............................................................. D-6

Table 37 - Group 8 center of gravity location ............................................................................ D-6

Table 38 - Survey of flying wing aircraft for airfoil selection ...................................................F-2

Table 39 - Calculating the relative merit of five airfoils (air categories)..................................... G-1

Table 40 - Fuel cell candidates.............................................................................................. J-2

Table 41 - Sizing oxygen storage methods .............................................................................. J-5

Table 42 - Hydrostatic data ............................................................................................. K-1

Table 43 - Tank loading conditions..................................................................................... K-2 


\section{List of acronyms}

$\begin{array}{ll}\text { Acronym } & \text { Definition } \\ \text { AIAA } & \text { American Institute of Aeronautics and Astronautics } \\ \text { AIP } & \text { Air-independent propulsion } \\ \text { AFC } & \text { Alkali fuel cells } \\ \text { AVCAT } & \text { Aviation carrier turbine fuel } \\ \text { BG } & \text { Separation between the center of buoyancy and the center of gravity } \\ \text { BP } & \text { Between perpendiculars } \\ \text { CAA } & \text { Civil Aviation Authority } \\ \text { CISD } & \text { Center for Innovation in Ship Design } \\ \text { CONOPS } & \text { Concept of operations } \\ \text { COTS } & \text { Commercial off the shelf } \\ \text { CTD } & \text { Conductivity, temperature and depth } \\ \text { DARPA } & \text { Defense Advanced Research Projects Agency } \\ \text { DMFC } & \text { Direct methanol fuel cell } \\ \text { ECPMS } & \text { Electrical control power management system } \\ \text { EO-IR } & \text { Electro-optical and infra-red } \\ \text { GM } & \text { Metacentric height } \\ \text { GMl } & \text { Longitudinal metacentric height } \\ \text { GMt } & \text { Transverse metacentric height } \\ \text { GZ } & \text { Righting arm } \\ \text { GPS } & \text { Global positioning system } \\ \text { hp } & \text { Horsepower } \\ \text { HP } & \text { High pressure } \\ \text { PAFC } & \text { Phosphoric acid fuel cell } \\ \text { PEM } & \text { High temperature polymer exchange membrane } \\ \text { INS } & \text { Inertial navigation system } \\ \text { LCG } & \text { Longitudinal center of gravity } \\ \text { LOX } & \text { Liquid oxygen } \\ \text { MBT } & \text { Main ballast tank } \\ \text { MCFC } & \text { Molten carbonate fuel cell } \\ \text { MCM } & \text { Mine counter-measures } \\ \text { MEng } & \text { Master of Engineering } \\ \text { MOD } & \text { Ministry of Defence } \\ \text { MSc } & \text { Master of Science } \\ \text { MTOW } & \text { Maximum take-off weight } \\ \text { NACA TN } & \text { National Advisory Committee for Aeronautics Technical Note } \\ \text { NSWC } & \text { Naval Surface Warfare Center } \\ \text { PEM } & \text { Polymer exchange membrane } \\ \text { PV } & \text { Pressure vessel } \\ \text { RHIB } & \text { Rigid-hulled inflatable boat } \\ \text { ROB } & \text { Reserve of buoyancy } \\ \text { SAS } & \text { Synthetic aperture sonar } \\ \text { SFC } & \text { Specific fuel consumption } \\ \text { SOFC } & \text { Solid-oxide fuel cell } \\ \text { TCG } & \text { Transverse center of gravity } \\ & \text { The } \\ \end{array}$


U3V Unmanned Three-Environment Vehicle

UAV Unmanned air vehicle

UCL University College London

UK United Kingdom

USN United States Navy

USV Unmanned surface vehicle

UUV Unmanned underwater vehicle

UXV Unmanned vehicle

VCG Vertical center of gravity 


\begin{abstract}
Design of an unmanned autonomous vehicle capable of operating in air, on the surface, and underwater was explored to assess technical and technological issues required by such a vehicle. A goal of the vehicle was a footprint comparable to an $11 \mathrm{~m}$ Rigid Hull Inflatable Boat (RHIB) to facilitate shipboard compatibility. Characteristics of the design are gross weight less than 8 tonne, wing span of $11 \mathrm{~m}$, length of $5 \mathrm{~m}$, and height of 2.4m. Airborne cruise speed is estimated to be over 100 knots. Maximum submergence depth is $50 \mathrm{~m}$. A major objective of the project was to explore the complex design issues associated with a vehicle that operates in the three fluid domains and document the design process used.
\end{abstract}

\title{
Administrative information
}

The work described in this report was performed by the Center for Innovation in Ship Design (CISD, Code 8202) of the Naval Architecture and Engineering Department at the Naval Surface Warfare Center, Carderock Division (NSWCCD) by UK MoD Defence Science and Technology Laboratory (DSTL) engineers posted to CISD under the Navy International Programs Office (NIPO) Engineer and Scientist Exchange Program (ESEP).

\section{Introduction}

\section{Aims}

The primary aim of the project was to assess the feasibility of an unmanned autonomous vehicle that may operate across three environments: air, surface and underwater. The secondary aim was to capture the design rationale and range of alternative solutions on the path to the final concept. The feasibility of the design was to be assessed, and the prerequisite technologies identified and prioritized.

\section{Objectives}

- Identify suitable requirements and realistic performance objectives through surveying unmanned vehicles (air, surface and underwater) and multienvironment vehicles (seaplanes and subplanes)

- Reduce the potential set of solutions for an Unmanned Three-Environment Vehicle (U3V) to a single concept through down-selection of arrangements and subsystems

- Size and balance the selected concept for volume and weight including the basic sizing of subsystems

- Perform analyses of stability, trim and compensation and structural design for feasibility and insight into the unique challenges of a multi-environment vehicle 


\section{Significance of study}

This study identified a number of potential solutions to the requirement for a multi-environment unmanned vehicle and developed a concept from among those design choices that are most feasible assuming current or near-future technologies. The resulting performance data provide strategists and mission planners with an idea of the capabilities of a vehicle that does not yet exist to help establish operational concepts that make full use of their unique characteristics. It provides designers with a 'firstpass' estimate of a U3V and a new design point on the path toward other concepts. This study also provides a design methodology and a list of the tools and documents that may assist their development.

\section{Background}

\section{History of submersible aircraft}

Submarines are massive non-lifting bodies that must have the overall density of seawater to achieve neutral buoyancy whereas aircraft have wide slender wings and are as light as possible. This has not stopped people from trying to create the flying submarine - there have been numerous attempts to build vehicles that transcend traditional operating envelopes and regions, but few have overcome the disadvantages of a design that is compromised by the need to operate in very different environments.

The submersible aircraft was first proposed by Boris Ushakov (Figure 1) at the Naval Engineering Institute in the Soviet Union in $1934^{1}$. The vessel was intended to achieve 150kts in air and 3kts when submerged. However, the design was periodically suspended during development and never proved successful in testing. The next attempt was made privately by Donald Reid, a submarine model enthusiast, from $1962^{2}$. This concept was also a floatplane and, similarly, the final vessel was a failure. It operated both underwater and in air, but never without alteration and refitting in between. In addition, the aero engine was found to be underpowered.

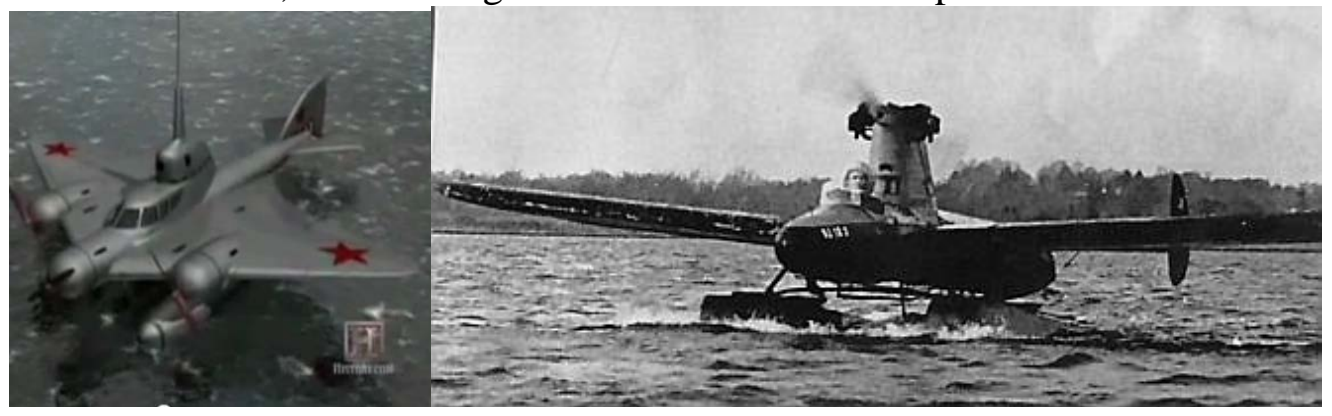

Figure 1 - Ushakov (left) and Reid flying submarines (right)

At a similar time, Convair was tasked with developing a submersible aircraft that never left the drawing board [2]. The Convair 'subplane' (Figure 2) would have had turbojets that closed shut with butterfly valves ${ }^{3}$. The temperature shock would be

\footnotetext{
${ }^{1}$ tnorton12000, 2007. Secret Russian Aircraft of WW2. Available from:http://www.youtube.com/watch?v=xxyf3O_SyYQ [Accessed on May 8, 2012]

${ }^{2}$ Bernhard CF Kline Collection. http://1000aircraftphotos.com/Contributions/KleinBernhard/6559.htm [Accessed May 8, 2012]

${ }^{3}$ Waterufo. The U.S. Navy and Flying Submarines. Available from: http://www.waterufo.net/flyingsubs/NavyFlyingSubHtml1.htm [Accessed on 2nd July 2012]
} 
mitigated by using the starter motor to blow air into the engines after landing. Everything except the cockpit, avionics and engines would be free-flood. This included the fuel tank, where contents were protected by a rubber membrane.

Prior to this, Convair had developed the Sea Dart, a seaplane fighter aircraft that employed hydroplanes rather than floats ${ }^{4}$. Although not submersible, the Sea Dart merits mention because it reached an advanced stage of production (four prototypes), considerable size $(7,500 \mathrm{~kg}$ ) and performance (supersonic in a shallow dive).

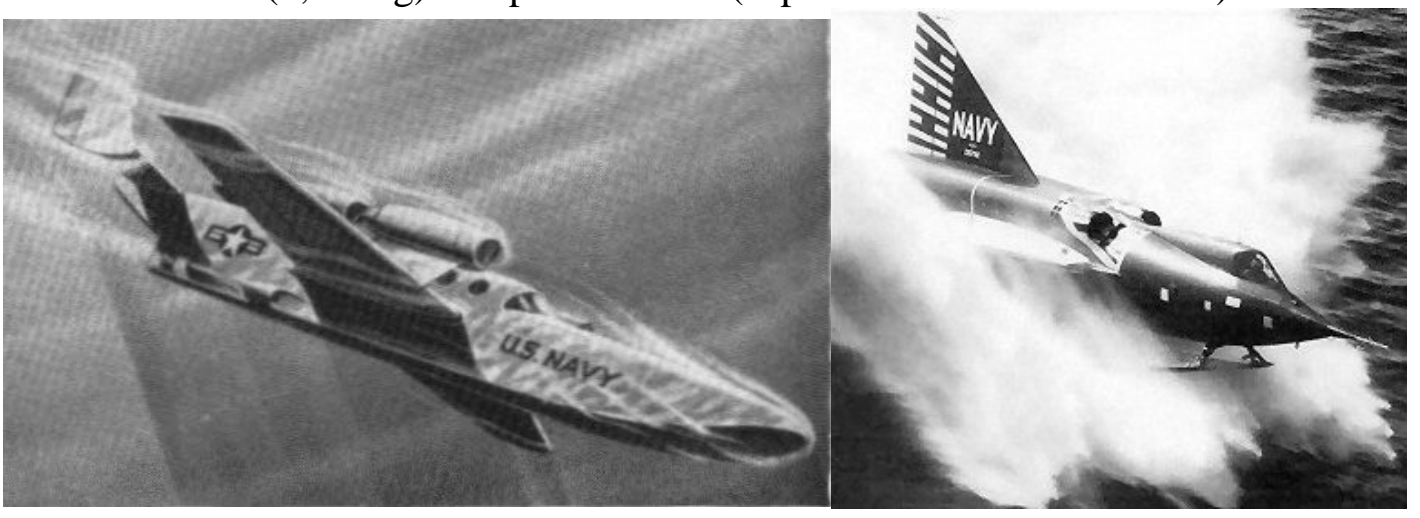

Figure 2 - Convair 'subplane' (left) and Sea Dart (right)

In 2008, DARPA produced a solicitation for concept designs and technology demonstrations of a manned submersible aircraft that could carry eight soldiers in an eight-hour mixed-environment mission reaching over $1,000 \mathrm{~nm}^{5}$. The document observed that the challenge is to resolve 'diametrically opposed' requirements that can be categorized into research topics: weight, flow conditions, structures, wing geometry and power generation/storage. Perhaps due to these challenges, little response was generated. Most recently, Rick Goddard and Jonathan Eastgate produced a concept for a manned flying submarine ("Flubmarine”) while working at the Center for Innovation in Ship Design (CISD) [1].

\section{Suggested missions for historical flying submarines}

This project does not include any specific objective to determine the operational utility of an unmanned submersible aircraft, but it is useful to examine the proposed uses of historical equivalents.

The Ushakov was expected to survey an area of the sea, spotting convoys of large ships. It would land ahead of the vessels, use its small periscope to identify battleships and cruisers, and then ambush and destroy them with its torpedoes ${ }^{6}$. The Convair subplane's role is not easily established ${ }^{7}$ since its anti-submarine capabilities

\footnotetext{
${ }^{4}$ Wikipedia. Convair F2Y Sea Dart. Available from: http://en.wikipedia.org/wiki/Convair_F2Y_Sea_Dart [Accessed on 2nd July 2012]

${ }^{5}$ DARPA BAA 06-09. Available from: https://www.fbo.gov/?tab=documents\&tabmode=form \&subtab=core\&tabid=05477ea2d5e82e0c5881b92 25d7f9ab1 [Accessed on 8th May 2012]

${ }^{6}$ Marks P., 2010. From Sea to Sky, Submarines that Fly. Available from: http://www.newscientist.com/article/mg20727671.000-from-sea-to-sky-submarines-that-fly.html [Accessed on 8th May 2012]

${ }^{7}$ Convair's Subplane. Available from: http://www.flightglobal.com/pdfarchive/view/1965/1965\%20-

\%200707.html [Accessed on 8th May 2012]
} 
are so compromised by its need to operate in the air, but suggested roles are as a managed and highly mobile listening post or for diver transport, rescue and re-supply. DARPA's solicitation suggested that up to eight 'operators' must be transported and supported for up to three days, and the 'Flubmarine' concept narrows down the mission to a special forces underwater insertion vehicle. These uses suggest a number of potential missions for an unmanned submersible aircraft.

\section{Requirements}

The design philosophy for the development of U3V was to move away from concepts of operations (CONOPS) and instead assessed whether the proposition was feasible. This approach made it possible to discover new capabilities and operating methods rather than restricting the design space to prescribed requirements. As such, the initial requirements were only that the U3V be transportable and deployable by ships that operate an 11m rigid-hulled inflatable boat (RHIB). Design constraints are outlined in Table 1.

\begin{tabular}{l|l}
\hline Section & Design Constraint \\
\hline Dimensions & $\begin{array}{l}\text { Limited to the volume of an } 11 \mathrm{~m} \text { RHIB in the DDG-1000 mission bay (L=11m, } \\
\mathrm{W}=4.1 \mathrm{~m} \text { and } \mathrm{H}=4 \mathrm{~m}) . \\
\text { Accommodate an existing } 11 \mathrm{~m} \text { RHIB in addition to the unmanned vehicle } \\
(\mathrm{UXV}) \text { within the mission bay. } \\
\text { Mass }\end{array}$ \\
$\begin{array}{l}\text { Not heavier than a fully-loaded 11m RHIB (8te) } \\
\text { Minimize weight for possible use on other host platforms with modifications to } \\
\text { davits. }\end{array}$ \\
\hline
\end{tabular}

Table 1 - Initial design constraints

It was considered unrealistic to expect the U3V to be capable of all missions in all environments; i.e. to demonstrate similar capabilities to that of a UXV specifically designed for a single environment. It was more realistic for U3V to have a balanced, but reduced, set of requirements. Hence, there are notable compromises in payload, speed, endurance and range. As a result of background research and broad surveys, a number of requirements were selected to serve as reasonable design objectives. These are outlined in Table 2. 


\begin{tabular}{|c|c|}
\hline Section & Requirements \\
\hline Endurance & $\begin{array}{l}\text { - Air: } 3 \text { hours cruise } \\
\text { - Surface: } 4 \text { hours at } 12 \text { knots } \\
\text { - Submerged: } 3 \text { hours at } 4 \text { knots and at least } 24 \text { hours station-keeping } \\
\text { untethered } \\
\text { Long term loiter for longer than } 2 \text { weeks (tethered or otherwise) }\end{array}$ \\
\hline Speed & $\begin{array}{l}\text { - } \quad \text { Air: Cruise Mach } 0.3 \\
\text { - } \quad \text { Surface: Maximum } 30 \text { knots; Transit } 12 \text { knots; Operation } 4 \text { knots } \\
\text { - } \quad \text { Submersed: Maximum } 4 \text { knots; Operation } 2 \text { knots }\end{array}$ \\
\hline Diving Depth & $\begin{array}{l}\text { Maximum operating depth of } 50 \mathrm{~m} \text {; defined by sea-state surface wave effects, } \\
\text { communications and sonar effectiveness. }\end{array}$ \\
\hline Weapons Outfit & $\begin{array}{l}\text { Provision for onboard weapons fit for self-defense and prosecution of low-level } \\
\text { threats, keeping in mind ethical and legal issues. } \\
\text { Active Mine Counter-Measure (MCM) suite embarked as necessary. }\end{array}$ \\
\hline $\begin{array}{l}\text { Adaptable } \\
\text { Payload }\end{array}$ & $\begin{array}{l}\text { Look to maximize volume and weight of adaptable payload. } \\
\text { Emphasis on deployability and variety of embarkiable equipment, especially } \\
\text { deployable sensors and communication arrays. }\end{array}$ \\
\hline Flexibility & $\begin{array}{l}\text { Option to trade fuel for payload. } \\
\text { Modular payload bays. } \\
\text { The parent vessel must be able to easily switch payloads on the vehicle, } \\
\text { depending on changing operational needs. }\end{array}$ \\
\hline $\begin{array}{l}\text { Sensors and } \\
\text { Communications }\end{array}$ & $\begin{array}{l}\text { Options for, or fitted with, a full range of sonar including synthetic aperture } \\
\text { sonar (SAS), cameras, communications and navigational equipment: } \\
\text { - } \quad \text { Energy efficient } \\
\text { - } \quad \text { Modular } \\
\text { - } \quad \text { Single systems solving tri-domain challenges }\end{array}$ \\
\hline Stealth & $\begin{array}{l}\text { Do not compromise the host platform. } \\
\text { Adopt "free stealth" philosophy; design to reduce signatures with no additional } \\
\text { cost to the vehicle (e.g. concealed intakes, faceted surfaces, small size) }\end{array}$ \\
\hline $\begin{array}{l}\text { Energy \& } \\
\text { Propulsion }\end{array}$ & $\begin{array}{l}\text { Aim for a single energy production plant for all three domains. } \\
\text { Use readily available fuel commonly found on host platform. } \\
\text { Minimize the number of moving parts in contact with the water. } \\
\text { Use regenerative technologies to preserve energy. }\end{array}$ \\
\hline
\end{tabular}

\section{Table 2 - Target requirements}

\section{Design procedure}

The U3V concept is novel and required a novel design procedure. However, the design procedure was not developed in a vacuum; there has been a great deal of literature on the steps for the concept design of ships, submarines and aircraft. For 
inspiration, experience with the ship and, more notably, the submarine design procedures from University College London (UCL) was used [3]. In addition, the conceptual sizing processes described by Raymer [4] and Corning [5] provided some early assistance from an air standpoint.

The most significant challenge was the integration of these independent design procedures into one that incorporated the emergence of new inter-dependencies. Figure 3 shows the design procedure followed for the U3V. It reflects the path taken over the duration of the project including down-selections and some of the rejected ideas that did not make it into the final design. The procedure began with an unusually broad sweep of vehicle surveys that informed the creation of a short requirements document. A substantial period of down-selection was necessary since there are few historical guides to the correct selection of systems and arrangements.

The design of the selected subsystems culminated in their incorporation into a balancing tool that iterates to find a balanced solution in the underwater condition. The stability calculations depended upon the internal and external arrangements. The structural optimization study was conducted after the completion of the concept as an evaluation of new software and to see the synergies available from a novel design approach.

It is worth emphasizing that the concept progressed without a clear, pre-defined procedure, but, instead, was based on prior experience with separate surface ship, submarine and aircraft concept design as well as the 'Flubmarine' concept [1]. As such, the procedure described here is historical and may not supply the best possible approach to the problem. 


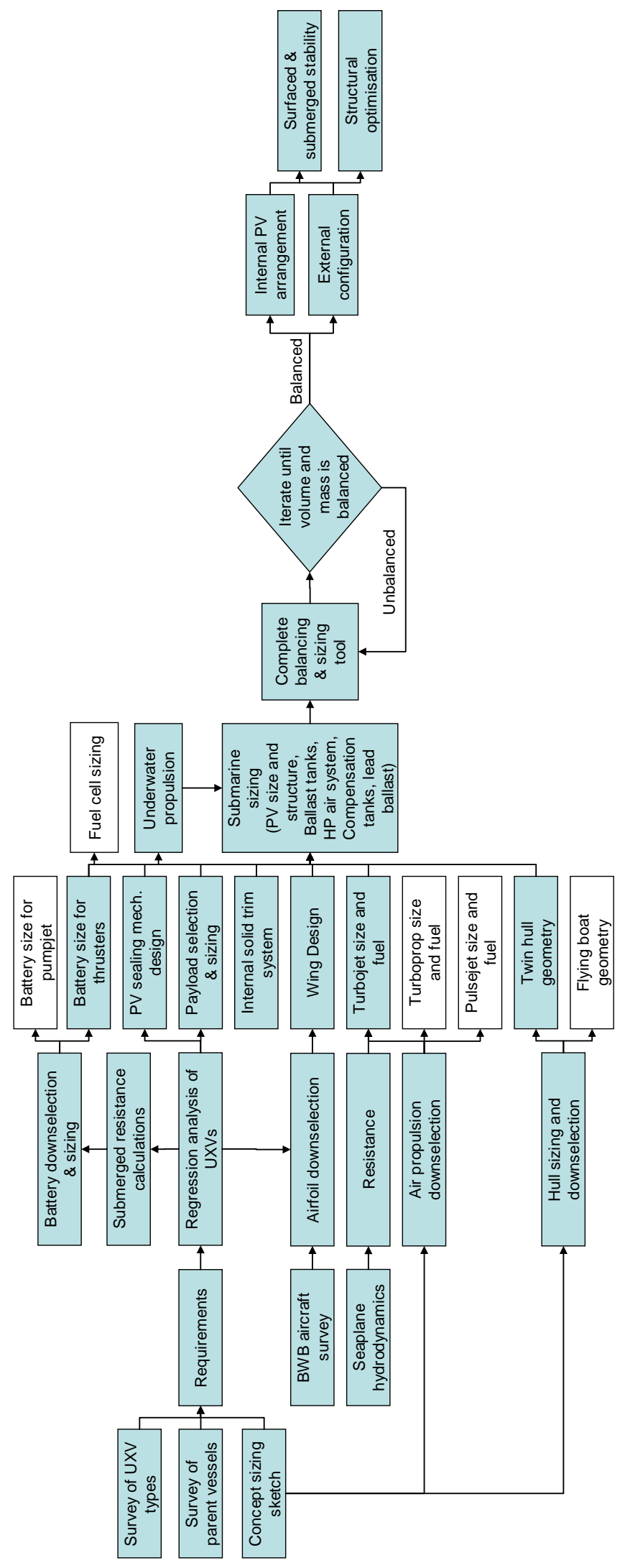

Figure 3 - Steps in the U3V design process 


\section{Background survey}

\section{Unmanned vehicles (UXVs)}

\section{Unmanned air vehicles (UAVs)}

Tens of thousands of UAVs are now in service with military and private organizations around the world. They vary from sub- $10 \mathrm{~kg}$ handheld tactical tools to very large medium- and high-altitude long endurance aircraft that require very long runways and have large wingspans. In between, there are high-speed, stealthy concepts such as the BAE Taranis and RQ-170 Sentinel. A database of unmanned vehicles was created to provide design inspiration and to assess potential comparators for this concept. See Appendix A for tables and figures.

Figure 4 shows a broad survey of UAVs comparing span to length. Two examples are highlighted that are close to the defined dimensional constraints of the U3V. The Gnat, with its traditional combination of slender fuselage and high aspect ratio wing, has sufficient wing area to support a vehicle weighing only $500 \mathrm{~kg}$. However, the RQ-170 Sentinel has much greater wing area within the same dimensions due to its blended-wing-body design.

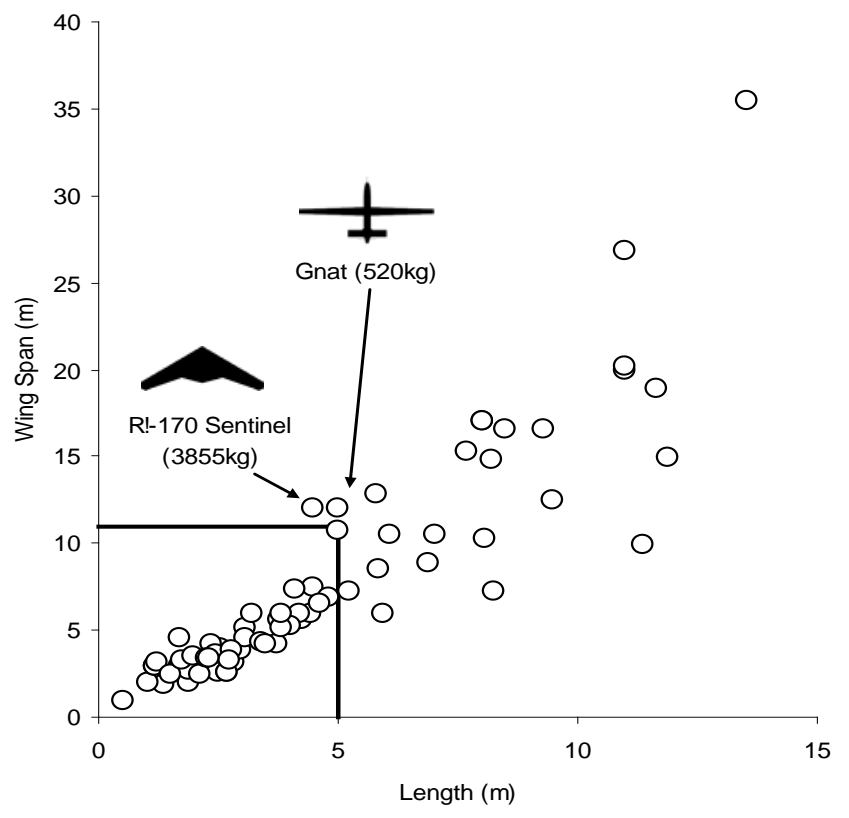

Figure 4 - UAV length-wingspan ratio for various craft weights

The RQ-170 is a high-performance, high-altitude reconnaissance aircraft weighing almost four tonnes with a powerful powerplant. It demonstrates that a blended-wing-body planform is better at providing sufficient lift within the dimensional constraints and provides first estimates of planform area $\left(20.4 \mathrm{~m}^{2}\right)$ and aspect ratio (7). The suitability of the RQ-170 Sentinel for comparison is limited as it is not a seaplane. Therefore, it will not carry additional equipment and floats for operation on the sea surface, nor will it have a sufficiently low take-off speed. The variable weight fraction for UAVs can be compared to a regression curve for variable sweep seaplanes [6] to give an idea of the proportion of the craft that must be given over to fuel and disposable payload. UAVs are able to carry considerably greater payload for a given size.

The UAV survey also shows that, on average, $19 \%$ of the weight is 'payload'. This suggests that a Sentinel-sized craft may be able to carry $700 \mathrm{~kg}$ of non-flight 
equipment comprising payload and, importantly, subsystems and additional structure for surface and underwater operation. As a result of the UAV survey, a basic aircraft sizing iteration using Raymer [4] could be conducted. This is detailed in Appendix B.

\section{Unmanned surface vehicles (USVs)}

Given the range of potential forms for surface vehicles (Figure 5), there are relatively few examples of innovative configurations in present designs. Most are based on rigid-hulled boats with planing hulls. Notable exceptions include snorkelling semisubmersibles such as Lockheed Martin's WLD-1 Remote Minehunting System (RMS) and large SWATH-type concepts ${ }^{8}$, but neither offers a reasonable form for flight and underwater operation as well.

Hydrofoils are supported by lifting surfaces generating hydrodynamic lift at speed. They offer the potential to use lifting surfaces both underwater and in the air. However, hydrofoil craft still require a conventional planing hull. In addition, the difference in center of action of thrust and drag when using the aero engine make such a configuration unrealistic.

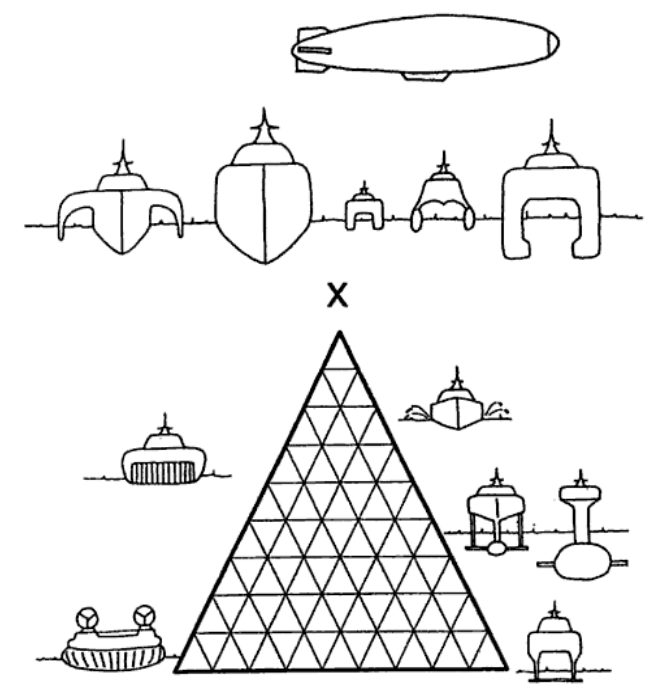

Figure 5 - Sustension diagram

\section{Unmanned underwater vehicles (UUVs)}

Traditionally, UUV shapes have been of a similar style to large scale submarines, adopting the conventional cigar style tubular form. This is a result of the pressure hull shape and hydrodynamic requirements.

An interesting alternative are the blended wing underwater gliders, specifically $\mathrm{X}$-Ray, pictured in Figure 6. In regards to the U3V design, X-Ray ${ }^{9}$ was rather appealing due to its resemblance to airborne vehicles. However, the sawtooth trajectory this and many other underwater gliders follow was undesirable as it would limit U3V's operational effectiveness.

\footnotetext{
${ }^{8}$ Fetsch M., 2008. USV Capability: UUXO Partnership Workshop. Navsea, Norfolk.

${ }^{9}$ AUVAC. AUV System Spec Sheet: XRAY Liberdade platform. Available from: http://auvac.org/uploads/tiny_mce_uploads/XRAY\%20Liberdade\%20sm.jpg [Accessed on 2nd July 2012]
} 


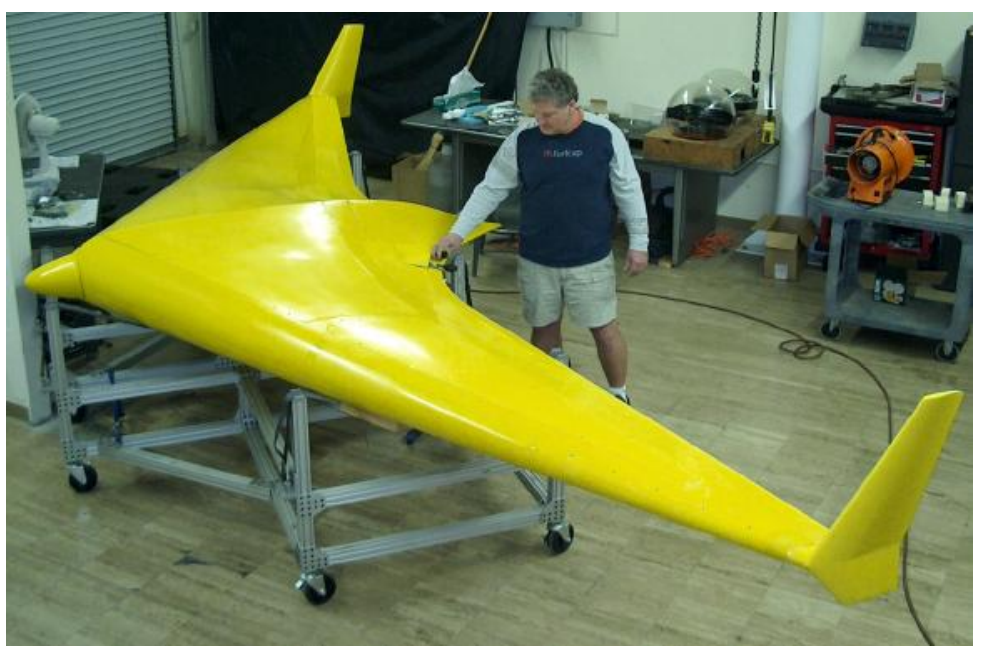

Figure 6 - X-Ray underwater flying wing style glider

From the outset, U3V was conceived as a submersible aircraft, rather than a flying submarine. As a result, the air environment dominated the early stages of design. Early analysis of water based systems indicated that the volume of the equipment required would be easily housed within the large wing cavity. As a result, little initial regression analysis was undertaken on UUVs other than to determine ballpark values for submerged speed, endurance and hotel load. This is documented in the underwater power requirements section.

\section{Seaplanes}

Seaplanes are aircraft that can use water for take-off and landing. Float seaplanes have dedicated floats that provide buoyancy in the water but are otherwise parasitic whereas flying boats incorporate a buoyant hull into the central fuselage. In addition to providing buoyancy, the floatation devices must plane to enable take-off speeds and offer sufficient stability for this to occur safely. Finally, the craft must deal with both aerodynamic and hydrodynamic forces in the transition take-off and landing phases; seaplanes require more thrust than a similar conventional aircraft [7].

The CISD Seaplane Database ${ }^{10}$ was used to analyze historical seaplane data. The database contains information on several hundred historical seaplanes including flying boats, float planes and amphibians. Note that the dataset comprises manned craft, most of which are outdated by today's technology.

The data suggests a linear relationship between maximum take-off weight (MTOW) and wing area, although the correlation is poor due to variations in performance and wing loading. Given the dimensional constraints, a wing area of around $33 \mathrm{~m}^{2}$ is suitable, although real-life examples have a range of $25-70 \mathrm{~m}^{2}$. Below a MTOW of 50 tonnes, the variable load fraction is well correlated at $37 \%$. While the breakdown of variable load will be very different in the U3V due to the lack of human cargo, the fraction should be a good design guide.

The seaplane database was also used to gain some idea of powering and propulsion. Up to a maximum speed of 170 knots $(200 \mathrm{mph})$, the data correlated well with a power to weight ratio of 0.1 (horsepower / MTOW), a first estimate for designers [4]. For a 4 tonne craft, this equates to a thrust of 1,700 lb-force. In general, the

${ }^{10}$ CISD. Seaplane Database. (Internal Document). CISD, MD USA 
installed thrust in lb-force is equal to $0.42 \times$ MTOW (kg). See Appendix B for supporting data.

\section{Survey results}

Caution is important in comparing results from regression analysis on datasets of very different craft, in particular when attempting to use them for a starting point to a craft that combines aspects of all in a novel form. With this in mind, the findings can be summarized as follows.

The craft may displace no more than 4 tonnes and will need a flying wing or blended-wing-body planform to provide the area required, $25-70 \mathrm{~m}^{2}$. The additional weight margin for submersed operations will trade off against payload weight, and will sum to $20 \%$ of the total weight. Fuel and variable weight is approximately an additional $20 \%$.

Planing hulls will be used for surface operation. To minimize ineffective structure, they should be integrated into the blended form. The maximum thrust required above water will be no more than $1,700 \mathrm{lb}$ thrust.

With the air domain offering the primary means of transit to areas of operation, long stretches of sustained submerged speed are not necessary. As a result, the requirement for 3 hours at a speed of 4 knots was deemed sensible. This would be at full, or peak, hotel load. The aim being that when operating at a lean hotel load, U3V may loiter for at least 24 hours.

\section{Downselection of concepts}

The survey revealed the need for a large planform craft. The design style adopted was to ensure that the various components required for operation in the three domains were incorporated into a blended design. Prior to sizing and balancing, the solution space was first narrowed in terms of external arrangement and propulsion selection. This was because the external form fundamentally affects the performance of the craft while the sizing (and arrangement) of the internal equipment and the propulsion selection determines whether the design is weight-limited or buoyancylimited when submerged (which consequently drives the selection of other subsystems).

\section{External arrangement}

Regardless of the wing design or hull type selected, the craft required sufficient floatation to support its weight when on the surface. Two hull configurations were considered: twin hulls with separation determined by stability requirements and a single hull with outboard floats sized using an empirical formula. Figure 7 shows the likely position of the aero engine (white circle) and pressure hulls (grey) in each case. Note how the wings and aero engine must be located as far above the sea surface as possible. The pressure hulls must be located as low as possible for stability on the surface and when submerged. 


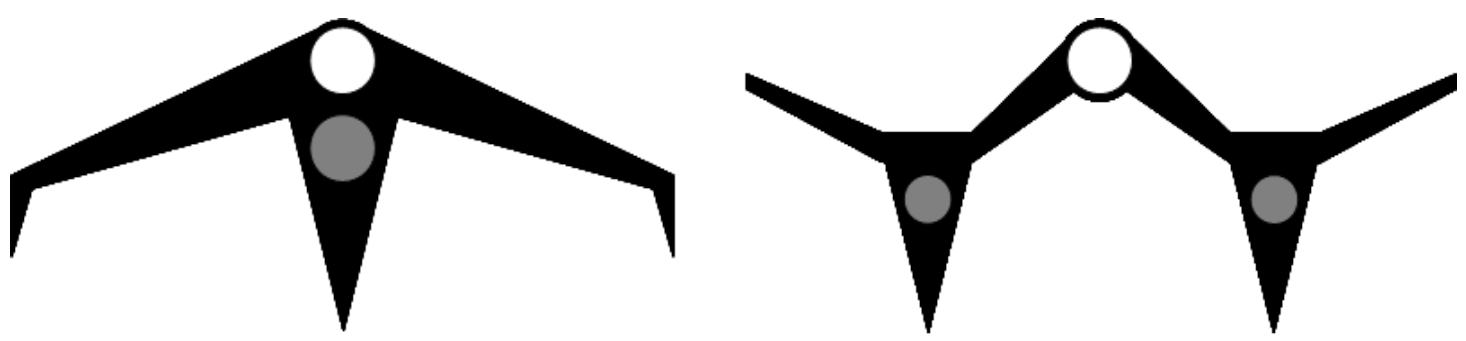

Figure 7 - External arrangement options

The normal waterline draft was calculated in each case for a displacement of four tonnes with the twin-hull beam of $1.35 \mathrm{~m}$ and single hull beam of $1.8 \mathrm{~m}$. The Civil Aviation Authority (CAA) provides guidelines for float reserve of buoyancy in seaplanes, but there is significant variation in military $\mathrm{craft}^{11}$. A Reserve of Buoyancy (ROB) of $60 \%$ was selected giving the minimum total volume of the floats.

\section{Sizing and locating the single hull}

For the single hull, auxiliary floats on the wing tips were used for transverse stability. Since wing tip floats should not normally be submerged, a static stability analysis cannot be performed. Instead, an empirical relation was used that relates the size of the wing tip float to principal dimensions of the craft [7]. The minimum size ellipsoidal float dimensions were calculated to be $0.4 \mathrm{~m} \times 0.4 \mathrm{~m} \times 1.7 \mathrm{~m}$.

\section{Sizing and locating the twin hulls}

For a twin hull configuration, auxiliary floats are not required for transverse stability; instead, the separation between the two main hulls is designed to be sufficient to provide sufficient transverse metacentric height (GM). Figure 8 shows a plot of two empirical methods for required GM. The recommendation of NACA Technical Note (NACA TN) 183 generates a linear relation for float planes.

Knowing the waterplane area of each hull and the required GM, the separation of the hulls can be calculated directly. The minimum separation is $4.6 \mathrm{~m}$ (CAA) and 2.9m (NACA TN 183) respectively. Note that this is the total separation, so the distance of each hull from the centerline will be half this.

Using similar equations provided by the CAA and the NACA TN, the minimum longitudinal GM was calculated to be $10 \mathrm{~m}$ and $38 \mathrm{~m}$ respectively. After calculating the total waterplane moment of inertia and assuming the worst case GM, the required float length is $5.2 \mathrm{~m}$.

\footnotetext{
${ }^{11}$ Civil Aviation Authority Safety Regulation Group British Civil Airworthiness Requirements (Section VLH - Very Light Helicopters) Available from: http://www.caa.co.uk/docs/33/CAP750.PDF [Accessed on 9th January 2013]
} 


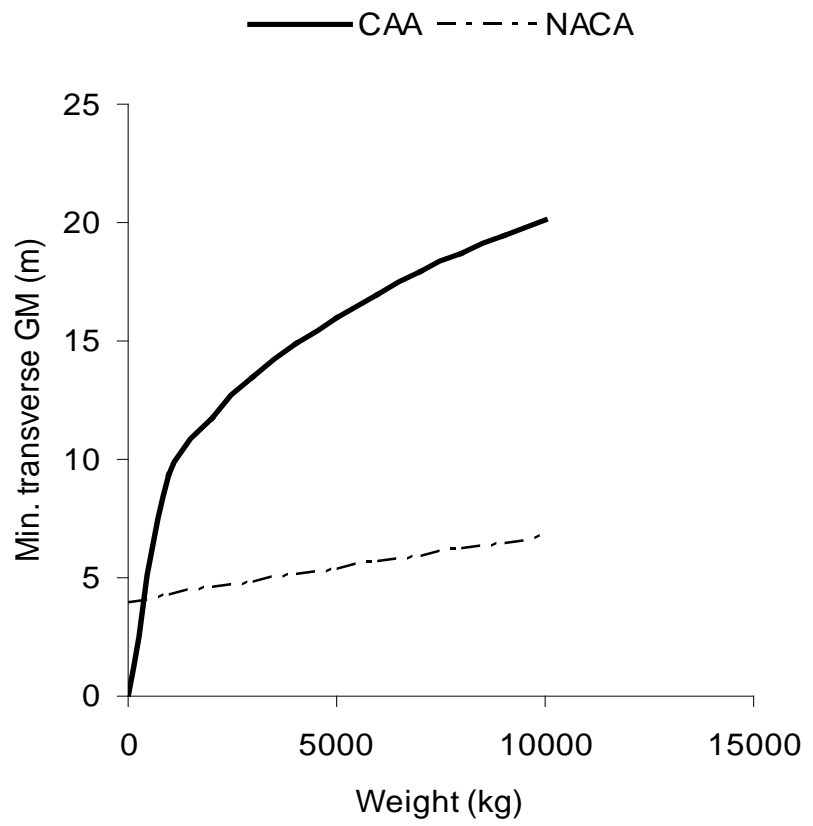

Figure 8 - Estimating transverse metacentric height for a twin hull seaplane

\section{Design decision}

In summary, the analysis provided the two possible configurations illustrated in Figure 9. The twin-hull type was selected as they permit a W-form lifting surface that balances the need for the wing and engine to be above the waterline and should result in a more efficient design requiring less structure to separate floats, hulls and wing elements. Furthermore, conventional seaplanes of comparable size more often use twin floats whereas the flying boat variant is reserved for the larger designs. Finally, the limit on overall length means that the single hull design has a very low length to beam ratio resulting in higher resistance in all domains.
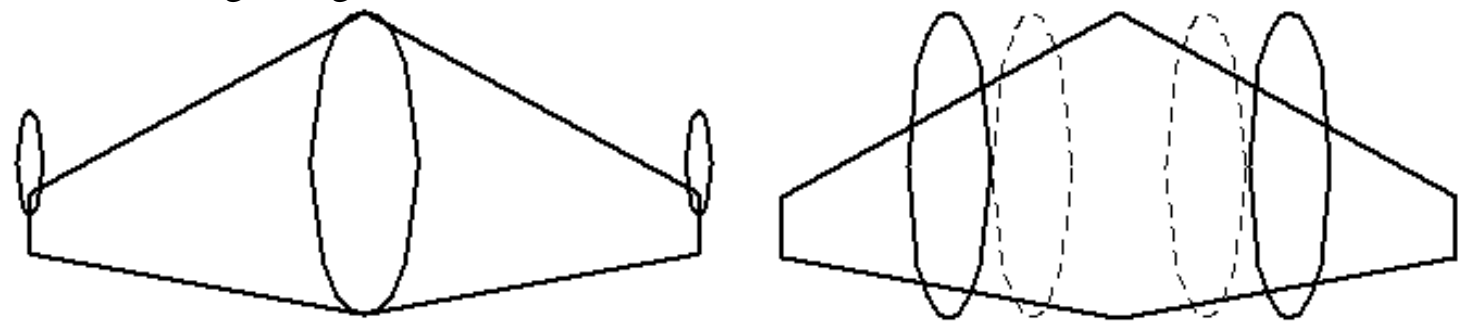

Figure 9 - Flying boat and twin-hull seaplane configurations

\section{Air propulsion}

The selection of the aero engine and propulsor was required early in the design as they had a substantial impact overall. A propulsor and/or motor that could be used in all environments was one of the initial requirements, the ambition being to reduce design complexity and total number of systems. The only methods that were thought to achieve this were a pulsejet which could perform in air using standard aviation fuel and underwater using torpedo style fuels or a fully electric system using air-independent 
propulsion (AIP) and an electric motor. There were a number of issues associated with these two options:

Pulsejet use in all three domains - The pulsejet was found to be very fuel inefficient in air and little information could be found on torpedo style fuels, especially any data that could be used to determine the volume of fuel required onboard. Data was available for the Spearfish torpedo used by the British Royal Navy. This has a gas turbine engine and uses a monopropellant called Otto fuel II which is also used in the Mark 48 and Mark 46 torpedoes $^{12}$. Otto fuel II is capable of combusting without an oxidant, as the three constituent parts react with each other on heating.

Fully electric system - The AIP options available were determined to be batteries or AIP. Given the mass and volume requirements calculated for underwater performance, it was anticipated that the sizing results for air propulsion were prohibitive.

Both options would be potentially hazardous to ship’s crew as well as the ship; Otto fuel II is toxic. AIP generally requires an oxidant and, in some cases, hydrogen which could cause explosive consequences. Therefore, refueling of the U3V would be relatively dangerous and, in some locations where $11 \mathrm{~m}$ RHIBs are handled (e.g. stern ramps) the refueling process would be ill-advised. Therefore, a propulsor and/or motor that can be used in all environments was judged to be technically infeasible. Instead, the propulsion systems were separated. There remained, however, a further decision to be made as to which aero engine to adopt for the design. Requirements to possibly have to enclose the aero engine in a pressure vessel (PV) meant the design could be either volume-driven or weight-driven in the submerged condition.

To make an informed decision prior to the concept sizing, certain properties of the craft were assumed and the required thrust calculated. With an estimate of the thrust, four engine types are assessed for size, weight and fuel consumption.

\section{Thrust estimation}

The required installed thrust was calculated using four means: linear-fit estimate of weight/horsepower for flying boats, power-fit estimate of horsepower/weight for flying boats, thrust matching based on a blended-wing lift-drag ratio, or seaplane parametrics with horsepower/weight based on seaplane speed. These methods provide a power range of 590-800 hp at 1,350-2,200 lb thrust at Mach 0.3. The thrust-matching method also provided a cruise thrust that was used to estimate fuel requirement.

\section{Engine sizing and fuel}

The thrust matching technique provides thrust at take-off and in cruise. This meant engine sizing and fuel estimates based on work conducted for the Flubmarine concept study [1] may be performed. The study provides a sizing method for four engine types: a scaled ARGUS pulsejet [17] with additional efficiencies in the thrust coefficient (bypass cowling) and specific fuel consumption (timed ignition), and a scaled HS-1A pulsejet [16], a generic 'rubber engine' turbofan (with moderate bypass ratio), and a

\footnotetext{
${ }^{12}$ Otto Fuel II. Available From: http://en.wikipedia.org/wiki/Otto_fuel_II [Accessed on 7th September 2012]
} 
'rubber engine' turboprop. The original project sizing tool went into considerable detail, particularly for the pulsejets; the methodology is described briefly in Table 3.

\begin{tabular}{l|l}
\hline $\begin{array}{l}\text { Modern } \\
\text { Argus }\end{array}$ & $\begin{array}{l}\text { Thrust coefficient is a sixth-order polynomial fit against Mach number, augmented 80\% for the addition of } \\
\text { a bypass cowl. Specific fuel consumption is a sixth-order polynomial fit against Mach number, reduced } \\
15 \% \text { for the inclusion of timed ignition. Engine weight is determined from cross-sectional area, which } \\
\text { depends upon maximum thrust. Mounting, fairing and accessory weights are scaled from the engine } \\
\text { weight. }\end{array}$ \\
\hline HS1A & $\begin{array}{l}\text { Thrust coefficient is fixed. A sixth-order polynomial fit against Mach number determines specific fuel } \\
\left.\text { consumption (for } \mathrm{C}_{\mathrm{f}}=3, \mathrm{sfc}=2.53 / \mathrm{hr}\right) . \text { Weights are determined in a similar manner to Argus. }\end{array}$ \\
\hline Turbofan & $\begin{array}{l}\text { Specific fuel consumption and engine weight are determined from thrust, based on best-fits with real- } \\
\text { world engines. }\end{array}$ \\
\hline Turboprop & $\begin{array}{l}\text { Stroke horsepower is back-calculated from maximum thrust and speed through standard conversion. } \\
\text { Specific fuel consumption and engine weight are determined from stroke horsepower, based on best-fits } \\
\text { with real-world engines. }\end{array}$ \\
\hline
\end{tabular}

Table 3 - Propulsion sizing methodologies

Engine size and weight is derived from the maximum thrust required (usually take-off). However, fuel weight is calculated predominantly from cruise thrust. At this stage, the following simple relation is used:

\section{Equation 1 Fuel weight $(\mathrm{lb})=\mathrm{SFC}(/ \mathrm{hr}) \times\{0.9 \times$ cruise thrust $(\mathrm{lb})+0.1 \times$ take-off thrust $(\mathrm{lb})\}$}

Table 4 shows that the turboprop is the most efficient engine. However, the turbofan engine is very light, minimizing displacement, hence hydrodynamic resistance above water. The pulsejet options are heavy due to their large size with the bypass duct included. In addition, the engines have high fuel consumption even with 'thrust augmentation' and assumed reductions in specific fuel consumption. In summary, turboprops and turbofans (including fuel) are likely to make up 10-15\% of maximum weight whereas the pulsejets will likely comprise upward of $50 \%$ of total weight.

\begin{tabular}{l|cccc}
\hline Engine type & Argus & HS1A & Turbofan & Turboprop \\
\hline Engine weight (kg) & 325 & 346 & 115 & 370 \\
Fuel weight (kg) & 2,498 & 1,563 & 279 & 138 \\
Engine and fuel as a fraction of total weight & $71 \%$ & $48 \%$ & $10 \%$ & $13 \%$ \\
\hline
\end{tabular}

Table 4 - Air propulsion and fuel weights

\section{Endurance and speed}

With these propulsion tools, it was possible to evaluate the effect of varying speed and endurance on fuel and engine weight. Figure 10 shows the variation of combined fuel and engine weight for the four engine types. For the turbofan and turboprop, the variation in weight is very small with increasing speed. This is because maximum thrust is required at take-off, hence cruise speed can be increased to Mach 0.5 or more at very little cost. In fact, increasing cruise speed will have a beneficial impact on range with no more fuel required. 

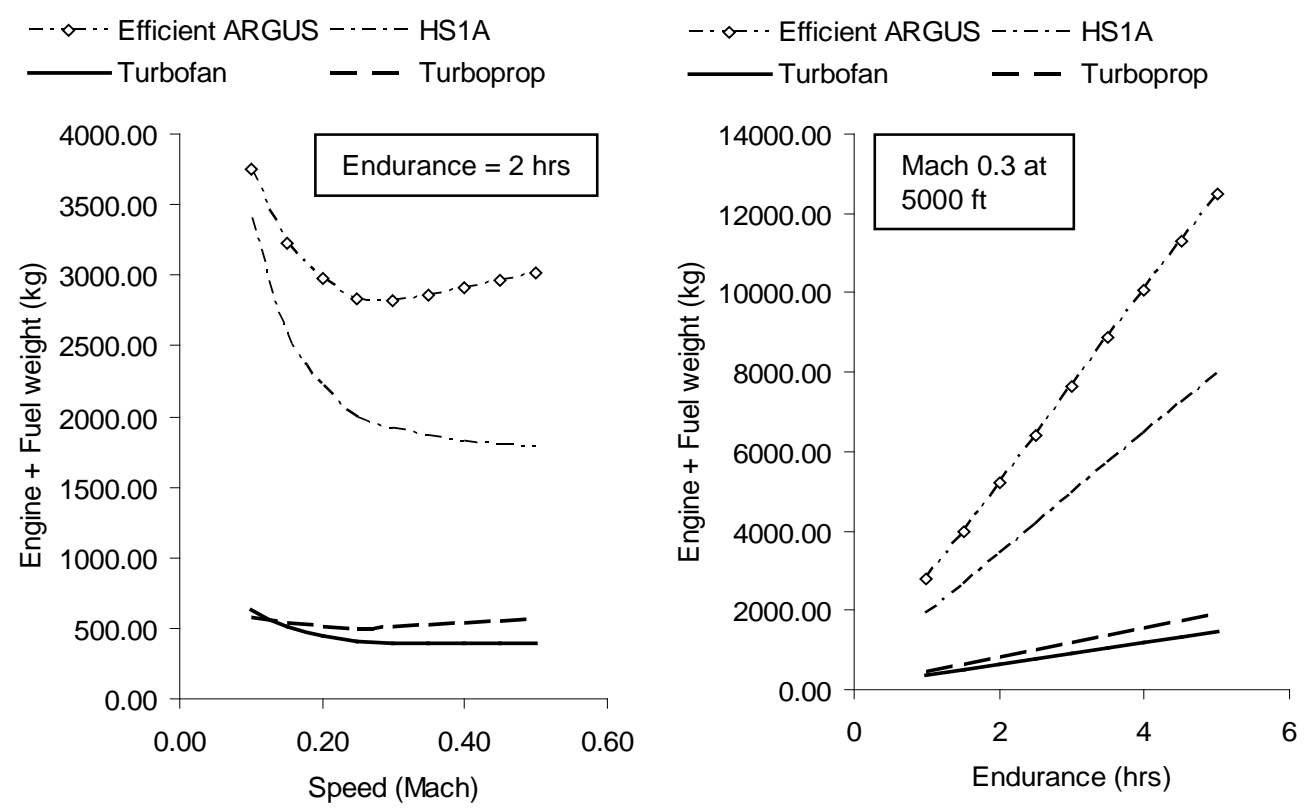

\section{Figure 10 - Sensitivity of propulsion weight to speed and endurance}

\section{Design decision}

The primary attraction of a pulsejet was that it may be immersed in water whereas a turbofan or turboprop would have to be encased within a PV for excursion at depth. This PV will add weight in all domains and buoyancy when submerged. Hence, the choice to have a PV, or not, created the buoyancy-driven or weight-driven problem. This decision would have significant impacts on the overall design and would dictate how a number of sub-systems would appear in the final vehicle. There was also an urgency associated with making this decision as, without it, the project could not progress. Unfortunately, it had to be made early in the design process when the sizing and balancing tool was not fully populated. However, despite this, a sensitivity analysis was decided as the best course of action and was undertaken using the balancing tool in its condition at the time.

The study showed that an encased aero-engine, hence a turbofan or turboprop, would produce a mass and volume balanced design due to the extra volume created which was useful underwater. In contrast, at around 1.8 times the mass of the encased aero-engine design, the pulsejet alternative would remain unbalanced as a result of too much mass or too little volume. To counter this, volumes allocated for nothing but air in the wing cavity or PVs would need to be introduced to balance the sizing model. This remedial action was viewed to produce an inelegant design.

As a result, the encased aero-engine was selected for the vehicle and, of the two options available, the turbofan was chosen due to its only slightly superior weight efficiencies.

Due to project time constraints, the sensitivity analysis was not revisited once the balancing tool was fully populated. It is recommended that re-analysis should be undertaken which may deliver an improved design outcome.

\section{Outfitting}

In the early design stages, it was also important to select the appropriate equipment to be used onboard U3V to establish weight, power, and volume 
requirements. A survey of existing unmanned vehicles in all three environments provided a list of equipment required. This is presented in Table 5.

\begin{tabular}{|c|c|c|c|c|}
\hline Equipment & Purpose & Air & Surface & Sub-Surface \\
\hline $\begin{array}{l}\text { Obstacle Avoidance and Threat } \\
\text { Sonar }\end{array}$ & $\begin{array}{l}\text { Detect oncoming } \\
\text { obstacles or threats }\end{array}$ & - & - & Required \\
\hline $\begin{array}{l}\text { Bathymetric Synthetic Aperture } \\
\text { Sonar (SAS) }\end{array}$ & $\begin{array}{l}\text { Bottom profiling and } \\
\text { surveying }\end{array}$ & - & Required & Required \\
\hline Small Tactical Radar & $\begin{array}{l}\text { Determining key targets } \\
\text { and the environment }\end{array}$ & Required & Required & - \\
\hline Acoustic Communications & $\begin{array}{l}\text { and below water surface } \\
\text { assets }\end{array}$ & - & Required & Required \\
\hline $\begin{array}{l}\text { Inertial Navigation System } \\
\text { (INS) }\end{array}$ & $\begin{array}{l}\text { Underwater covert } \\
\text { navigation system }\end{array}$ & - & - & Required \\
\hline Computer & $\begin{array}{l}\text { Processing of control } \\
\text { systems and storage of } \\
\text { sensory data }\end{array}$ & Required & Required & Required \\
\hline $\begin{array}{l}\text { Gimbaled Electro-Optical and } \\
\text { Infra-Red (EO-IR) Camera }\end{array}$ & $\begin{array}{l}\text { Optical and infra-red } \\
\text { viewing in all three } \\
\text { environments. }\end{array}$ & Required & Required & Required \\
\hline Temperature/Depth Sensor & $\begin{array}{l}\text { Data sensing and depth } \\
\text { control }\end{array}$ & - & Required & Required \\
\hline Pressure/Speed Sensor & $\begin{array}{l}\text { Air-speed and altitude } \\
\text { control }\end{array}$ & Required & - & - \\
\hline Chemical Agent Detector & $\begin{array}{l}\text { Atmosphere sensor, for } \\
\text { manned safety operations }\end{array}$ & Required & Required & - \\
\hline Mine Neutralizer & $\begin{array}{l}\text { Small torpedo to } \\
\text { neutralize mines }\end{array}$ & - & Required & Required \\
\hline Gateway Buoy & $\begin{array}{l}\text { Provide acoustic, satellite } \\
\text { iridium, radio and Wi-Fi } \\
\text { communications and GPS } \\
\text { navigation }\end{array}$ & Required & Required & Required \\
\hline
\end{tabular}

\section{Table 5 - Equipment required for U3V}

As indicated in Table 5, a gateway buoy is included onboard U3V. This includes a number of systems necessary for general operation; for example radio, satellite iridium communications, GPS, acoustic communications and Wi-Fi. The buoy is tethered to the U3V and provides electrical, physical and data connections. This makes for straightforward integration with the U3V after the buoy reattaches. Once reattached, the U3V can use all systems within the gateway buoy as though integrated permanently. The majority of these systems are not replicated within the U3V. Reasons for this include the following: reduced complexity, energy demand and vehicle mass; a number of the systems within the gateway buoy only operate above water and, as the buoy will only be deployed when U3V is submerged, they would not provide any benefits if fitted directly onto the U3V. Only one system is replicated within U3V, the acoustic communications. The reason for this was to allow the U3V to communicate with other assets in the area independent of the gateway buoy to improve the networking potential of the vehicle.

Another feature used on U3V is the expendable mine neutralizing device. This is stowed external of the outer structure and assumes neutral buoyancy, hence can be an optional addition with little impact on underwater performance. This device runs on its own integrated power supply. Guidance, however, may need to be delivered via a 
tether. It is anticipated that a man-in-the-loop will be required for the foreseeable future when firing weapons, hence the gateway buoy may need to be deployed prior to and during the use of the mine neutralizing device. As a result, above and under water currents and waves may tug at the tethers for each device causing problems with stability and maneuvering. While adequate control should be available via the propulsion system, flaps, compensation and trim systems, further modeling is required to assess these impacts.

It was anticipated that the equipment in Table 5 was not exhaustive. As a result of the significant range of possible sensor and processing systems currently available and likely to become available in the future, U3V also included an additional mass and volume allocation for unknown payloads. This was separated into two packages, one internal and one external. The internal variable payload was compensated using the water compensation tanks. For simplicity, the external variable payload was assumed neutrally buoyant, so not to affect the compensation system. In addition, should the article that is being placed in the vehicle externally not be neutrally buoyant, available volume could be allocated from the total external variable payload allocation to compensate accordingly.

\section{Sizing U3V}

\section{Sizing and balancing strategy}

The UCL procedure for sizing a submarine [3] was adopted with a number of modifications made to account for bespoke features including unmanned subsystems, PV seals and air systems. In a conventional submarine design, it is necessary to iterate only three terms - the total volume, total weight and the weight of the fixed ballast. The other terms and systems scale and balance with these three. This is a result of the conventionally configured single PV submarine. However, U3V has 3 categories of PV.

In addition, many of the aero systems, including the jet propulsion, flaps, seaplane features and aircraft fuel are heavily dependent on the overall mass of the vehicle. It was desirable to know the 'mass in air', equal to the mass of the vehicle minus ballast and compensation water, in order to size these systems. As a result, the submarine model evolved into a bespoke U3V balancing tool where the component features scaled with the design.

In summary, the features that needed to be iterated included, total volume, mass with ballast water, volume of the main sensory PVs, volume of electric motor PVs, volume of turbojet PV, mass in air and mass of fixed ballast.

\section{Sizing model}

The model was separated into the following weight groups:

Group 1 - Structure: Included the structure for; the pressure hulls, turbojet hull sealing mechanism, wing plating, wing cavity and planing hull structure;

Group 2 - Propulsion: Included the turbojet and turbojet auxiliaries, electric motors and thrusters and the lithium ion batteries;

Group 3 - Electrical Services: Included internal and external cabling and the electrical control power management system (ECPMS); 
Group 4 - Control, Communications and Payload: Included sonars, radar, communications, sensors, navigation equipment and computer equipment for processing and data storage;

Group 5 - Services: Included ballast tank operating hardware, trim rail system and flaps;

Group 6 - Outfit and Furnishings: This group included navigation lights;

Group 7 - Fixed Ballast: Included lead ballast internal to the main sensory PVs;

Group 8 - Variable Items: Included the gateway buoy, mine neutralisers, air in high pressure (HP) air bottles, aircraft fuel, internal and external variable payload bays and compensation and ballast tank water.

A full breakdown of weight, internal volume and external volume for the final design is given in Appendix D.

\section{Margins}

Margins were integrated on a risk and complexity basis; i.e. the more risky or complex a feature may be, the greater the weight and volume margin. These ranged by:

Weight - Design Margin: $1 \%$ to $15 \%$ on the following scale of novelty:

High novelty (15\%) - Turbojet PV sealing mechanism, electrical services, trim rail system and flaps;

Medium novelty (5\%) - Wing structure, planning hull structure, fuel trunking, compensation and ballast tank services and compensation water requirement;

Low novelty (1\%) - Most other features.

Growth Margin: 2\%

Volume - Applied to all items in the same way as the design margin and at the same percentage.

Packing Density - Applied to U3V's internal items and tank systems (at a percentage of $20 \%$ to $50 \%$ ) to ensure ease of packing, efficient access and spare volume for air cooling.

Mass and volume margins were not applied to ballast tank water and fixed lead ballast because these items had been precisely sized to provide neutral buoyancy and are highly sensitive to changes in mass.

\section{Weight and space overview}

The mass and volume breakdowns for various features of U3V are given in Figure 11 to Figure 16. 


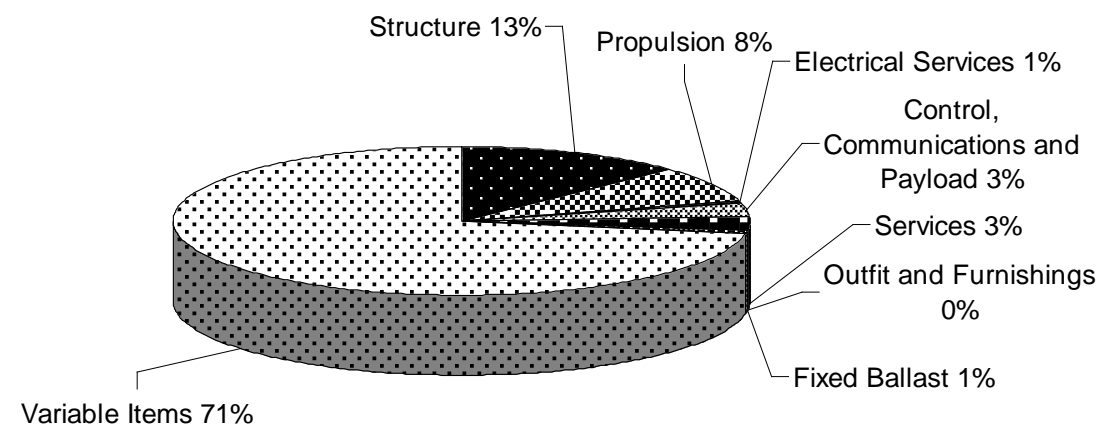

Figure 11 - Submerged mass breakdown

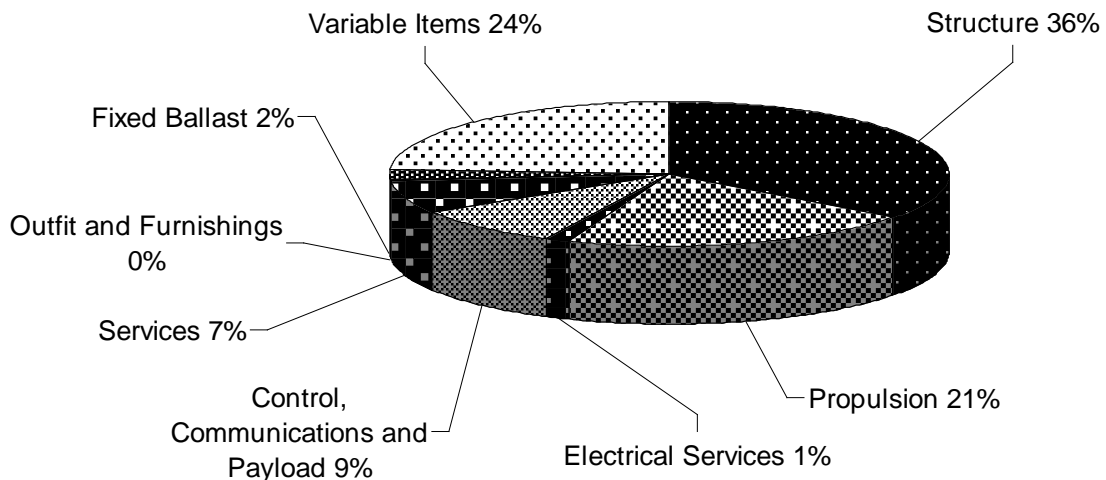

Figure 12 - Air (dry) mass breakdown

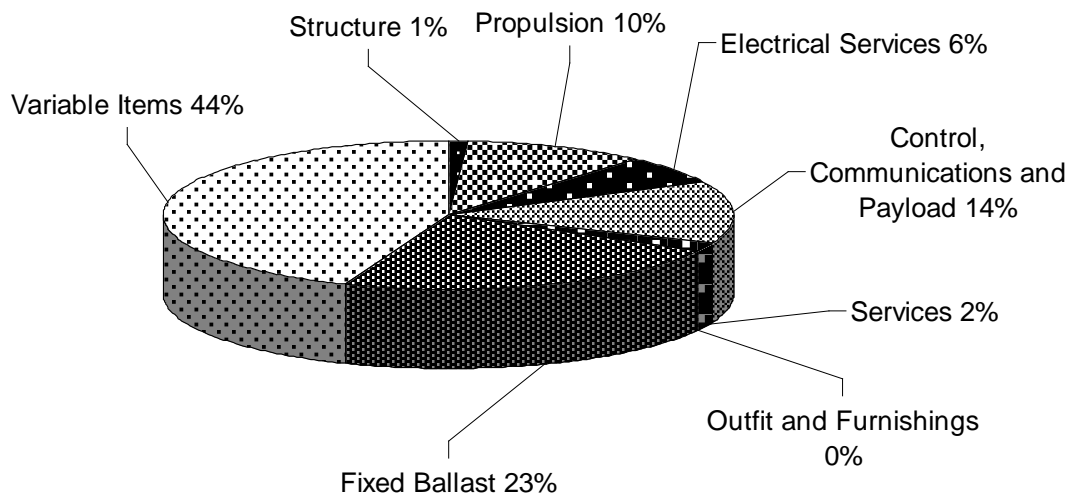

Figure 13 - Internal volume breakdown of main sensory PVs 


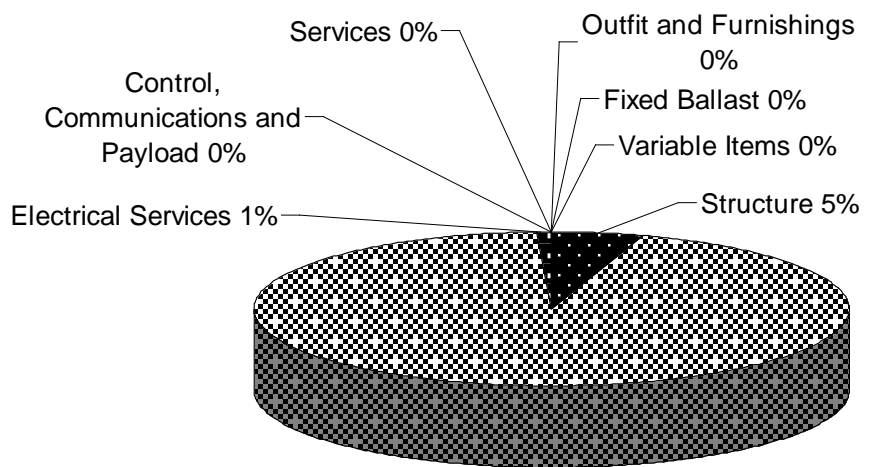

Propulsion $94 \%$

Figure 14 - Internal volume breakdown of electric motor PVs

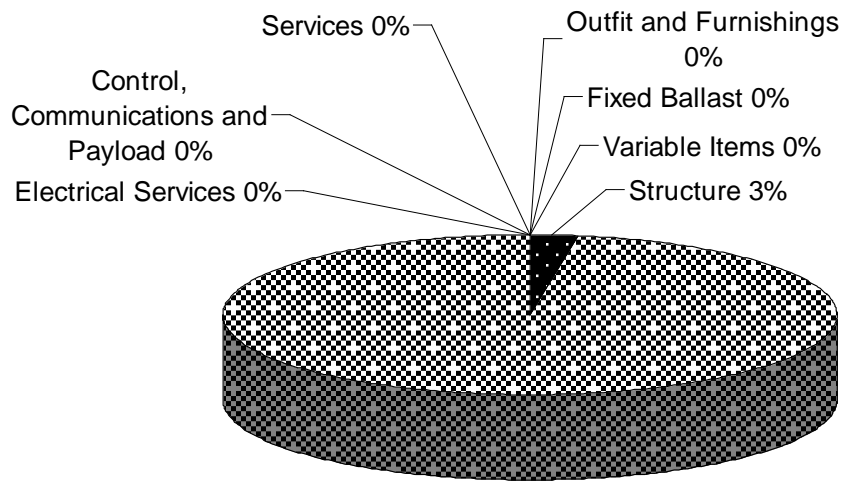

Propulsion 97\%

Figure 15 - Internal volume breakdown of turbojet PVs

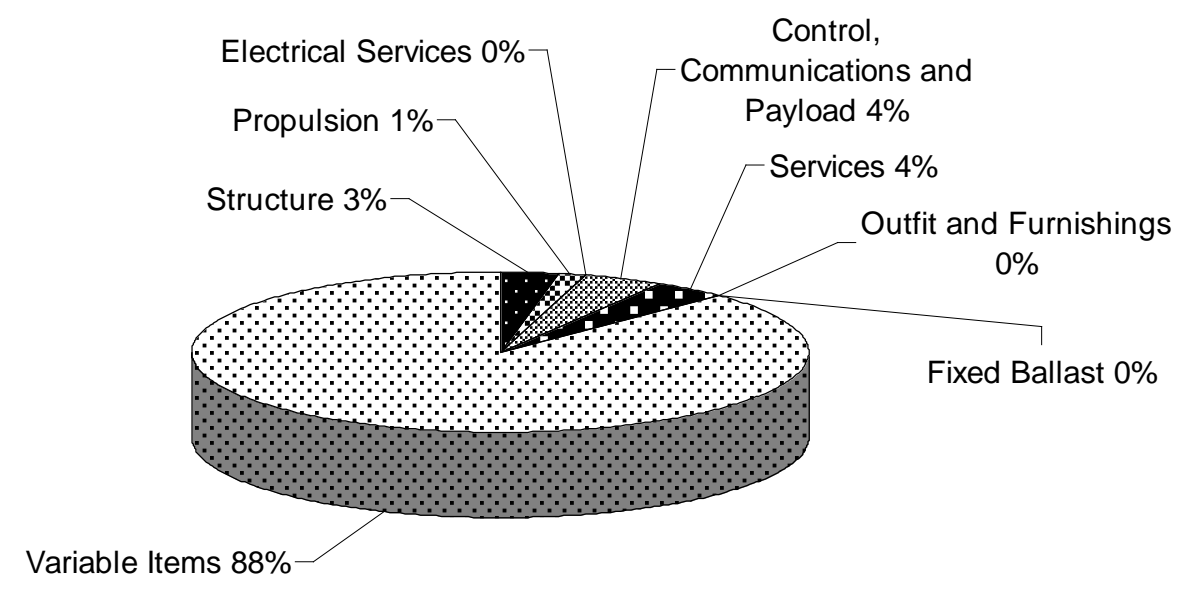

Figure 16 - External volume breakdown 


\section{Layout}

\section{Internal arrangement}

Of the three types of PV used onboard U3V, only the main sensory PV was designed with a detailed internal layout. The other two types contain, almost exclusively, the electric motors and the jet engine, hence were sized, but not arranged.

Space was allocated for six tanks per main sensory PV, four for the compensation water and two for the self-compensating AVCAT. The compensation water is split equally between the four tanks, two of which are located at the forward end and two at the aft end. When compensating, these will be filled and emptied according to the variable items used onboard. Separating the tanks provides a means of controlling trim and reducing free surface effects for stability.

To satisfy trim requirements in the air, the lead ballast trim system was located towards the aft end of the pressure hull. This allowed trimming by the stern for takeoff. However, it was also desirable to have a center of gravity as far forward as possible so as to maintain static stability in flight. Satisfying both scenarios made layout particularly complicated. As a result, it was desirable to move fixed mass as far forward as possible. This was achieved using the remaining components. These were clustered together into two groups, batteries and additional items. The additional items are listed in Table 6 . The batteries had a density of $1,900 \mathrm{~kg} / \mathrm{m}^{3}$ and the additional items a density of $980 \mathrm{~kg} / \mathrm{m}^{3}$. Therefore, the most efficient solution was to move the batteries to the forward end of the PVs. The additional items then filled the remaining cavity. It was assumed that the mass and volume was halved equally between the two hulls.

\begin{tabular}{l|cc}
\hline Item & Volume $(\mathrm{m} 3)$ & Mass $(\mathrm{kg})$ \\
\hline Electrical Control Power Management System & 0.041 & 11.7 \\
Acoustic Communications & 0.001 & 4.3 \\
Inertial Navigation System (INS) & 0.013 & 8.8 \\
Computer & 0.008 & 4.0 \\
Temperature/Depth Sensor & 0.002 & 1.3 \\
Pressure/Speed Sensors & 0.007 & 4.1 \\
Chemical Agent Detector & 0.059 & 44.9 \\
Variable Payload Internal & 0.055 & 103.0 \\
Total & $\mathbf{0 . 1 8 5}$ & $\mathbf{1 8 2 . 2}$ \\
Total per Hull & $\mathbf{0 . 0 9 3}$ & $\mathbf{9 1 . 1}$ \\
\hline
\end{tabular}

Table 6 - Additional items

A layout for each main sensory PV is given in Figure 17. The remaining volume, depicted by areas of white, would accommodate the additional items. 


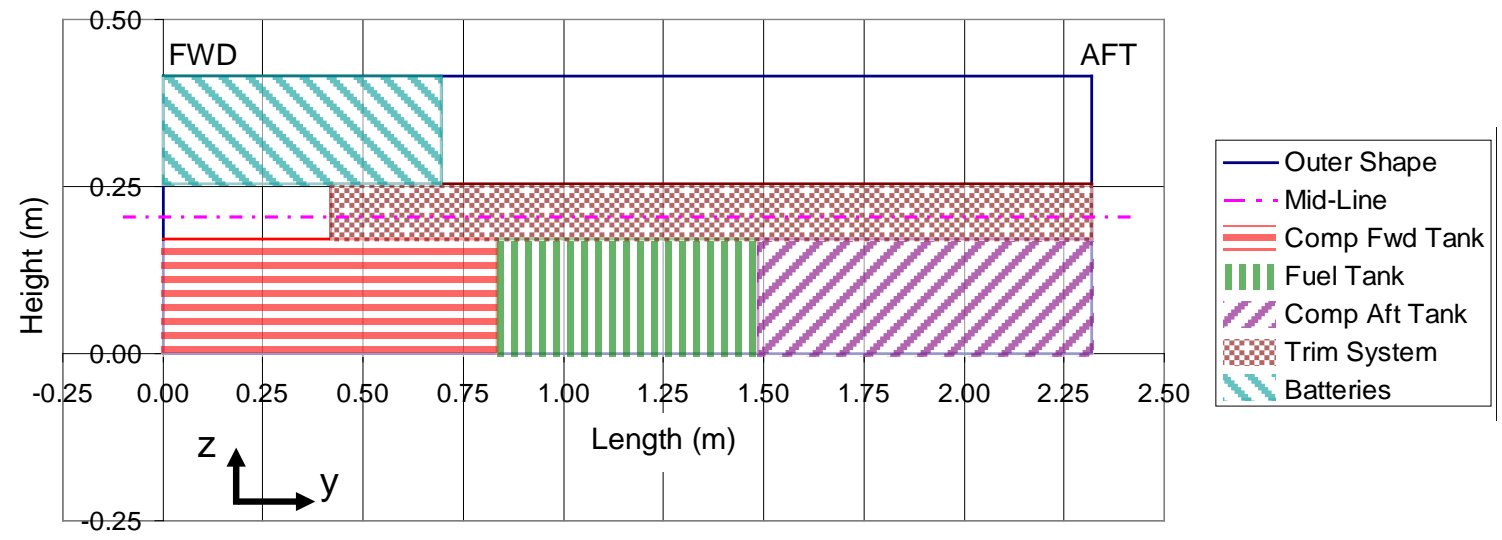

Figure 17 - Internal layout of the main sensory PV

The cylindrical shape of the PV meant that components, like the lead ballast and lithium ion batteries, had to be formed to the shape of the hull. For the latter, this may be difficult and is an area of the design that requires technical development. It is anticipated that the work BAE is doing on structural batteries and shape forming of batteries with the Lola electric race car concept may yield results. Although currently nickel based, BAE hopes to develop lithium based batteries which are far more power dense $^{13}$.

\section{External arrangement}

The NURBS surface modeling tool RHINO was used to develop and refine the external form during concept sizing. Figure 18 shows a wireframe view of the RHINO model. See Appendix E for details on how the shape was constructed.

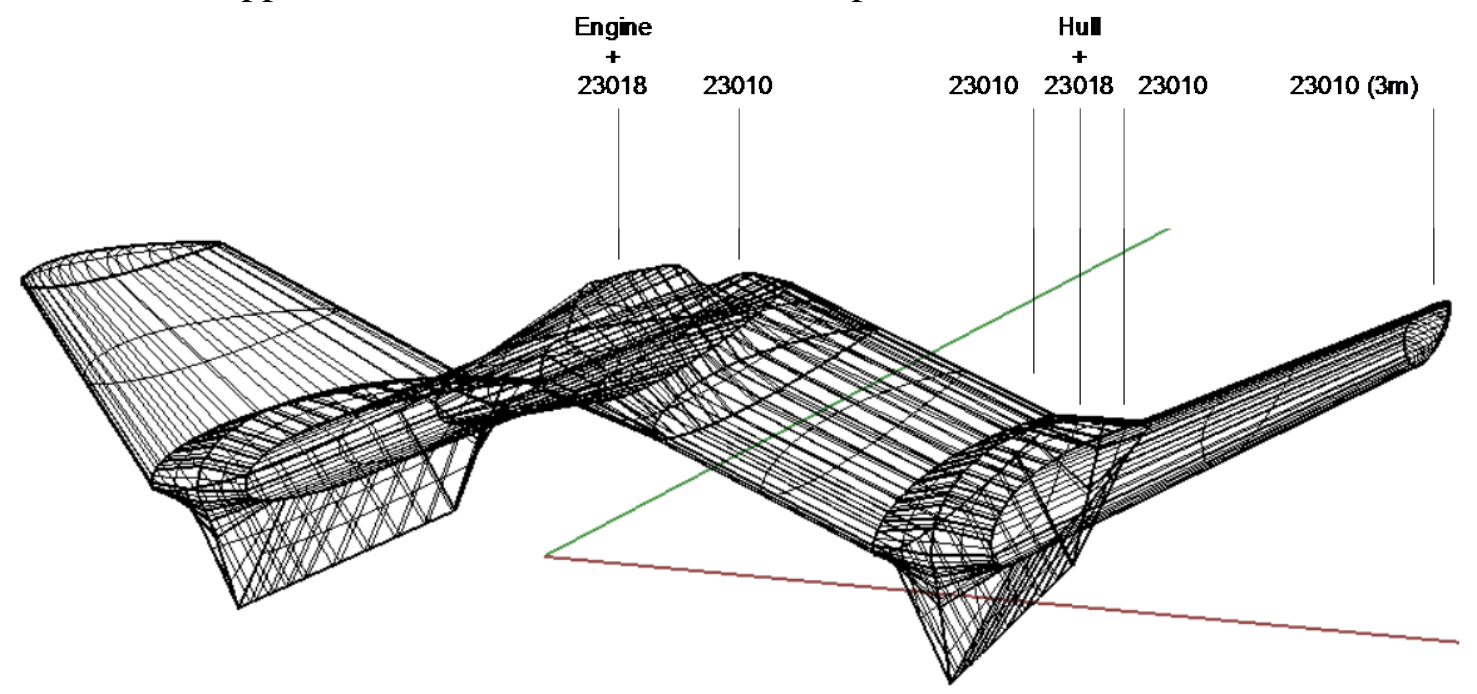

Figure 18 - Wireframe view of the refined external form

Stability requirements in air drove placement of the subsystems within the wing cavity. This meant that the center of gravity would be ideally placed directly below the center of lift. Many of the items were mirrored in the centerline of the vehicle to reduce

\footnotetext{
${ }^{13}$ BBC. BAE provides details of 'structural battery' technology. Available From: http://www.bbc.co.uk/news/technology-17014808 [Accessed on 10th September 2012]
} 
transverse stability issues. Those items that were not mirrored along the centerline were distributed as a result of their mass and operational requirements; for example:

Obstacle avoidance \& threat sonar and radar - forward facing and located at the forward end.

Gateway buoy - on the upper surface of the wing.

Bathymetric SAS - the component parts were located inline as per their requirement to work effectively.

An illustration of the subsystems within the wing cavity is given in Figure 19.

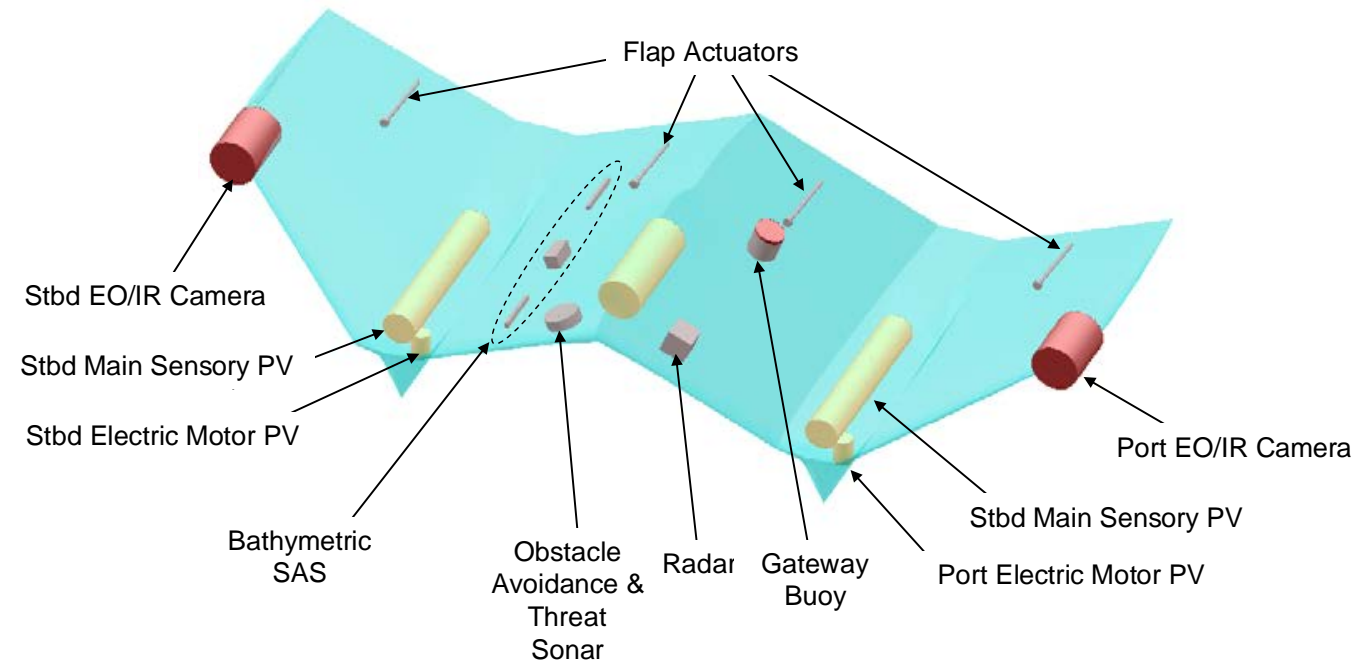

Figure 19 - External arrangement of the wing

Mine neutralizing torpedoes are located above the wing to escape slamming loads which may result from landing on the water surface. A possible design development is to incorporate the torpedoes within the wing cavity so not to affect aerodynamic and hydrodynamic resistance.

\section{Wing design}

\section{Overview}

In this concept, the wing design will determine the vessel's performance in all three domains since it makes up the external form of the vehicle. In addition, the design depends upon compromise between each of the domains of air, surface and subsurface. The design process is iterative; a change in the weight or weight distribution will affect the shape and properties of the optimal wing as will dozens of other variables.

Two programs have been used in sequence, the two-dimensional airfoil analysis and design tool XFOIL and the three-dimensional panel method wing design tool TORNADO. The procedure adopted in this study is illustrated in Figure 20. Note how the output from the wing design affects the size and configuration of a number of systems that are a part of the sizing and balancing tool. These will, in turn, affect other systems such as ballast and compensation. These interrelationships can be resolved through iteration, the judicious selection of components, margins, stepped changes or compromise. 


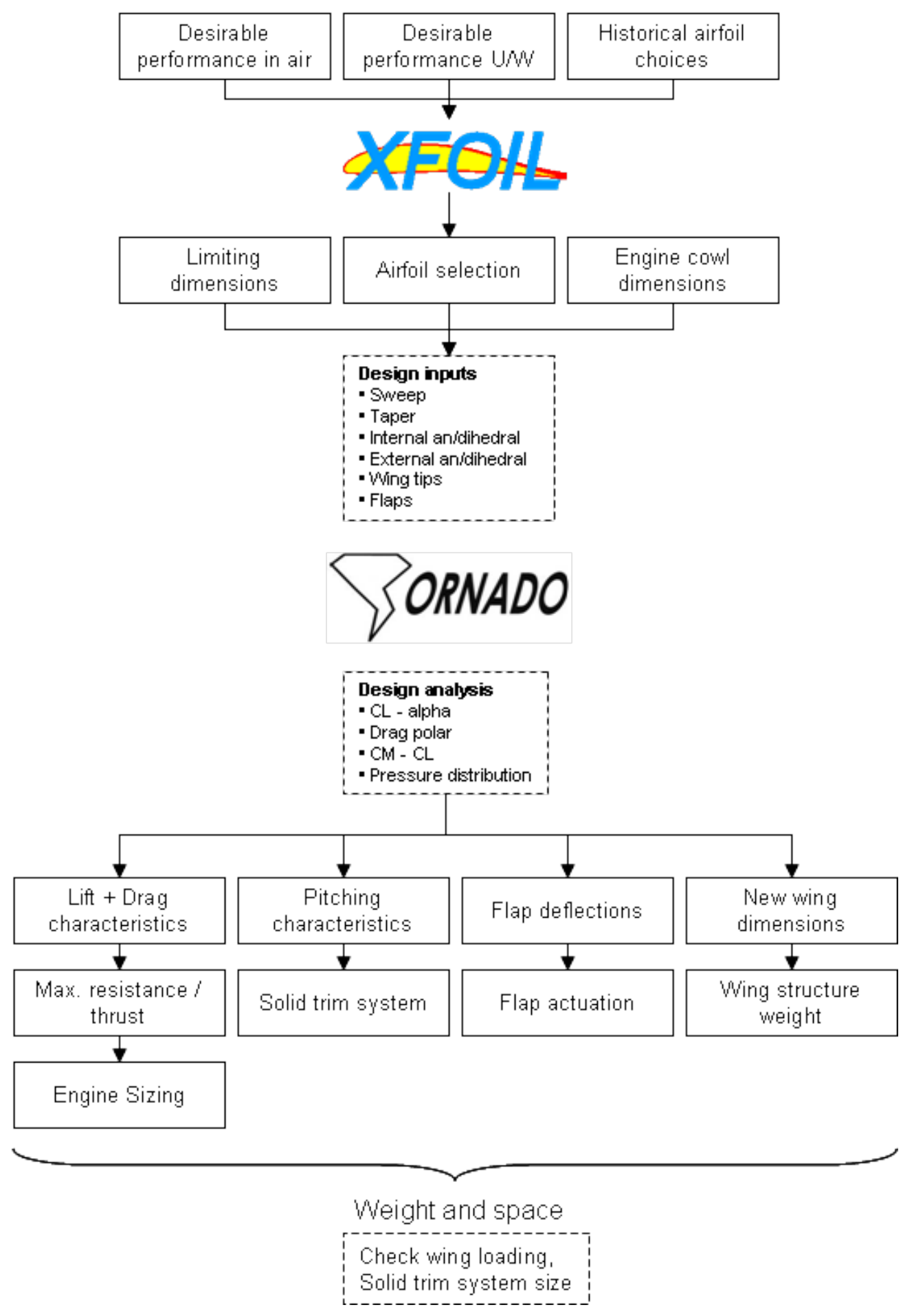

Figure 20 - Overview of the wing design process

\section{Airfoil selection}

\section{Airfoil selection objectives}

The selected airfoil must, like the rest of the concept, meet the requirements of operation in all three environments. As such, it must have sufficient thickness to be a suitable envelope for systems and payload. It must be suitable for underwater operations, that is, both low drag and low (or zero) pitching moment at zero angle of 
attack. The airfoil must be able to provide high lift at moderate angles of attack with minimal assistance from high-lift devices, so that a relatively simple configuration can take off from the sea surface. In the cruise, the airfoil must operate efficiently at low angles of attack with manageable pitching moment.

\section{Survey of aircraft}

Past aircraft were examined for initial guidance on airfoil selection. Online sources provide a wealth of information on medium-sized, lightweight blended wing body aircraft and their inboard and outboard airfoils ${ }^{14}$. It is important to be mindful of 'false friends', such as the Northrop Grumman B-2 Spirit which has an airfoil optimized for flight in the supercritical regime. Appendix F lists the applicable candidates after the aircraft survey. It is apparent that many aircraft share similar or identical airfoils. As such, the airfoil selection process was narrowed down to four options, plus a fourseries symmetrical foil (NACA 0015) for comparison:

NACA 23018

Wortmann FX 05-191

NACA M6

NACA 66-018
Baynes Bat (glider)

Mitchell U-2 Superwing (glider)

Hoffman (flying wing)

Northrop XB-79 (fighter)

\section{Airfoil selection}

The tool XFOIL was used to assess the performance of each airfoil against requirements derived from the objectives described earlier. XFOIL is a terminal-based program for the design and analysis of subsonic airfoils ${ }^{15}$. Only the analysis segment was used. Viscous analysis was performed at the take-off state $\left(\operatorname{Re}=9 \times 10^{5}\right.$ and Mach 0.12 ) for the possible airfoils.

The airfoils were compared by normalizing against a maximum or minimum value and weighted according to the relative importance of each category (see Appendix $\mathrm{G}$ for more details). The resultant figure of merit shown in Table 7 demonstrates that the best compromise between these, at times, conflicting requirements is a five series NACA airfoil with very little camber, the NACA 23018 (Figure 21). The NACA 23018 was preferred for the 'Baynes Bat', a tailless experimental flying wing glider. Suggested as a means to carry tanks into battle in the Second World War, its proposed role was almost as unusual as the subject of this report. The selection of the NACA 23018 is in agreement with available AIAA initial concept design guidance.

\footnotetext{
${ }^{14}$ University of Illinois. UIUU Airfoil Coordinates Database. Available from: http://www.ae.illinois.edu/m-selig/ads/coord_database.html [Accessed on 23rd May 2012]

${ }^{15}$ MIT. XFOIL. Available from: http://web.mit.edu/drela/Public/web/xfoil/ [Accessed on 23rd May 2012]
} 


\begin{tabular}{l|c}
\hline Airfoil & Figure of Merit \\
\hline NACA 0015 & 2.1 \\
NACA 23018 & 3.3 \\
Wortmann FX 05-191 & 0.1 \\
NACA M6 & 1.8 \\
NACA 66-018 & 0.8 \\
\hline
\end{tabular}

Table 7 - Airfoil figure of merit

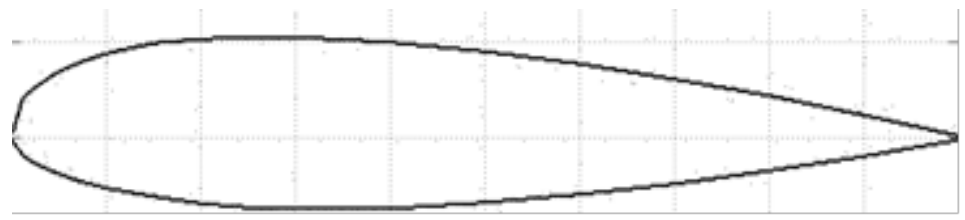

Figure 21 - NACA 23018 airfoil section

\section{Selected airfoil properties}

Figure 22 shows the results of an alpha sweep on the selected airfoil. The central plot shows the relationship between angle of attack (x-axis), section lift coefficient ( $C_{l}$, inner y-axis) and section pitching moment $\left(C_{m}\right.$, outer y-axis). The section lift coefficient is the upper curve on the plot and increases linearly until 10 degrees after which the lift continues to increase at a slower rate. The section pitching moment coefficient is almost zero until 10 degrees angle of attack, after which it becomes slightly and increasingly negative.

The plot on the left side of the figure shows the drag polar, with the section drag coefficient on the x-axis. The slope of the curve changes abruptly at the $C_{l}$ for $10^{\circ}$ angle of attack. The right-hand plot shows the points of transition (from laminar to turbulent boundary layer) and separation of flow, although these are not pertinent to this analysis.

There are diminishing returns to increasing angle of attack above $10^{\circ}$ as drag and pitching become greater problems. These data can serve as a guide in the general objectives of the wing design. 

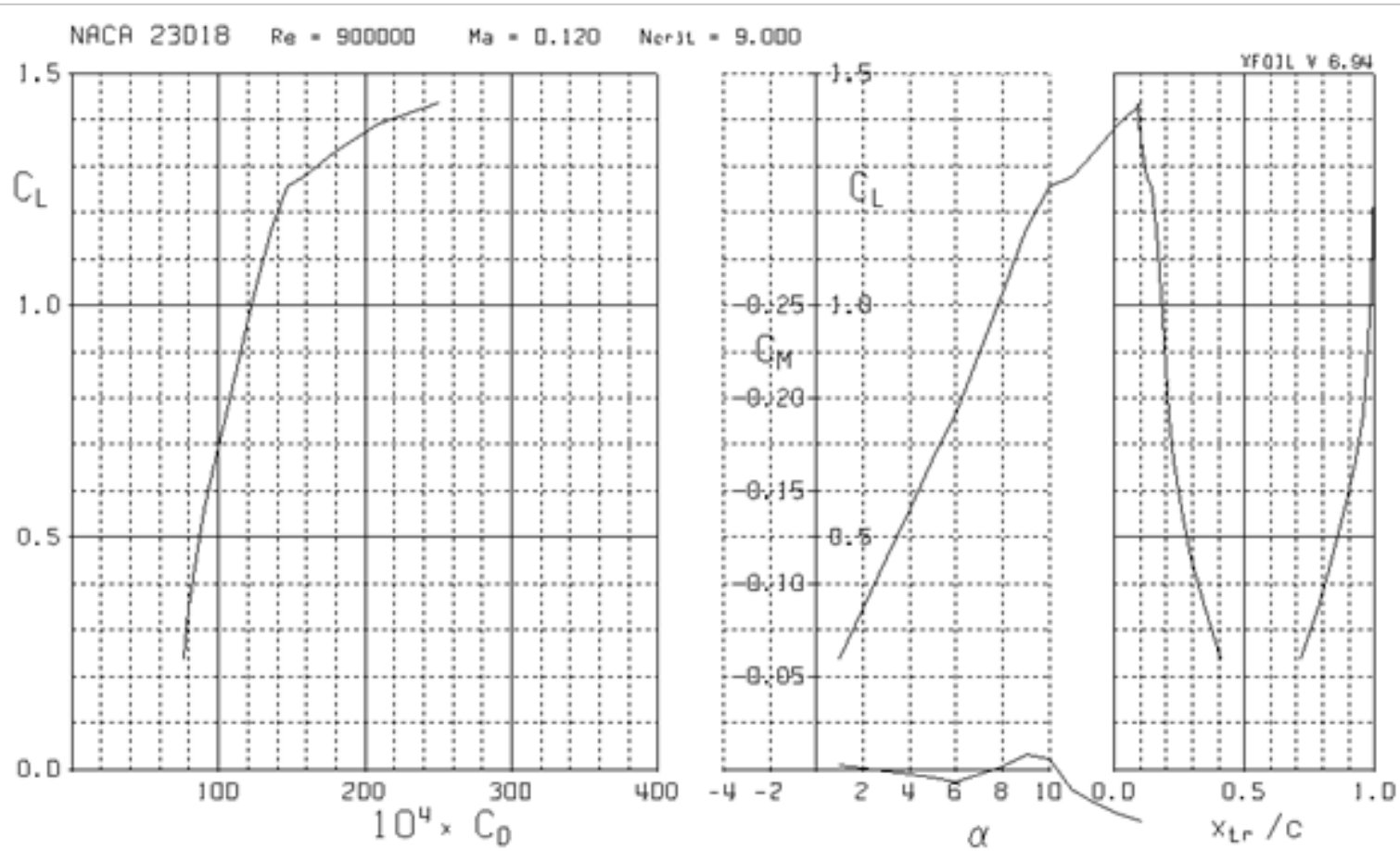

Figure 22 - Properties of NACA 23018

\section{Wing design}

\section{Wing design objectives}

With the airfoil selected, the characteristics of the wing may be selected. It was assumed that there is one air engine and that it is located on the centerline for greater efficiency and maximum water clearance. It was also known that there are two hulls and that they must be separated by a distance sufficient to provide lateral stability. Take-off is the limiting condition where lift and drag are the greatest. This is because the craft will be at its maximum take-off weight and the wing will be at the greatest angle of attack (resulting in greater drag). The engine sizing showed that the dimensions and weight of the propulsion is relatively invariant with thrust, so lift is the most important design objective. The greater the lift, the lower the required take-off speed and/or the less wing area is necessary.

The engine intake must be located sufficiently above the surface to avoid ingesting water during take-off or landing and may be additionally protected from spray by positioning it above the wing and aft. The wing itself must have sufficient lifting area exposed to generate sufficient aerodynamic lift during the take-off run (but minimized to reduce drag, particularly underwater).

\section{Wing design tool - TORNADO}

The TORNADO tool ${ }^{16}$ was used to analyze the suitability of different external forms and configurations in the air domain. TORNADO builds the wing from straight 'partitions' that can have different inboard and outboard airfoils as shown on the upper part of Figure 23. Each partition comprises panels spanwise and chordwise, the number

\footnotetext{
${ }^{16}$ Tornado. Available from: www.redhammer.se/tornado [Accessed on 23rd May 2012]
} 
of which are defined by the user. For comparative design decisions, the number of panels in each direction is as low as 5 for each partition. For final calculations and complex geometries, the number of panels per partition will be greater than 400 . The only high-lift devices permitted in TORNADO are simple single flaps, which are similarly paneled.

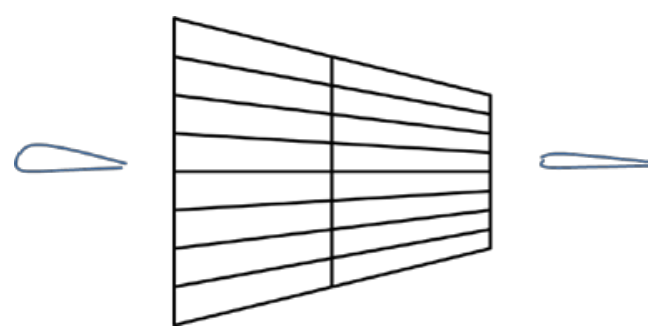

Figure 23 - TORNADO paneled partition

\section{Wing design geometry}

It is worth considering the key variables in a simple geometry model. Figure 24 shows one potential frontal profile and the key variables that are required to build up the wing. The clearance can be modified through introducing a spanwise angle to the wing; anhedral means wings lower outboard, while dihedral means wings higher outboard. This will assist in generating sufficient freeboard for the engine and wings.

The geometric guidance provided in Figure 24 is flexible. For example, the 'hull' may be a separate entity to the 'wing' or it may be possible to use some part of the wing volume as the hull, especially considering the very large available volume of the wing. However, the hull must clearly be designed watertight whereas much of the wing is designated free-flood when submerged.

Sweep can be used to introduce an effective dihedral [4] to move the lifting area away from the sonic cone at high speed and to control the position of the aerodynamic center. It is the last of these uses that is relevant to this design. Increasing sweep also moves the center of gravity, since the wing weight moves aft.

The taper ratio at the inboard and outboard wing sections can be used to control the total wing area. The degree of taper ratio can be varied between the wing sections if more or less control is required at the outboard points.

Aircraft wings also have twist, a variation in the angle of attack along the span. This is designed for stability and control purposes, but has not been calculated in this concept.

\section{Integration of hulls and engines}

Appendages such as the engine nacelles will have an effect on the performance of the wing. They can be integrated with the wing or located on sponsons in pods above or below the wing as illustrated in Figure 25. The former has the advantage of reduced structural weight and no bluff body drag while the latter preserves maximum lift across the wing. In this concept, the hull and engines are all integrated into the airfoil. This is represented in TORNADO by creating custom airfoils that include the integrated elements. 

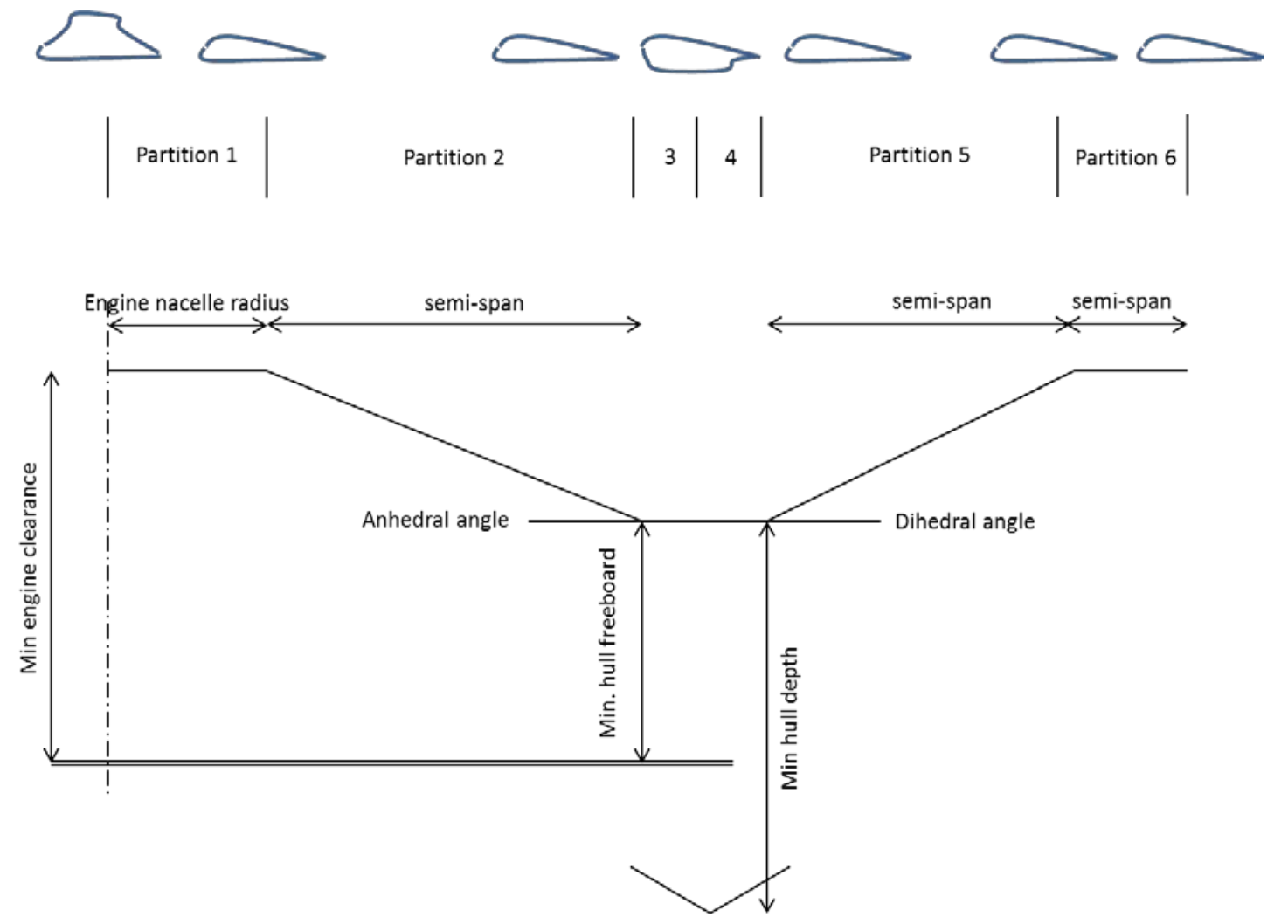

Figure 24 - Simplified wing geometry variables (frontal view)

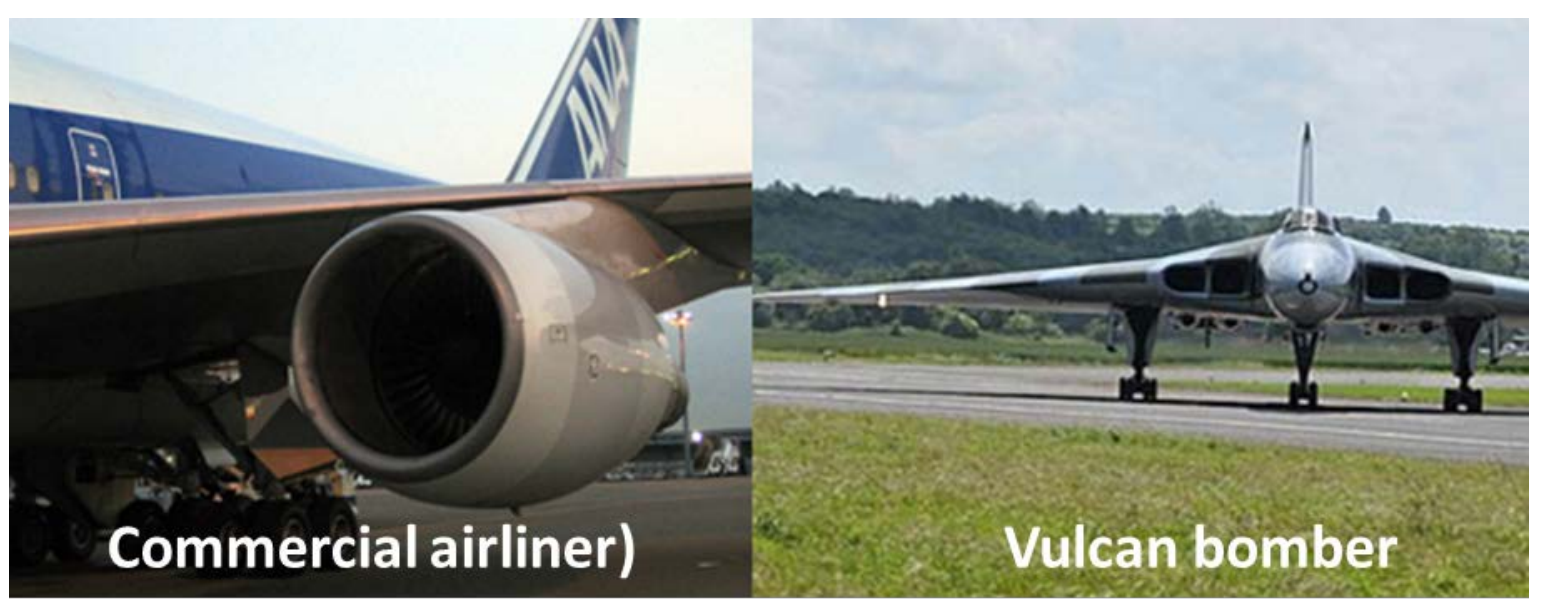

Figure 25 - Sponsoned versus integrated engines

For 90 kts airspeed at sea level, six degrees angle of attack and 15 degrees flaps, Table 8 shows the loss of lift as a percentage of a totally clean wing. In addition, integral hulls and engine necessitate the introduction of a dihedral. The data show that the integration itself has less of an effect on lift than the dihedral. Although estimates of sponson drag are not available, the availability of internal wing volume suggests that integration is a sensible approach and that the reduction in lift is more than outweighed by the reduction in structural weight and bluff body drag. 


\begin{tabular}{l|c}
\hline Component & Loss of lift (\%) \\
\hline Bare wing, no dihedral & 0.00 \\
Bare wing, dihedral & -5.99 \\
Integral hulls, dihedral & -8.02 \\
\hline Hulls and nacelles, dihedral & -8.15 \\
\hline
\end{tabular}

Table 8 - The incremental effect of dihedral and integration of appendages on lift

\section{Relative partition size}

The separation between twin hulls on a seaplane is normally driven by lateral stability. Separation also affects the spanwise distribution of lift as shown in Figure 26. The equations for lateral stability are for classically configured craft which is certainly not the case here, so there is some argument for flexibility to maximize the performance of the blended wing. The charts in Figure 27 show the effect of varying the size of the central partition using the same wing geometry as in the previous section.

The first chart shows that lift does increase with greater central span. However, the second chart shows that while lift increases, drag increases more than proportionally. Finally, the third chart shows a reduction in the total wing lift coefficient with increasing semi-span. This means that the increase in lift cannot be attributed to a more efficient total wing. Indeed, it means the opposite. The increased lift comes only from the increase in total area of the wing. While the central wing is permitted a greater area, the outboard wings are not substantial enough to develop the elliptical spanwise lift distribution which leads to this result. The results imply that totally separated partitions (not just minor changes in sweep or dihedral) should have equal span, within the limits of lateral stability of the craft on the sea surface.

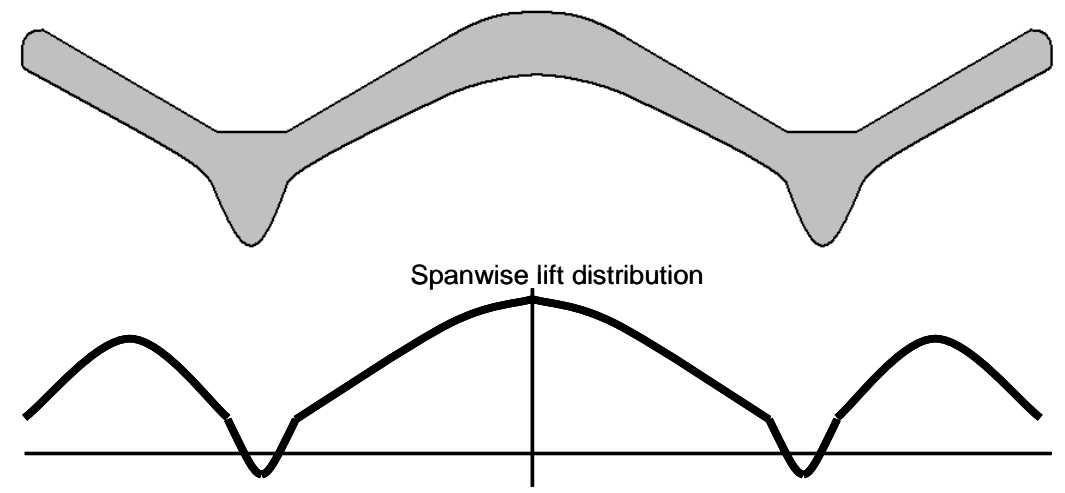

Figure 26 - Typical spanwise lift distribution 

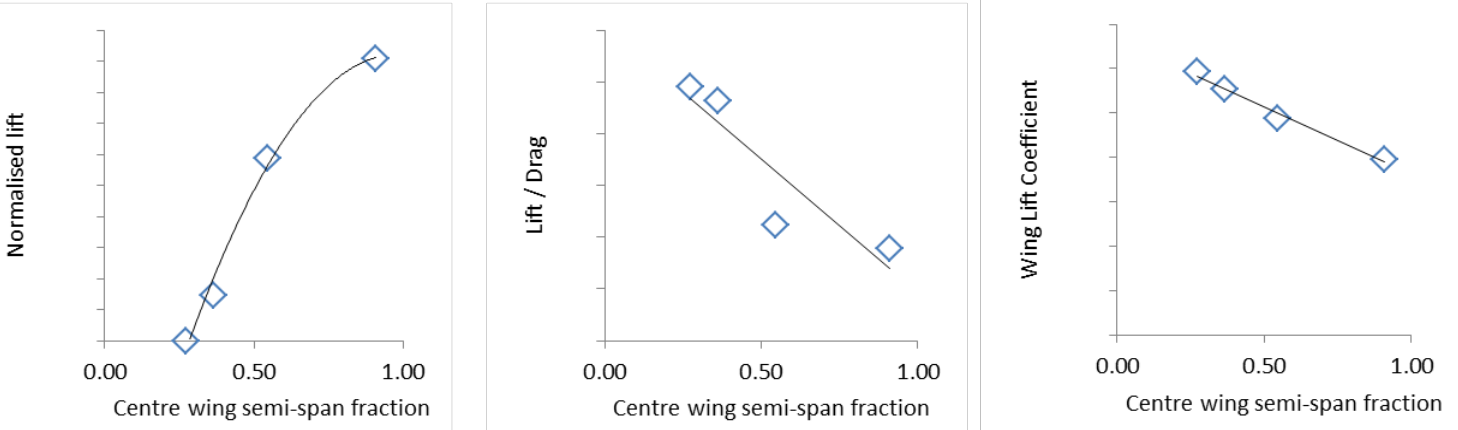

Figure 27 - The effect of relative partition size on wing performance

\section{Angle of attack and high-lift devices}

Since the craft is close to a flying wing in layout, it is not necessary to calculate the angle of incidence of the wing to the central fuselage. However, an efficient and relatively simple combination of angle of attack and high-lift devices is necessary to take-off at a reasonable speed.

A multitude of high-lift devices are available at the leading and trailing edges, including blown systems. However, the need to operate in such a range of harsh environments demands that the system is simple and rugged. In addition, the chosen devices will need to assist with the roll and pitch of the craft above and under water and resist any loads resulting from accidental immersion at speed. Single-section 'flaperons' comprising $20 \%$ of the chord were selected for this concept. Since the design does not have a tailplane, the high-lift devices act as both flaps (for pitch) and ailerons (controlling roll).

Having selected the flaps, it was necessary to assess the correct combination of wing and flap angle of attack for most efficient lift. Table 9 shows the effect of four wing-flap combinations on lift, normalized against six degrees wing angle of attack and 15 degrees on the flaps. As would be expected due to its far greater area, it is preferable to increase wing angle of attack, but it is important to remember that airfoil performance deteriorates above $10^{\circ}$.

\begin{tabular}{c|cc}
\hline $\begin{array}{c}\text { Angle of Attack } \\
\text { (deg) }\end{array}$ & $\begin{array}{c}\text { Flaps } \\
\text { (deg) }\end{array}$ & $\begin{array}{c}\text { Increase in lift } \\
\text { (\%) }\end{array}$ \\
\hline 6 & 15 & 0 \\
12 & 15 & +44 \\
6 & 30 & +38 \\
\hline 12 & 30 & +42 \\
\hline
\end{tabular}

Table 9 - The effect of four wing-flap combinations on lift

\section{Wing geometry summary}

The final wing design incorporates equally sized wing sections with the geometry described in Table 10. The engine cowl on the centerline and hulls are accounted for through partitions with modified profiles. The flow through and around the engine 
cannot be accurately calculated in TORNADO. The final wing area is $51 \mathrm{~m}^{2}$ and results in a very low aspect ratio of 2.4, necessary to reduce take-off speed.

\begin{tabular}{l|cccc}
\hline Partition number & 1 & 2 & 3 & 4 \\
Description & Center wing & Hull, inboard & Hull, outboard & Outboard wing \\
Taper ratio & 1 & 1 & 1 & 0.6 \\
Root chord (m) & 5 & 5 & 5 & 5 \\
Tip chord (m) & 5 & 5 & 5 & 3 \\
Inboard airfoil & $\begin{array}{l}\text { NACA } 23018+ \\
\text { engine cowl }\end{array}$ & NACA 23018 & NACA 23018 + & NACA 23018 \\
Outboard airfoil & NACA 23018 & NACA 23018 & NACA 23018 & NACA 23018 \\
Semi-span (m) & 2.1 & hull & & 2.4 \\
Dihedral (m) & -21 & N/A & N/A & 20 \\
Flap chord fraction & 0.2 & & & 0.4 \\
Take-off flap setting & 20 & & & 20 \\
\hline
\end{tabular}

Table 10 - Summary of wing properties

\section{Wing performance}

The performance of the wing is most important in three states. First, the craft must be able to take-off at a high angle of attack and with flaps fully activated. Second, cruise should occur at high speed at lower angle of attack and with minimal flaps. Finally, lift and drag must be minimized and pitching moment nearly zero when submerged.

The performance data in the previous table are calculated as follows. With the wing geometry and flap settings fixed for take-off and cruise, an alpha sweep can be used to determine the performance of the wings across a range of angles of attack. TORNADO produces a similar output to that of XFOIL except that it is for the whole wing. Since lift must equal weight, it is possible to calculate the angle of attack of the wing required for a given speed.

Since it is easier to express speed as an output, the angle of attack can be specified and the speed checked for acceptability. The $C_{L}$ versus $\alpha$ curve is approximated to the first order (equation 2), the 'guessed' alpha entered and the speed is calculated (equation 3).

Equation 2

$$
C_{L}=f(\alpha) \approx C_{L 0}+\frac{\Delta C_{L}}{\Delta \alpha} \alpha_{\text {guess }}
$$

Equation 3

$$
U=\sqrt{C_{L} \frac{1}{2} \rho S}
$$


Once an acceptable angle of attack is determined, the drag coefficient is simply from the drag polar (equation 4 - as in XFOIL, except in that program the coefficients are sectional). Thus, the thrust required can be calculated (equation 5) at take-off and in the cruise by approximating the relationship with a second order polynomial.

\section{Equation $4 \quad C_{D}=f\left(C_{L}\right)$}

Equation $5 \quad T=D=C_{D} \frac{1}{2} \rho U^{2} S$

Table 11 summarizes the performance of the wing in three states. The highlighted values are those that are specified while the other values emerge from these specifications. For example, the wing in air must support the weight of the craft and angles of attack were proscribed based on analysis detailed above. Minimal lift and drag, zero pitching moment and speed were requirements in the underwater arena. The drag results from TORNADO in the underwater case were so low as to be implausible. A bluff body resistance build-up is detailed in the submerged power and propulsion section and Appendix C.

\begin{tabular}{|c|c|c|c|c|c|c|}
\hline State & $\begin{array}{l}\text { Angle of } \\
\text { attack } \\
\text { (deg) }\end{array}$ & $\begin{array}{c}\text { Flap angle } \\
\text { (deg) }\end{array}$ & $\begin{array}{l}\text { Lift } \\
\text { (N) }\end{array}$ & $\begin{array}{l}\text { Drag } \\
\text { (N) }\end{array}$ & 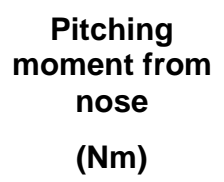 & $\begin{array}{c}\text { Speed } \\
\text { (kts) }\end{array}$ \\
\hline Take-off & $\underline{12}$ & $\underline{20}$ & = Weight & 2,618 & $-36,130$ & 63 \\
\hline Cruise & $\underline{4}$ & $\underline{2}$ & $=$ Weight & 2,104 & $-32,178$ & 100 \\
\hline $\begin{array}{l}\text { Underwater } \\
\text { sprint }\end{array}$ & -1.2 & 0 & Negligible & Negligible & $\underline{0}$ & $\underline{4}$ \\
\hline
\end{tabular}

Table 11 - Wing performance in three states

\section{Basic stability considerations}

This section discusses only the simplest stability requirements of equilibrium and the pitch restoring moment.

The aircraft is in equilibrium when the lift force equals the weight, when these forces act through the same point, and when there is no net longitudinal pitching moment. Static stability also requires that a deviation from the desired angle of attack (such as by a gust of wind) results in a restoring moment.

The condition necessary for static longitudinal stability is that that an increase in lift coefficient results in a negative pitching moment. This is best demonstrated in Figure 28. 

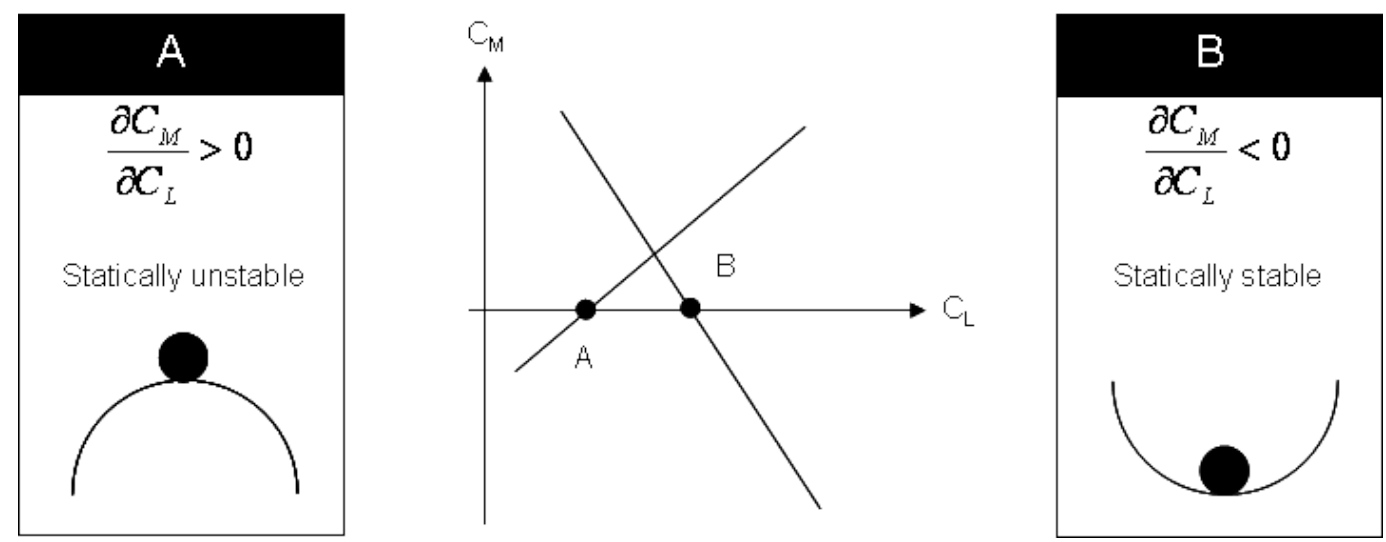

Figure 28 - Illustration of static longitudinal stability

The simplest analysis of static stability occurs when the control surface angles are fixed, known as the stick-fixed condition. The contributions to pitch response are expressed as the summation of each of the contributing elements of the craft: wing, fuselage, tail and engine(s). Since the flying wing has no tail or discernible fuselage and there is no directional control of thrust from the engine, the equation simplifies considerably [4]. The simplified equation shows that stability can be achieved by moving the center of gravity forwards $\left(x_{c g}\right)$, the aerodynamic center aft $\left(x_{a c}\right)$ and/or by manipulating the size, position and orientation of the flaps (the last term on the righthand side of equation 6).

Equation $6 \quad \frac{\partial C_{M}}{\partial C_{L}}=x_{c g}-x_{a c}-\frac{C_{L p}}{C_{L}} \frac{\partial \alpha_{p}}{\partial \alpha}\left(x_{c g}-x_{p}\right)$

The aerodynamic center is the position at which the pitching moment remains constant for all angles of attack. Since the wing dimensions are fixed, it is almost impossible to manipulate aspect ratio and sweep to move the aerodynamic center aft. An increase in the wing angle of attack will also increase the flap angle of attack, hence the flaps produce a stabilizing restoring moment in pitch because they are located aft. The use of flaps in this way effectively increases the camber of the wing and will cause increased drag.

The center of gravity can be manipulated by careful positioning of payload items and the use of moveable items can be used to control the craft. It is this that is primarily used to introduce the necessary stability in flight.

The concept attempts to place as much weight forward of the aerodynamic center as possible, assumes that a state of 'relaxed static stability' is sufficient, and that the control system can maintain stability using the control surfaces and moveable solid ballast.

\section{Powering and propulsion}

\section{Air power and propulsion}

The most demanding element of surface operations is the take-off run in which the air engine must overcome both hydrodynamic and aerodynamic resistance [8]. In addition, the craft must maintain the correct trim so that the wing can offer the maximum possible lift without dipping the trailing edges into the waves. Both are illustrated in Figure 29 [8]. 


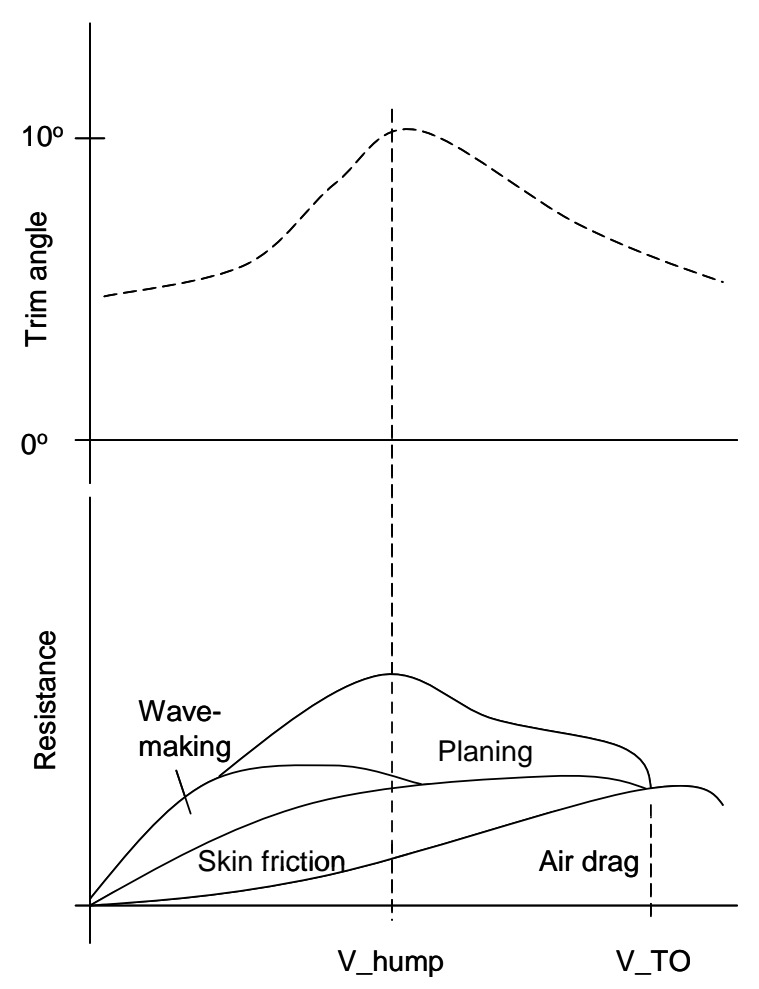

Figure 29 - Drag buildup at take-off

The variation in resistance with speed can be calculated [7] as part of an iterative sizing and balancing process. The aerodynamic and hydrodynamic forces interact and their calculation is not trivial. The aerodynamic lift force for a given wing depends upon the designed angle of incidence of the wing to the hull and the trim of the craft to the sea surface. This lift force combines with the lift generated by the hull to affect the fraction and form of the hull that is submerged. In addition, the performance of the planing hull depends upon the selection of deadrise, any trim tabs and the chine angle and position as well as the position of the step. The calculation of air resistance and powering are detailed in Appendix $\mathrm{H}$. Values at the hump speed are:

Hump speed

Aerodynamic lift

Air drag

Water drag
32.15 kts (50\% of take-off speed)

$1,439 \mathrm{lb}$

$120 \mathrm{lb}$

$411 \mathrm{lb}$

\section{Submerged power and propulsion}

\section{Submerged resistance}

To establish propulsion power requirements for submerged transit required an estimate for hydrodynamic drag. A resistance build up was calculated using wing planform area, engine cowling dimensions and float surface area. Further information can be found in Appendix C. 


\section{Submerged shaft power requirement}

Using resistance, the required shaft power was calculated. Initially, the effective power $\left(P_{e}\right)$ was calculated using equation 7 .

\section{Equation $7 \quad P_{e}=\sum(D) v=1.68 \mathrm{~kW}$}

To account for additional resistance as a result of appendages, a 10\% margin was applied, delivering an effective appended power $\left(P_{e a}\right)$ of $1.84 \mathrm{~kW}$. A shaft power margin (65\%) and a sea margin (10\%) were also used, hence the required shaft power $\left(P_{s}\right)$ was found to be $3.12 \mathrm{~kW}$.

To validate results, equation 8 , a formula for ideal submarine hull form effective power [9], was used on a range of UUVs to act as comparators.

Equation $8 \quad P_{e}=K_{P} V_{\text {Form }}^{0.64} U^{2.9}$

Where:

$K_{p}$ : Power factor (equal to 20 for ideal, cigar shaped, boats)

$V_{\text {Form: }}$ Form volume

$U$ : Velocity

The form volumes were estimated for each UUV using their dimensions to size torpedo shaped bodies. A margin of $10 \%$ was applied for appendages to provide the effective appended power. Results are illustrated in Figure 30.

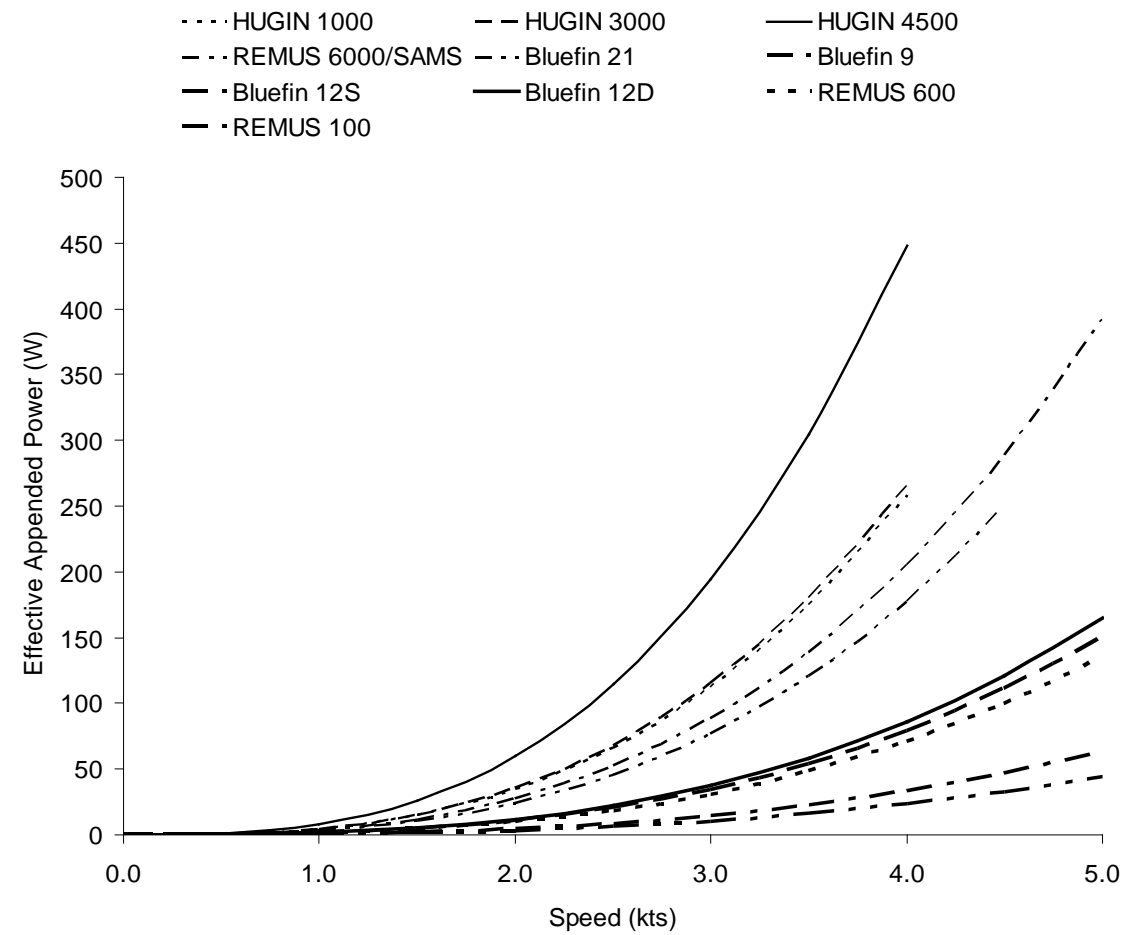

Figure 30 - Effective power against speed for a range of torpedo shaped UUVs 
The maximum power was calculated to be $450 \mathrm{~W}$; this was for the HUGIN 4500 at a maximum speed of $4 \mathrm{kts}$ (the same maximum velocity as U3V). The effective appended power of U3V was estimated at 1,840W. This significant difference in power was a product of the differences in size and shape of the two vehicles as expected. Despite this, order of magnitude accuracy was established and the calculations assumed reliable.

\section{Hotel load requirement}

The analysis of existing UUVs provided a means of estimating the hotel load requirements. This was found to be 200W. The process is discussed in more detail within Appendix C. This hotel load power was substantiated by a subject matter expert. Additional features which traditional UUVs do not require were added to the 200W. This included the flaps (which may be used underwater to aid depth control), the sealing mechanism for the jet engine and various ballast and compensation pumps. As a result, an additional hotel load of around $624 \mathrm{~W}$ was calculated. Calculations for the jet engine sealing mechanism power requirements are located in Appendix I. The total hotel load was therefore assumed to be $824 \mathrm{~W}$.

\section{Energy storage}

Traditionally, UUVs have used batteries as the prime energy storage method. The majority use the lithium ion variety. Over and above their competitors (namely lead acid and Zebra batteries), lithium ion batteries offer high power and energy densities, low maintenance, relatively inexpensive replace costs, and efficient recharging times. Other forms of batteries used in UUVs are the semi-fuel cell variety used in the HUGIN 3000 and HUGIN 4500. This technology is bespoke to these large HUGIN variants due to their operating requirements for high sustained speeds for a long endurance time (4 kts for 60 hours) and high hotel load (multibeam echo sounder, sidescan sonar, subbottom profiler and Conductivity, Temperature and Depth (CTD)).

Within the marine environment, lead-acid batteries are traditionally used in submarines. They offer the advantage of being relatively robust and inexpensive. However, they have inferior energy densities compared to lithium ion and Zebra and, for this particular application, are not well suited for the purpose of minimizing volume and weight.

Flubmarine adopted Zebra batteries because, at the time, they were a more proven technology than lithium ion batteries in both commercial and military applications. In addition, Zebra batteries are less prone to problems associated with fires and explosions which is particularly important when designing a manned vehicle. However, U3V is not manned and, with a range of UUVs having adopted the superior lithium ion batteries, a number of the technological and safety issues associated with them have been overcome. In addition, car companies have introduced lithium batteries into their hybrid vehicles and they are being considered for some submarines including the stateof-the-art Type 216 design, suggesting the technology is safe enough to be in close proximity to a human operator. This is of importance when considering maintenance and swapping of battery packs for quick turn around when operating U3V.

As a result, the U3V design uses lithium batteries. Calculations for lead acid and Zebra style batteries were also completed to illustrate the weight and volume savings. The sizing procedure is given in Appendix C. The results, Table 12, show significant volume and weight savings with lithium ion batteries. 


\begin{tabular}{l|cc}
\hline Battery type & Volume (liters) & Weight (kg) \\
\hline Lead Acid & 167 & 342 \\
Zebra & 90 & 132 \\
Lithium Ion & 56 & 126 \\
\hline
\end{tabular}

Table 12 - Total battery volume and weight

The speed power curve, illustrated in Figure 31, was formulated for maximum hotel load (824W). The U3V endurance versus speed curve is shown in Figure 32. In loiter mode at zero velocity, 14.6 hours of endurance can be achieved.

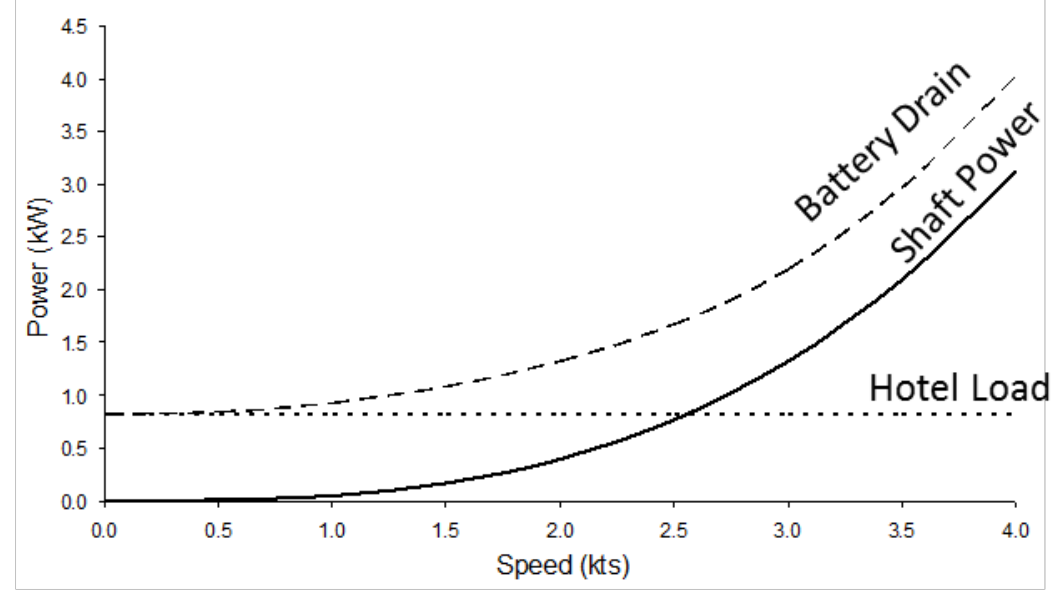

Figure 31 - Power against speed for maximum hotel load

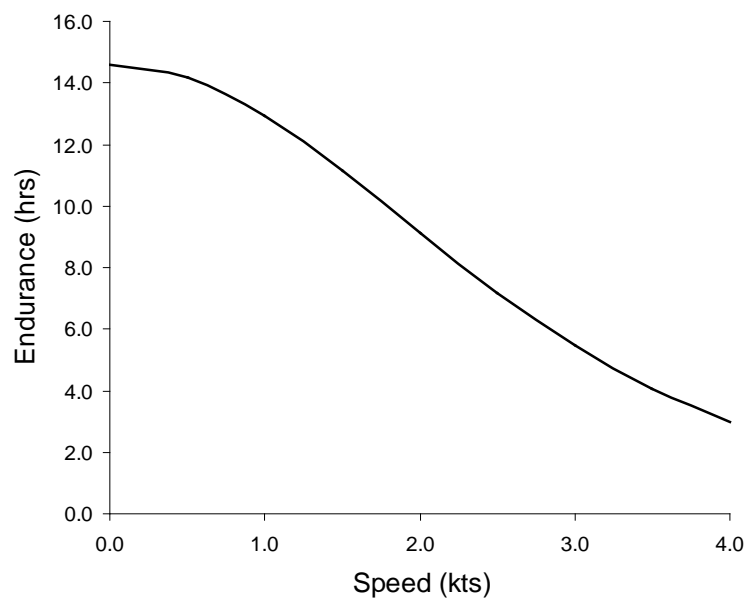

Figure 32 - Endurance against speed for maximum hotel load

However, it is unlikely the entire $824 \mathrm{~W}$ of hotel load will be required over the entire operating profile. Hence, similar graphs were created for a hotel load of 200W which, for a UUV, is coined the lean hotel load. Figure 33 and Figure 34 outline the speed power and speed endurance curves respectively for the lean hotel load. 


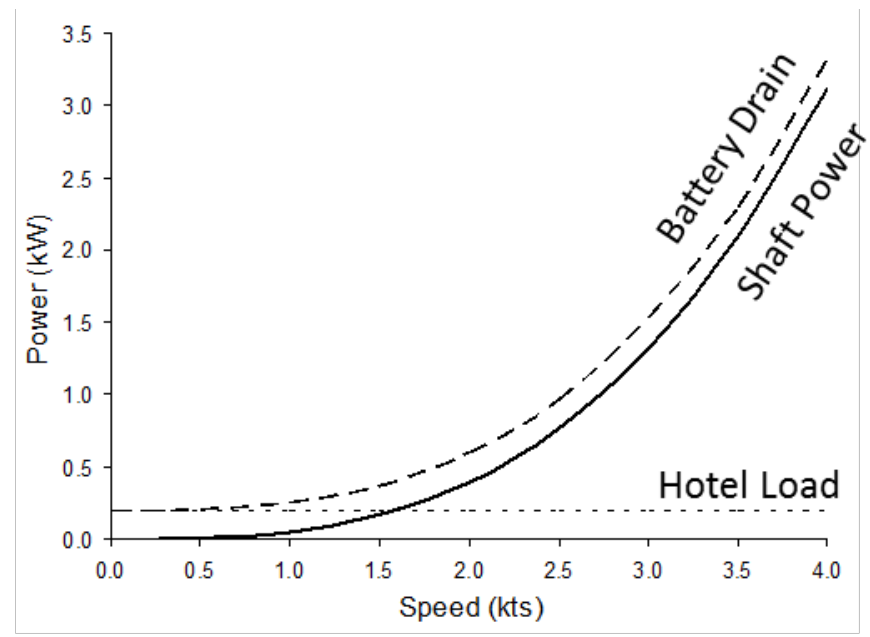

Figure 33 - Power against speed for lean hotel load

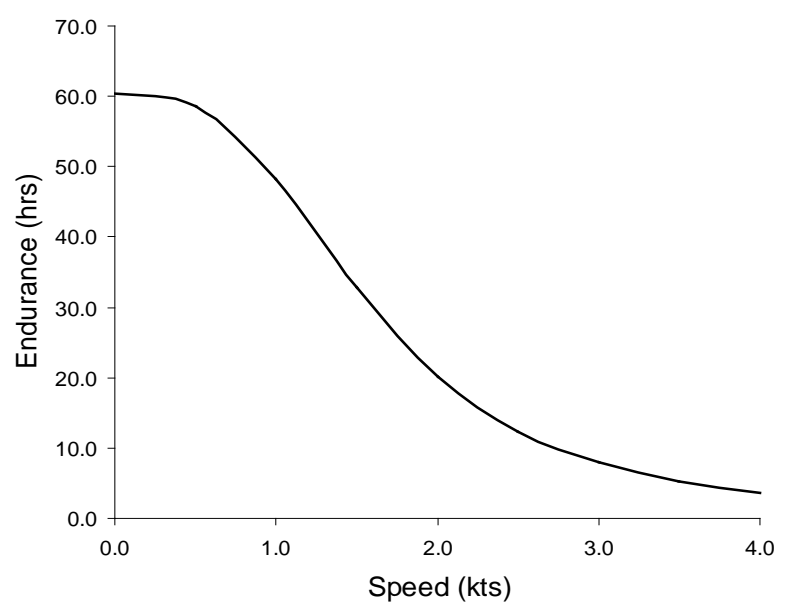

Figure 34 - Endurance against speed for lean hotel load

Comparison between the maximum and lean hotel load operating profiles, highlights a marginal reduction in power, but a significantly improved endurance at low speeds. This allows up to 60 hours endurance in loiter mode.

During actual operations, the maximum loiter time will be somewhere between maximum and lean hotel load. An onboard power management system will be needed to ensure enough power will remain to be able to ascend and enter surface operations. This process will require ballast pumps and trim modifications as well as possible flap manipulation.

In addition to battery sizing, a direct methanol fuel cell (DMFC) was sized to determine its feasibility as a useful method for prolonging submerged endurance. Appendix J holds information related to the DMFC. The additional complexity, weight, volume and safety risk were judged to be unfavorable and the DMFC was excluded from the final design.

\section{Propulsion options}

At this point in the design, it was important to decide how best to transfer the calculated power into motion. A number of options were considered including a fixed pitch propeller, azimuthing pod, pump jet and the underwater fuelled pulse jet. Reasons for disregarding a pulse jet were given in the air propulsion section. 
The fixed pitch propeller and shaft arrangement was seen to be unaerodynamically friendly and retractable shafts and propellers was complex, especially when coupling them with rudders.

Retractable azimuthing pods provide the maneuvering capability exhibited by traditional pods with the retractable functionality of some modern bow thrusters. In terms of their effect on battery sizing, it was assumed that the calculations using shaft power margins and sea margins were adequate. A number of small thrusters are produced by LEWMAR, two of which are shown in Figure 35 and Figure $36^{17}$.

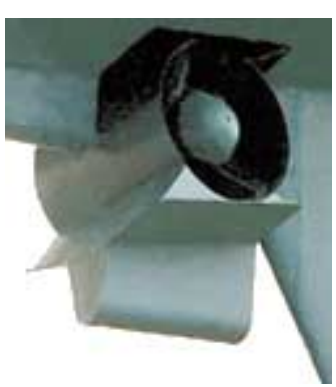

Figure 35 - Extendable bow thruster with moving keel piece

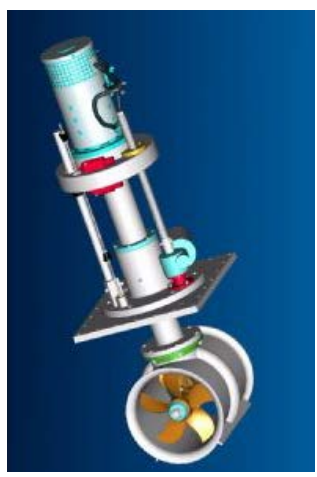

Figure 36 - LEWMAR extendable thruster

Pump jets have the advantage of fewer moving parts as they remain flush with the bottom of the hull as illustrated in Figure $37^{18}$. However, they are extremely inefficient; $40 \%$ less efficient than pods ${ }^{19}$. The mass and volume of lithium batteries required to power U3V was over double that required to power the pods. As a result, retractable pods were selected over pump jets. More information on pump jets can be found in Appendix C

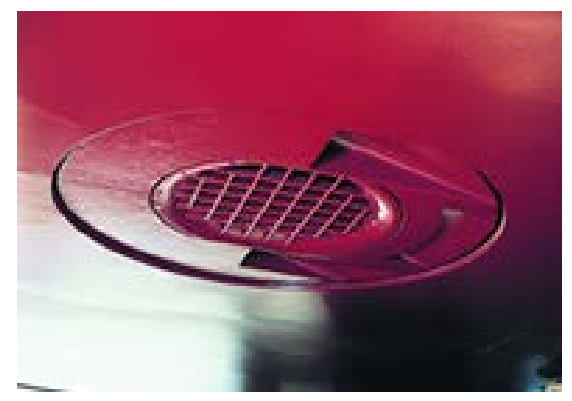

Figure 37 - Pump jet integrated with a ship’s hull

\footnotetext{
${ }^{17}$ LEWMAR. Thrusters. Available from: http://www.lewmar.com/ [Accessed on 2nd July 2012]

${ }^{18}$ Baltic Nordic. Nakashima Compact type thruster, Schottel pump jets thruster etc marine equipment assembly. Available from:

http://www.balticnordic.com/images/products/q/25/nakashima_compact_type_thruster_schottel_pump_je t_1306721686.jpg [Accessed on 2nd July 2012]

${ }^{19}$ Capt J, 2006. Jet, Jet Pump, Waterjet, Jet Drive vs Prop. Available from: http://www.boatdesign.net/forums/jet-drives/jet-jet-pump-waterjet-jet-drive-vs-prop-11254.html [Accessed on 2nd July 2012]
} 


\section{Motor and propulsion selection}

Characteristics of machinery to provide the surface and below water propulsion were derived from LEWMAR $2 \mathrm{~kW}$ pods (Table 13) ${ }^{20}$.

\begin{tabular}{l|c}
\hline Model & $140 \mathrm{TT} 2.0$ \\
\hline Voltage (V) & 12 \\
Power & $2.0 \mathrm{~kW}$ (2.7horsepower) \\
Gearbox material & Bronze \\
Propeller & Single 5 Blade \\
Thrust & $37 \mathrm{kgf}(81 \mathrm{lbs})$ \\
Weight & $13 \mathrm{~kg}(29 \mathrm{lbs})$ \\
\hline
\end{tabular}

Table 13 - Thruster data

These were modified to include the extendable feature, Figure 36, suggested previously by scaling other technologies that LEWMAR produce. The dimensions of the modified thruster are given in Figure 39. From this, mass and external and internal volumes were estimated for the mass and volume balancing tool.

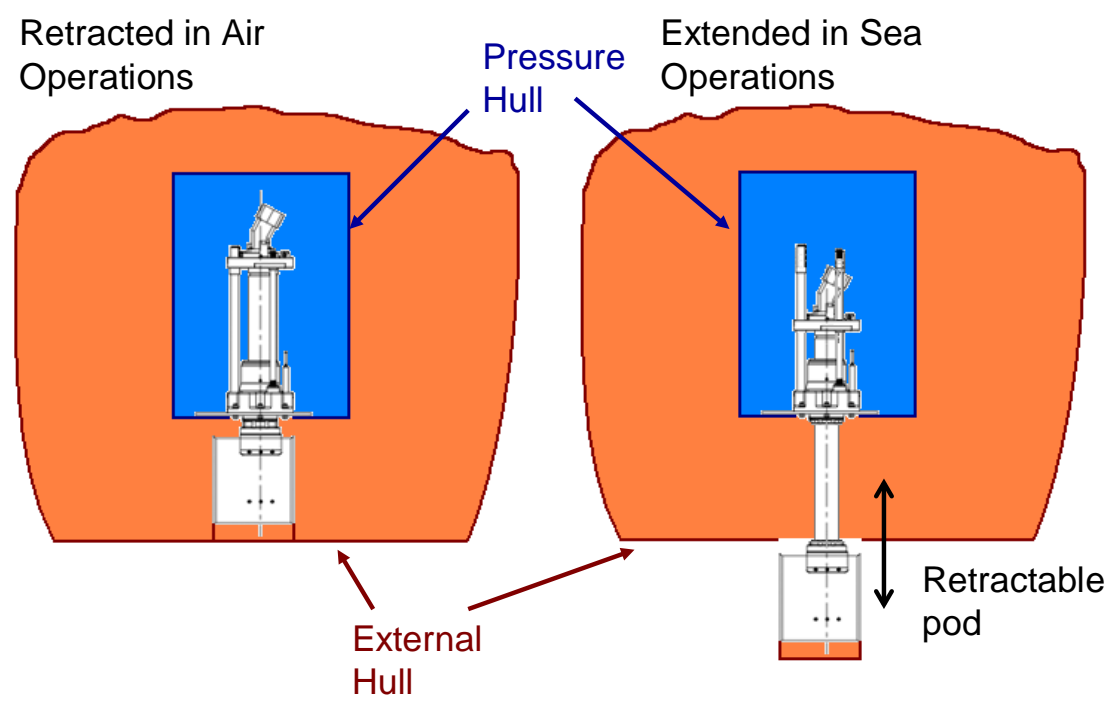

Figure 38 - Retracted and extended thruster locations for air and sea operations respectively

${ }^{20}$ LEWMAR. Thrusters. Available from: http://www.lewmar.com/ [Accessed on 2nd July 2012] 


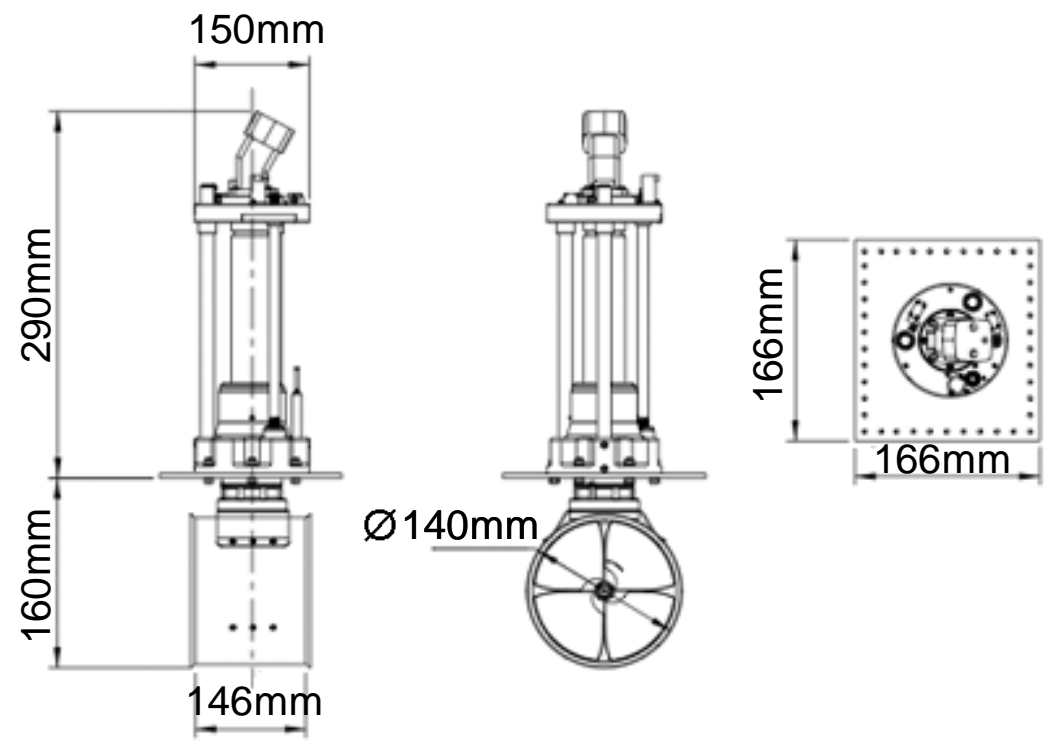

Figure 39 - Overall dimensions for the extendable thruster

\section{Surfaced propulsion}

From the outset, the surface environment was seen to be an intermediate state between air transit and underwater operations rather than an environment that may be used for significant tactical operations. To reduce the complexity of the design, designing for the surface environment was removed from the decision process. This motivation is similar to a submarine design where the propulsion system is sized for the more high profile underwater operating environment rather than above water. However, in the case of U3V, this includes operation in air also. Therefore, it was decided that surface propulsion will be by a combination of the two other propulsion systems: air propulsion for high speed and takeoff and submerged propulsion for station keeping, maneuvering and recovery.

In addition, accurate hydrodynamic resistance predictions were difficult. Traditional empirically based above water resistance formulae would have been ill placed in this instance due to the unusual shape of the U3V. Model testing and computational fluid dynamics analysis were beyond the scope of this feasibility design project, but, with more time, would help better define surface hydrodynamics.

This area requires much further work. Particular attention should be made to recovery of the U3V, notably the relative velocities between itself and the host vessel and overcoming waves generated through the wake of the host vessel.

\section{Maneuvering and control}

\section{Air maneuvering and control}

\section{Control through wing morphing}

The use of morphing structures would allow the design to maintain the clean, external shape of the vessel when deflecting the trailing edges in high-lift and maneuvering situations. The extent of morphing structures in this concept was limited to only this application due to the complexity of more complete morphing systems. A 
complete morphing wing where the airfoil shape is optimized for all flight conditions is very complex, at least using conventional methods as shown in Figure 40, involving hydraulics and many motors and moving parts [10].

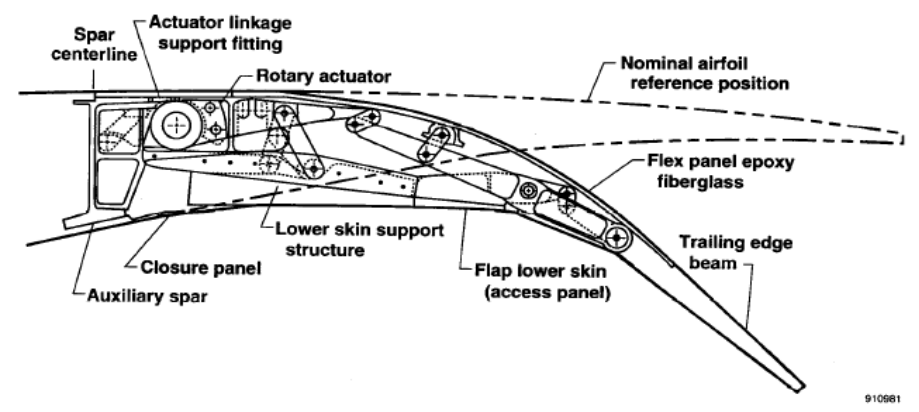

Figure 40 - Trailing edge section of AFTI/F-111 mission adaptive wing

In U3V, the upper surfaces need only resist the aerodynamic loads in the air and hydrodynamic loads when submerged, while the lower surfaces may be expected to react slamming and impact loads on the sea surface.

There is substantial literature on other possible adaptive wing technologies. For example, the concept shown in Figure 41 uses a multilayered skin with folded inner skin and flexible outer [11]. This is a relatively simple technology that has a high likelihood of success at full scale. Additionally, the skin is likely to be light and flexible. Most proposed morphing technologies either consist of overlapping metal layers, such as old-style swing-wing jets such as the Panavia Tornado, or are only presently feasible on the very small scale. The skin is supported by a conventional web and actuated by simple linear electrical actuators to eliminate the hydraulic system.

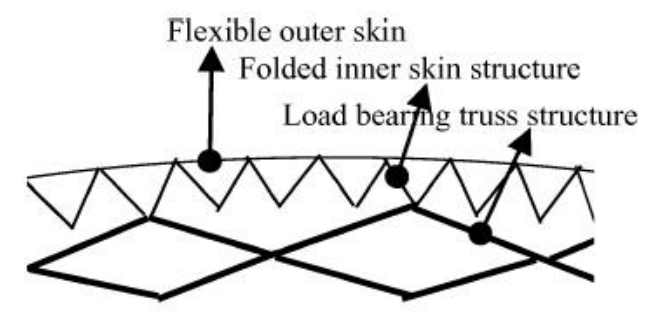

Figure 41 - Folded inner skins

Underwater, the vast majority of the vessel is flooded with only PVs and external equipment unexposed. To avoid putting any actuation equipment in a buoyant envelope, all actuators will be exposed to the water. As such, the selected system will need to be suited for use in water. There are two sources for flap actuation, underwater vessels (externally actuated submarine controls or UUV actuator) or systems designed for use on aircraft and subsequently marinized.

\section{Controls sizing}

The system was sized by assuming that the maximum fluid force on the flap occurs when changing deflection at high speed in the air. It was assumed that the resultant system power would be sufficient for low-speed, low-deflection trim alterations when submerged. The actuator size and power depend upon the deflection range, the size of the flap, the local fluid speed and the desired deflection change rate. It was assumed that two actuators were required for each flap. 
The required maximum deflection is equal to the sum of the wing angle of attack plus the relative angle of attack of the flap to the wing. The lift curve is assumed to be that of the flat plate approximation i.e. $C_{L}=2 \pi \alpha$. The lift force is re-dimensionalized in the usual manner at the take-off speed. It is worth noting that a reduction in take-off speed or required flap angle will also reduce the size of this system due to the reduced load. The actuator power was calculated assuming a maximum actuation speed and typical efficiency and the size and weight was estimated from similar electrical linear actuators (Figure 42) ${ }^{21}$.

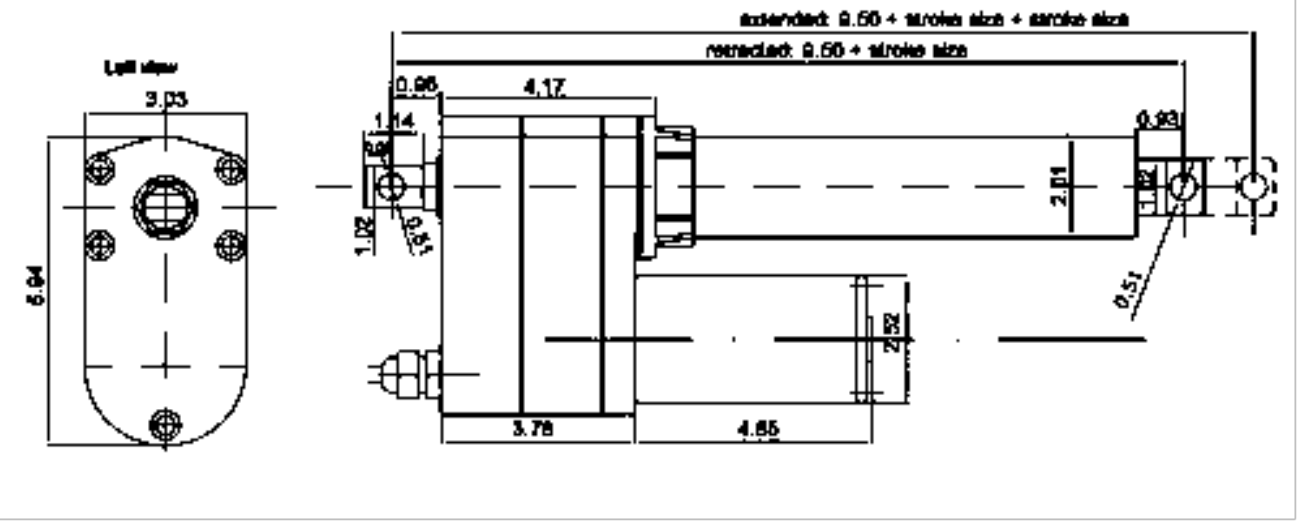

Figure 42 - Typical actuator geometry

\section{Surfaced maneuvering and control}

Podded thruster drives allow for $360^{\circ}$ control on the surface of the water. If the propulsors are controlled to thrust in opposite directions, they can rotate the entire vehicle towards the desired heading without the need for a large turning circle. Sway motion control by way of crabbing side-to-side is plausible but power requirements will be significant, hence speed will be minimal.

An area of further work is to look at adding rudders to the aft section of the two hulls as illustrated in Figure 43. This would improve yaw control in all three domains. However, design complexity would increase as well as the required installed power, requiring a significant redesign of the onboard systems.

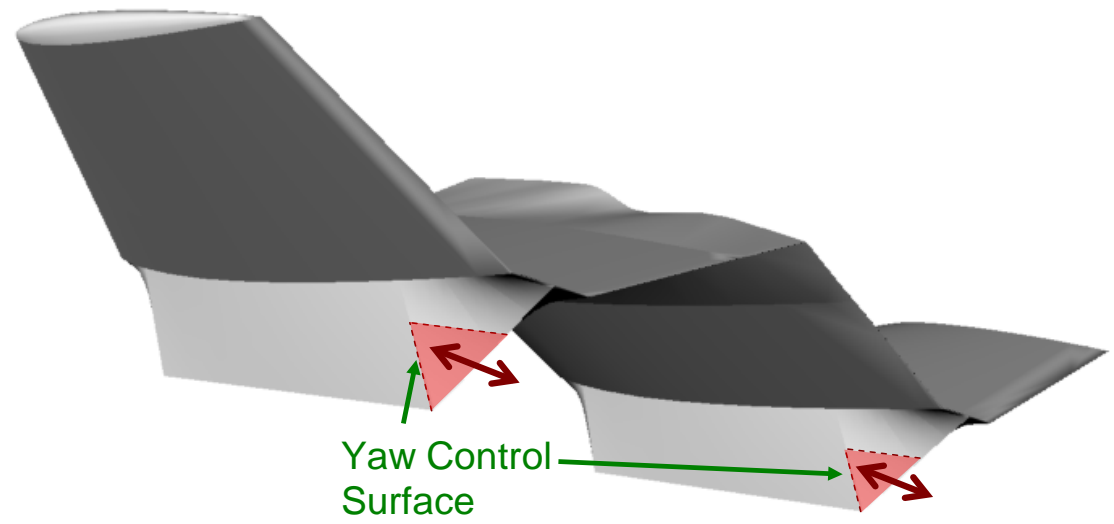

Figure 43 - Yaw control surface further work design

\footnotetext{
${ }^{21}$ Progressive Automations. Heavy Duty Linear Actuators (PA-17). Available from: www.progressiveautomations.com [Accessed on 2nd July 2012]
} 


\section{Submerged maneuvering and control}

A number of systems are present on the vehicle to aid control underwater. These include:

Azimuth podded propulsion system - pods provide yaw control in addition to surge and sway control. They offer $360^{\circ}$ maneuvering control.

Lead ballast trim device and flaps - provide control in trim and can be used to create a banked turn. However, the latter is not advisable in certain CONOPS where precise control is necessary (e.g. during mine countermeasure operations).

When submerging and surfacing, U3V works in the same way as a conventional submarine:

1. Water is taken onboard into the ballast tanks, sized to counter the buoyancy provided by U3V's components;

2. Once the free flood space floods with seawater, U3V becomes neutrally buoyant and lies just below the surface of the water;

3. To descend, lead ballast is moved forward. Trailing edge flaps may be used to aid descent;

4. Once at the correct operating depth, lead ballast and flaps are moved to create a zero lift condition to ensure that any forward motion does not cause U3V to surface or dive further;

5. U3V is now in a position to undertake missions at depth;

6. To ascend, lead ballast is moved aft. Again, flaps may help the process of ascent;

7. Just below the water surface, the ballast tanks are blown using the compressed air installed within the ballast tanks;

8. Water evacuates from the ballast tanks, aided by ballast pumps, and the buoyancy created elevates U3V through the water surface;

9. Water will evacuate the free flood cavity through holes in the external structure;

10. U3V can now operate on the surface, prepare for airborne takeoff or submerge once again.

\section{Stability}

A body is stable if, when displaced slightly from equilibrium, it tends to return to its original position. The U3V is unique because it must be stable in flight, on the sea surface and underwater. In addition, the concept must remain stable in the transitional stages during submergence/emergence and take-off/landing.

This section considers the stability on and under water while in-flight stability was addressed as part of the wing design. The concept ship design tool Paramarine was used to calculate hydrostatic properties including the longitudinal and transverse GMs and the GZ curve in both the deep and light conditions. Furthermore, some consideration was made for the transition from surface to underwater operations. 


\section{Load conditions and hydrostatics}

Two above water load conditions, 'deep' and 'light', represent the heaviest and lightest conditions of U3V respectively and bracket the most extreme ends of the mission profile. Tank states and trim values for each condition are tabulated in Appendix K. In the deep condition, mean draft is $0.808 \mathrm{~m}$ with some trim by the stern to introduce an initial angle of attack on the lifting surfaces. In the light condition, mean draft is $0.603 \mathrm{~m}$. Subsurface, there are no deep or light conditions, as U3V compensates for mass and volume, to ensure it remains neutrally buoyant.

\section{Surface and transitional stability}

Figure 44 shows that the vessel is statically stable on the sea surface. The positions of the waterline in the deep and light conditions are shown at the top of the figure on the left and right hand side respectively. The hull shape serves to ensure that the vessel rests level at the surface despite having a center of mass only $0.25 \mathrm{~L}$ from the bow. The GZ curve assumes that all volumes free-flood except the pressure vessels, external payload and main ballast tanks. The initial shallow slope on the GZ curve can be attributed to the free-flood space between the inboard and outboard main ballast tanks as illustrated in yellow in the center of the figure. The design provides acceptable performance with this assumption and justifies the decision to exclude complex valves and seals on volumes that will need to be free-flooding when the vessel is fully submerged.

The final pictures in the figure illustrate the transition from surface to submerged operation. In submarine operations, it is traditionally desirable to move through the transitional state as rapidly as possible so that the unstable situation where the buoyancy and mass centers cross is minimized. Since the outboard main ballast tanks on the U3V are above the waterline, the inboard main ballast tanks must be flooded first. Following this, the outboard tanks are immersed and can be naturally flooded. On ascent, the U3V can perform high pressure air blows and water removal can be assisted by ballast pumps. The images at the bottom of the figure show trim of the U3V during surfaceunderwater transition.

\section{Submerged stability}

The submerged displacement of U3V is 5.59 tonne in both the deep and light conditions, offsetting deployed equipment and consumables with compensating water. The submerged BG is $1.07 \mathrm{~m}$. The large BG has been driven by the desire to place the aero engine pressure vessel as high as possible.

\section{Stability risks}

Although transverse stability is usually of most concern for ship designers, the separation distance between the catamaran hulls results in a transverse GM that is more than adequate. However, the longitudinal righting moment on this vessel is small. The 


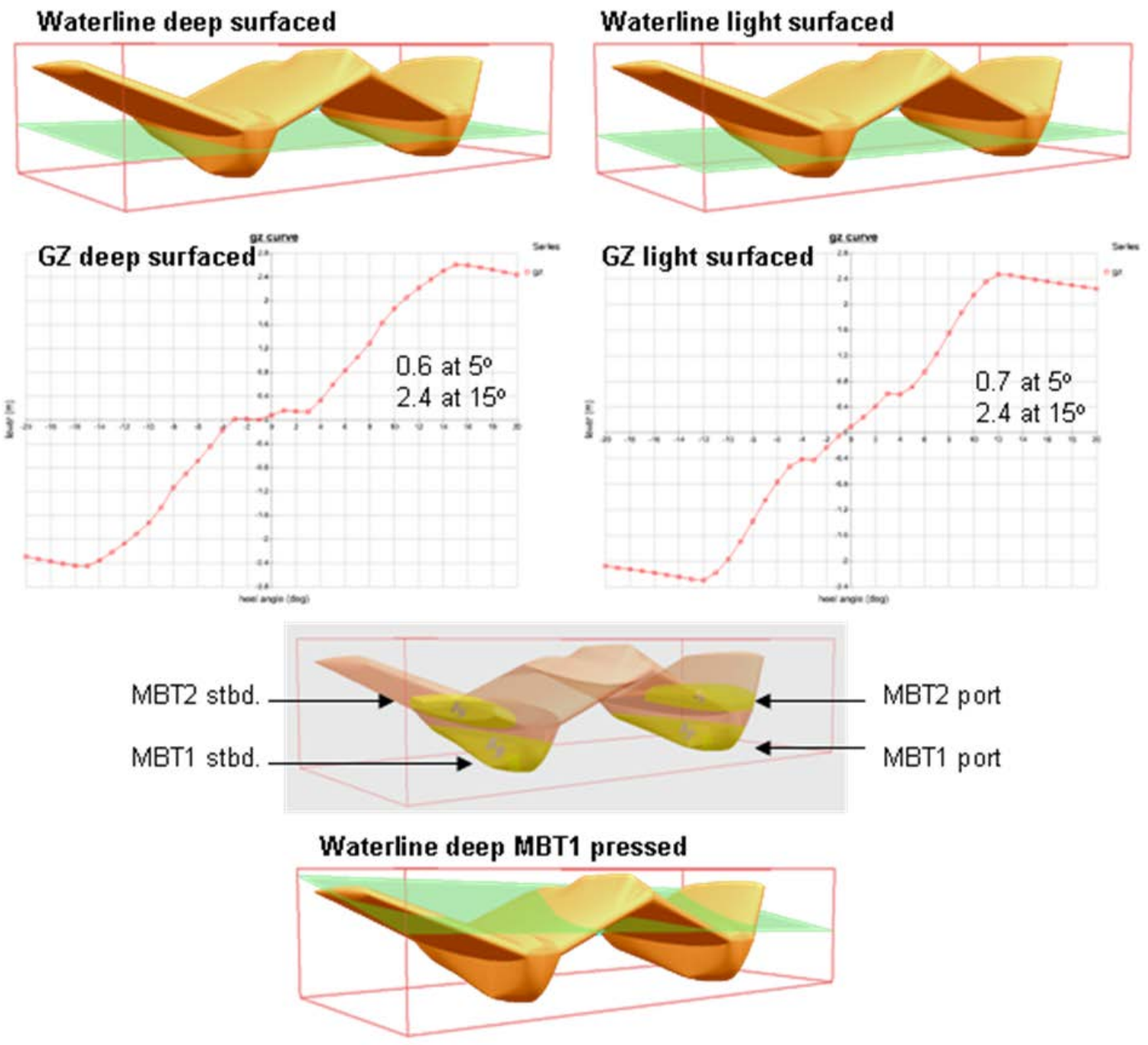

Waterline deep MBT1 pressed, MBT2@70\%

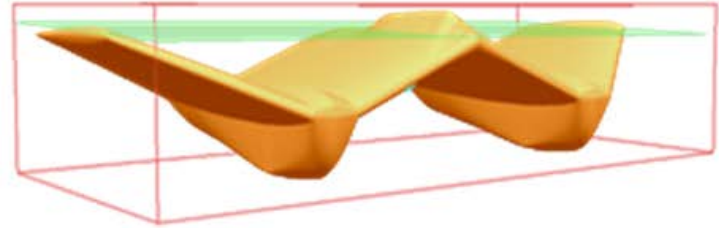

Figure 44 - Stability on the surface

catamaran hulls are short and the center of mass is unusually high. In addition, much of the remaining volume is free-flooding and does not contribute to the restoring moment. Without the dimensional constraints, it would be preferable to have longer hulls.

Longer hulls would also assist in a smooth run during take-off and landing. It is difficult to investigate the stability of the craft during take-off since hydrodynamic and aerodynamic forces work together. Tools to take all the complexities into account were not available for the study. The hull should lift out of the water and change trim as the vessel picks up speed and stability must be adequate throughout. This is not examined here, because the hull design was immature. Future development is recommended. 


\section{Structural design}

One approach to the structural design is to combine the traditional naval architecture and aeronautical engineering methods. This would likely result in the application of techniques and conventions that are not only inapplicable to this craft, but also highly inefficient. Such an unusual vessel merits the application of novel structural design techniques that are beyond the scope and resources of this concept. However, components of the vehicle were analyzed using less sophisticated techniques. This section is divided into underwater, air and surface design sections. In the underwater section, application of thin-walled pressure vessel theory to internal pressure vessels is discussed. The surface section discusses structural elements of planing hull design. In the air section, an approximate wing weight formula is discussed. Finally, a method for overall structural optimization is proposed. U3V is predominantly made from titanium due to its inherent strength and lightweight properties. It suffers from little degradation from depth cycling and no deterioration from seawater. It was therefore regarded as useful across all three environments. Beyond this, little analysis into other materials and manufacturing techniques was undertaken.

\section{Submerged structure}

Thin walled pressure vessel theory was used to size all the cylindrical components of the pressure hulls. They are rated down to 50 meters depth with a safety factor of 1.8 equating to an actual failure depth of 90 meters.

Flat end caps were used over hemispherical or torispherical end caps as, early in the design process, the U3V design was dominated by buoyancy which led to excessive amounts of lead ballast. The driver for this modification was an oversized aeropropulsion system that was required to power takeoff of the large mass. The thicker flat end plates provided greater mass and less volume. This reduced the need for lead ballast and resulted in a net reduction in total mass. Flat end cap structural analysis was done for both simply supported and clamped edges in both radial and tangential stress, the worst case being simply supported edges in radial stress. End plates were designed to the same failure depth as the cylindrical section.

In hindsight, more lead ballast would have been advantageous to contribute towards better control of trim. Hence, the dome end caps may have sufficed, but there could have remained an issue with takeoff power requirements.

Towards the end of the project, a subject matter expert highlighted that overpressuring the PVs would have delivered a more structurally efficient design. This is because PVs perform best in tension, rather than compression. Although feasible for the main sensory PVs in particular, it may not be practical onboard ship, especially when interchanging component parts just before a U3V is deployed. In contrast, without the addition of other equipment, this method was certainly infeasible for the aero engine PV which must be able to open and close at least twice in a mission. Despite the issues, this idea merits further consideration.

\section{Surfaced structure}

Little analysis into U3V's structural requirements for surfaced operations was undertaken as a result of unavailable data and time constraints. It is anticipated the most significant loading applied to U3V's structure on the water surface is slamming loads as a result of landing from air transit. Model testing should be used to determine these 
loads. Bending moments and shear data could be calculated with Paramarine for wave bending analysis. This was not done because the loads associated with bending are minor compared to slamming loads.

\section{Air structure}

An empirical equation for wing structural weight first suggested by Torenbeek [12], Equation 9, was used to calculate the air proportion of the overall structure. It uses the ultimate load factor $\left(N_{u l t}\right)$, the value of which depends upon the margin applied for maneuvering, and a number of representative dimensions to estimate the wing structural weight as a fraction of total weight. Appendix L provides a more complete description of the formula.

$$
\text { Equation } 90.0017 \times N_{u l t}^{0.55} t^{-0.3}\left[\frac{b}{\cos (\Lambda)}\right]^{1.05}\left[1+\sqrt{\frac{6.25 \cos (\Lambda)}{b}}\right]\left[\frac{W_{\text {MTоW }}-W_{f}}{b \times c}\right]^{-0.3}
$$

Where:

$$
\begin{aligned}
& t \text { : Root chord maximum thickness } \\
& b \text { : Wingspan } \\
& \Lambda: \text { Sweep } \\
& W_{\text {MTOW }}-W_{f} \text { : Maximum zero-fuel weight } \\
& c \text { : Maximum chord }
\end{aligned}
$$

\section{Proposal for structural optimization}

A fuller structural study is recommended using the Hyperworks suite of finite element and structural optimization programs. Hypermesh is a geometry editing and meshing program that links into Optistruct which is a structural optimization tool that iteratively maximizes the efficiency of a structure according to an objective function specified by the user. It is suggested that Optistruct employ topology optimization to gradually remove material from a design space that fills the free-flood space between the external form and installed equipment.

\section{Loads}

There are a range of load conditions in each environment that, for a full design, could be represented fully in the optimization protocol. Optistruct is capable of handling an objective function of this complexity, but a simpler approach is sufficient to get an indication of structural layout in this concept.

Instead, this section considers only the most extreme load case. There are two candidates for this, slamming into the water just after take-off and extreme maneuvering underwater. The former was selected for analysis since the latter can be avoided through careful attitude and speed control underwater. Thus, the most extreme load case assumed to be full aerodynamic lift just after take-off with maximum flaps coinciding with an unexpected high-speed water re-entry.

The loads comprise the weights of major items (forces), the flap hinge moment on the flap actuators (moment), the lift pressure on the external form due to aerodynamic lift (pressure) and the slamming load on the underside of the craft in the event of high-velocity impact with the water (pressure). Clearly, not all loads are applied as some items are too light to be relevant to the optimization. In addition, the fuel tank weights are not included as their position can vary dependent upon the final structural layout. In addition, the load case is not in a statically balanced condition, so 
traditional constraints should not be applied. Instead, the software was instructed to apply 'inertia relief', a means for simulating unconstrained structures.

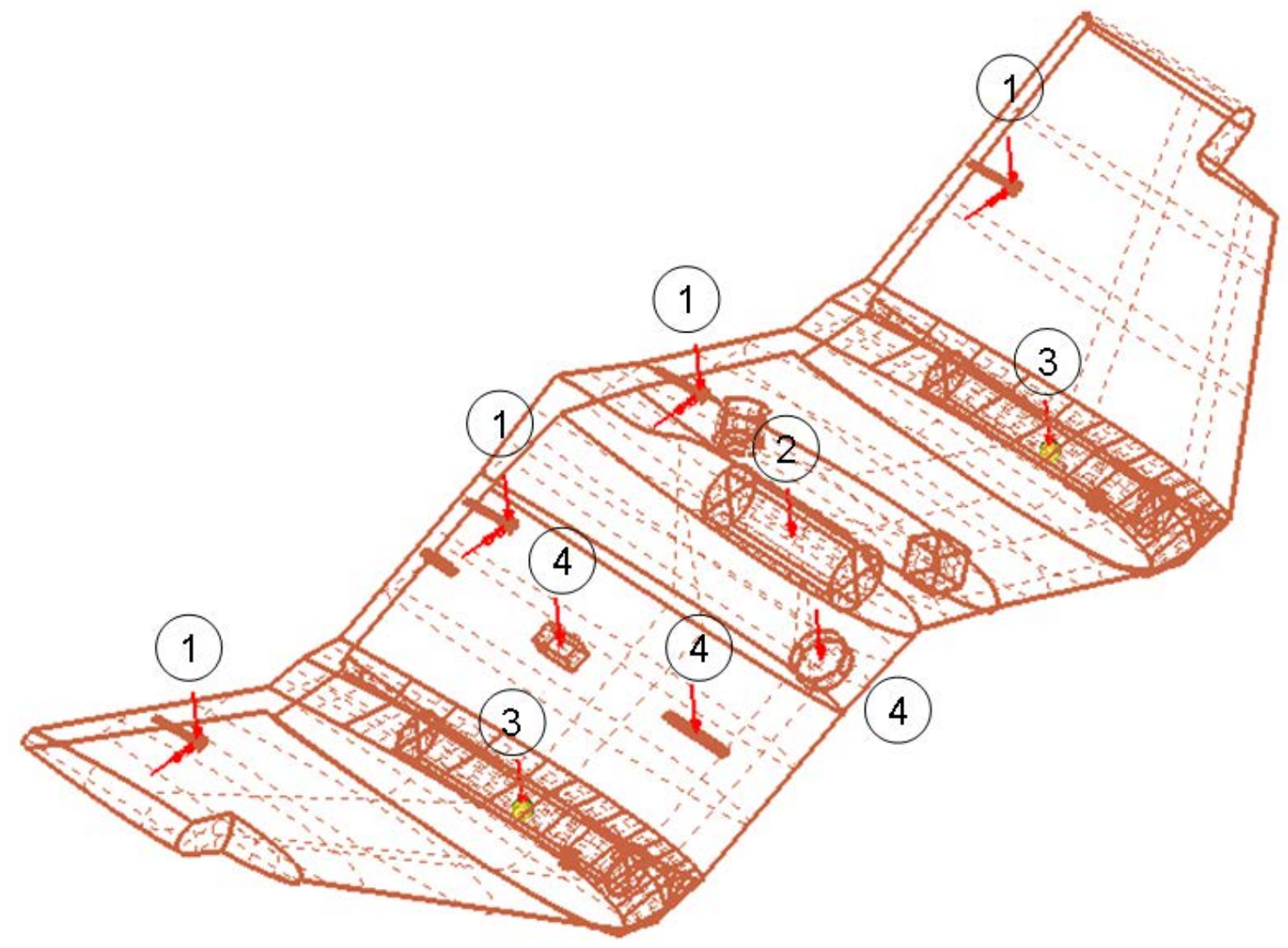

Figure 45 - Loads and moments (no pressures) on the Hypermesh model

With reference to Figure 45 the loadings are as follows:

1. Control surface forces and moments transferred onto structure through actuators;

2. Engine PV loads;

3. Payload PV loads;

4. Discrete equipment and sensor loads;

5. Aerodynamic and hydrodynamic maximum distributed skin loads (not shown in figure);

6. Slamming distributed skin loads (not shown in figure).

Lift pressure loads could be applied in two ways. The first, and simpler, method would equally distribute the mean pressure differential over the upper and lower surfaces. The second, and more accurate, method would import the calculated distribution of loads from the TORNADO analysis as a 'field load.' 


\section{Machinery and auxiliary systems}

\section{Ballast systems}

\section{Ballast tank size}

The ballast tank was sized as described in the UCL Submarine Design Exercise [3]. Important consideration was given to the Reserve of Buoyancy (ROB). Traditional western submarines adopt an ROB between 10\% and 20\% [9]. Smaller submersibles generally have a much greater ROB to ensure a greater minimum freeboard is achieved which is important for this design as water on the top of the wing, inside the free-flood space and water ingestion into the engine could greatly affect performance. Greater freeboard helps to minimize the effect of these risks.

When returning to a surfaced condition after being submerged, there may be a point at which the pressure hulls breach the surface of the water, no longer providing buoyancy to the vehicle. This is particularly a problem with the high mounted turbojet pressure hull. Therefore, the ROB was selected so that the buoyancy of the ballast tank alone would counter the total weight of the vehicle (ignoring the weight of ballast water).

The final ROB was selected to be $40 \%$. Resulting from this, the tank, structure and compressed air stored onboard for blowing the tanks, was sized.

\section{High-pressure air system}

The HP air bottles were sized for three ascents. Four ballast tanks were used, two port side and two starboard. Each side is serviced by three bottles, one per ascent per side. Although a larger bottle of considerably lighter mass could accommodate all three ascents per side, splitting the air volume between six HP air bottles provides redundancy to the system and maintains equally pressurized air for each ascent.

The HP air bottles are located within the ballast tanks which were sized to accommodate this extra volume. This reduces the need for excessive piping, reducing system complexity. The HP air, once used, is compensated using the water compensation tanks internal to the pressure hulls.

Because of the high power, mass and volume required, U3V was not fitted with an air compressor to recharge the HP air bottles. Instead, these bottles must be recharged once U3V is recovered by the parent vessel.

\section{Free-flood water management}

Excessive free-flood space may compromise surfaced stability when breaching the water surface. As a result, a number of vents were introduced on the wing surface to allow for air entry and ensure water drains from the internal cavity of the wing. To reduce the need for bilge pumps, the ballast tanks were oversized so that the waterline lies beneath the top of the tank. Hence the first vent is above the water surface as illustrated in Figure 46. 


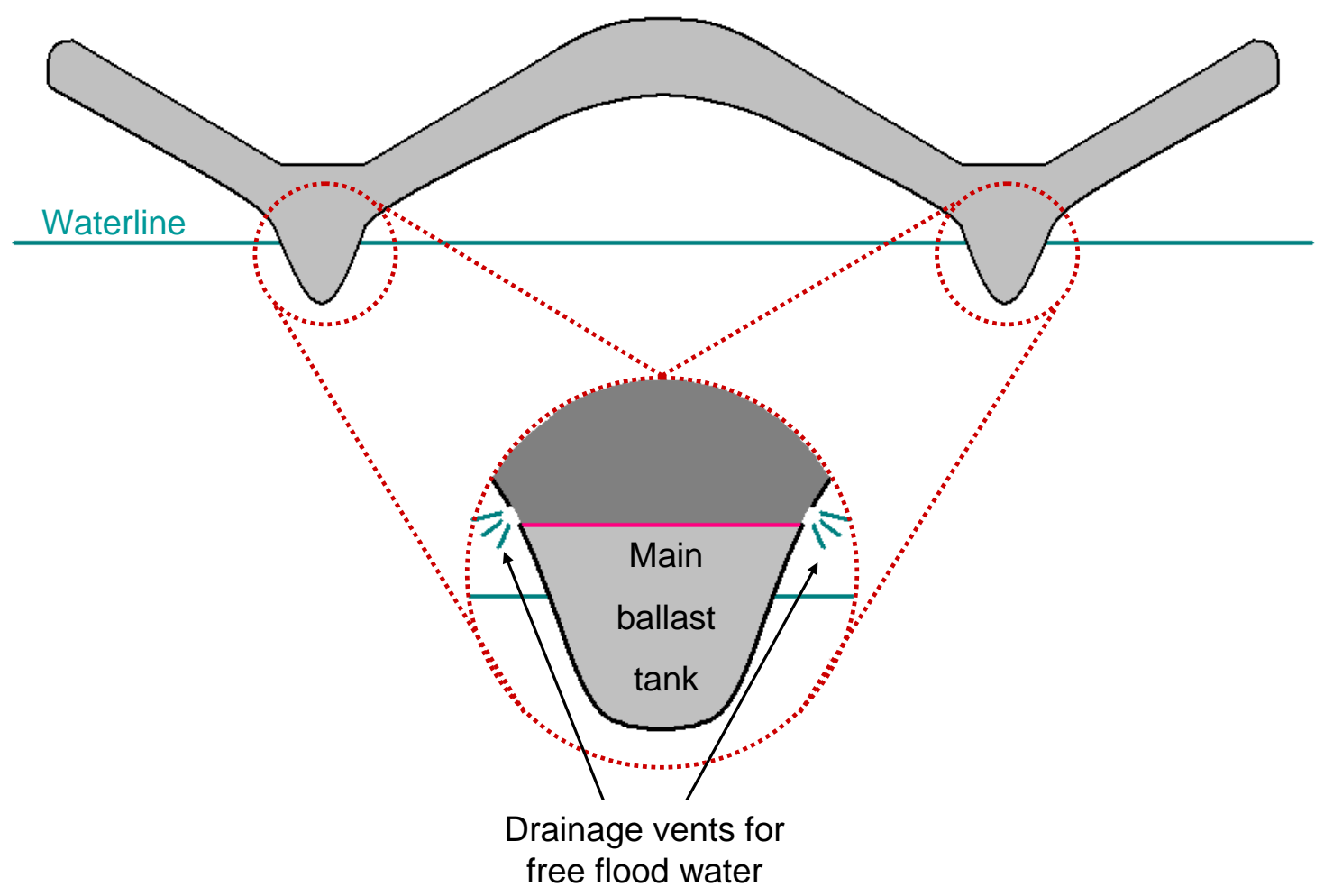

Figure 46 - Illustration of freeboard requirement for U3V

In principle, no bilge pumps would be required so long as water can freely drain from the wing cavity through specific shaping of surfaces. However, to ensure no free surface effects and minimal weight in air and at the water surface, bilge pumps are recommended. Also, rough seas may cause excess build-up of water in the wing, and relying on free drainage would be unadvised.

\section{Compensation systems}

\section{Water compensation system}

The compensation tanks are sized to accommodate the changes in mass and buoyancy of variable payload items onboard U3V. This includes the gateway buoy, expendable mine neutralizers, and variable internal payload and air in the HP air bottles. The calculation for the required mass and volume of the compensation tanks is given in Appendix M.

In addition, the separation of pressure hulls, and hence compensation tanks, makes this system a suitable aid for transverse stability if required. The tanks can be evacuated when switching to water surface operation mode. This will reduce the weight of the vehicle, prolong endurance and prepare the vehicle for take-off.

\section{Fuel compensation system}

The fuel is compensated in a different system. Although no fuel will be used underwater, the fuel that remains after air operations will vary and buoyancy needs to therefore be regulated. Fuel is stored in an external bladder and an internal tank. By separating the fuel between the external bladder and internal fuel tank, the fuel can selfregulate itself to ensure neutral buoyancy is maintained. The calculations behind this system are described in Appendix N. 
As a result of this setup, a fuel control system will be required to ensure the ratio between external and internal fuel is maintained constant. It should be noted this requirement is dissimilar to maintaining a constant flow rate for all tanks. If this were adopted, the fuel in the internal tank would be used up at a faster rate than the fuel in external fuel bladders as the internal tank has a smaller volume compared to the external ones. This self-regulating fuel buoyancy system has the added benefit that the pressure hull does not require the additional volume to hold compensation water due to the difference in buoyancy between the water and fuel. As a result, less fixed lead ballast is necessary as the size of the buoyant PV does not increase.

\section{Trim system}

Trim system requirements are summarized in table 14 . The trim system comprises two distinct elements. The first is the movement of solid ballast along a rail within each of the main sensory PVs. The second part is used only during take-off to obtain high angle of attack. This comprises partially filling an aft ballast tank with water. The water will drain out gradually, assisted by ballast pumps (as necessary) after the vessel has left the water surface and accelerates to cruise speed.

\begin{tabular}{l|cc}
\hline Condition & Required attitude(deg) & Trim system(s) in use \\
\hline Take-off & $12(+20$ flaps $)$ & Fixed ballast rail + water tank \\
Cruise in air & $4(+2$ flaps $)$ & Theoretically no trim required \\
Underwater & -1.2 & Fixed ballast rail \\
\hline
\end{tabular}

Table 14 - Trim systems for each condition

\section{Moveable solid ballast system}

A solid trim system reduces system complexity and makes constructive use of the fixed ballast required on the design. It comprises a moveable mass of fixed lead ballast within each of the main sensory PVs. The ballast is supported on rails and moved forward and aft by a ball screw system. Ordinary linear actuators were rejected because they require additional length to store the moving arm and there is little space for this inside the PV.

A high load factor is designed in from the start since the system will experience high accelerations when on the surface and it will need to be able to continue to operate throughout the take-off and landing segments. The pitching moment will be greatest in the take-off state.

Representative commercial off the shelf (COTS) data ${ }^{22}$ was used to select the shaft diameter based on the buckling load assuming a load factor of five over the trim mass and determine the required torque for the motor given the lead of the screw. Weight and volume of the screw housing, mounts and runners were estimated. A representative COTS stepper motor was selected to drive the ball screw shaft. A 'rubber engine' sizing produced the dimensions and weight for the final motor. Finally, the

\footnotetext{
${ }^{22}$ HepcoMotion. BSP Ballscrew Premier. Available from: http://www.hepcomotion.com/en/bspballscrew-premier-pg-14-get-26 [Accessed on 2nd July 2012]
} 
internal volume required for the movement of the fixed mass was estimated. The resulting system is illustrated in Figure 47. The trim system sizing calculations are described in Appendix O.

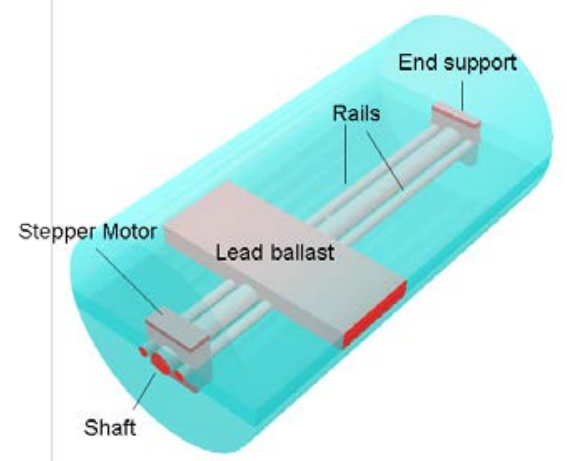

Figure 47 - Diagram of the solid trim system (not to scale)

\section{Electrical systems}

A schematic of the electrical system is given in Figure 48. It represents the flow of power between various components onboard U3V in the various operating domains. The ECPMS regulates power, voltage and current for the various components in the system.

During air domain operations, the turbojet, fitted with a generator, charges the lithium batteries and powers a number of electrical systems through the ECPMS.

Before U3V is deployed, the lithium batteries should be fully charged in case surface or sub-surface operations are necessary before air operations take place. Once the turbojet is shut down and sealed within the PV, all power to the electric motors and the required electrical systems is delivered by the lithium batteries via the ECPMS. 


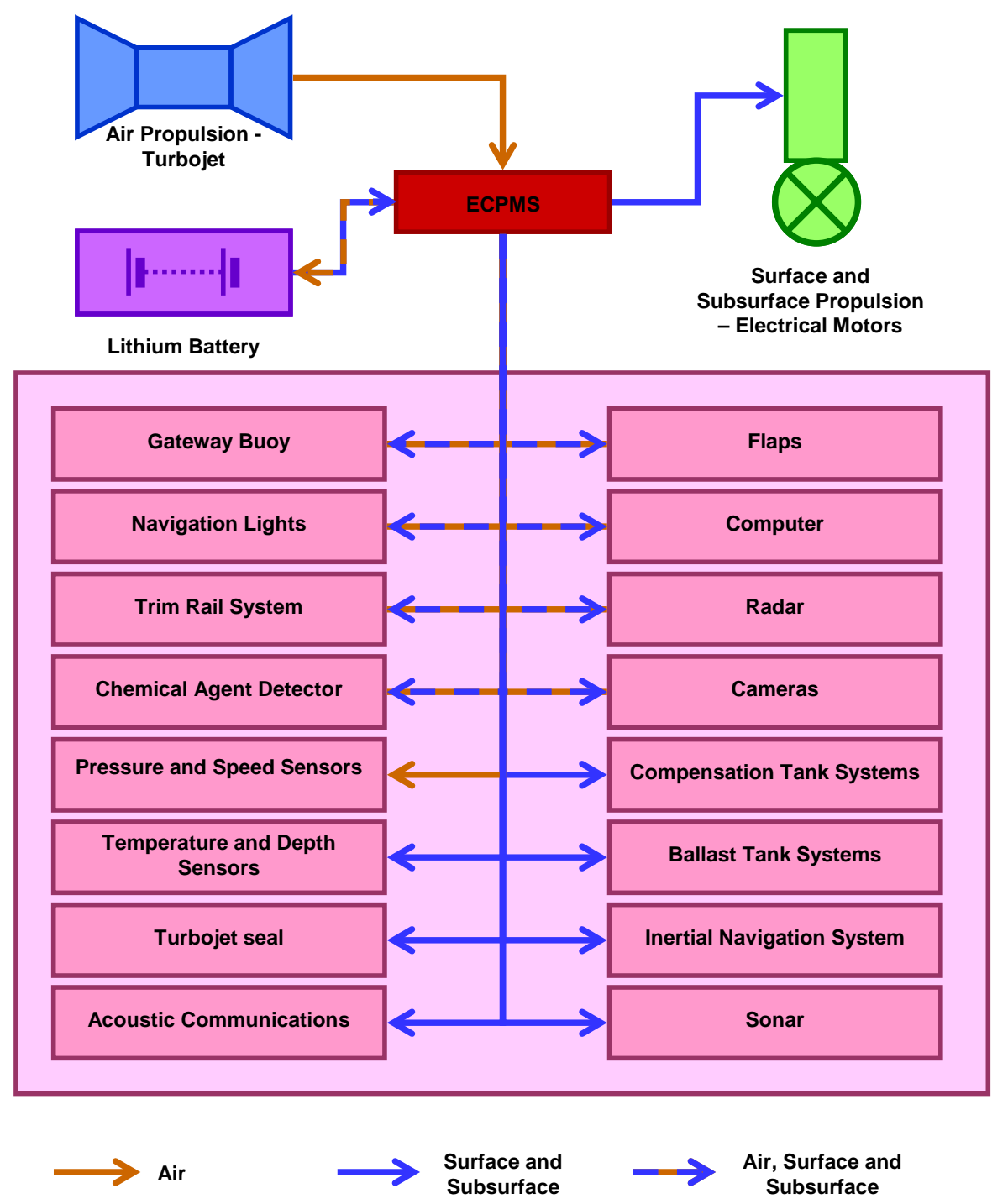

Figure 48 - Simplified electrical system schematic

\section{Jet engine pressure hull sealing mechanism}

\section{Background to sealing mechanisms}

Various alternative sealing concepts were hypothesized during the U3V design. The selected approach to sealing used the process adopted by torpedo tubes. These are rated to high pressures and create a perfect seal. A mechanically simple process was adopted which uses a worm drive that levers open and closes the pressure tube door as illustrated in Figure 49 and Figure 50 for the open and closed case respectively ${ }^{23}$. As it is already common in maritime vehicles, it represents a relatively low risk option.

\footnotetext{
${ }^{23}$ Maritime Park Association. Chapter 3 The Breech and Muzzle Doors. Available from: http://www.maritime.org/fleetsub/tubes/chap3.htm [Accessed on 2nd July 2012]
} 


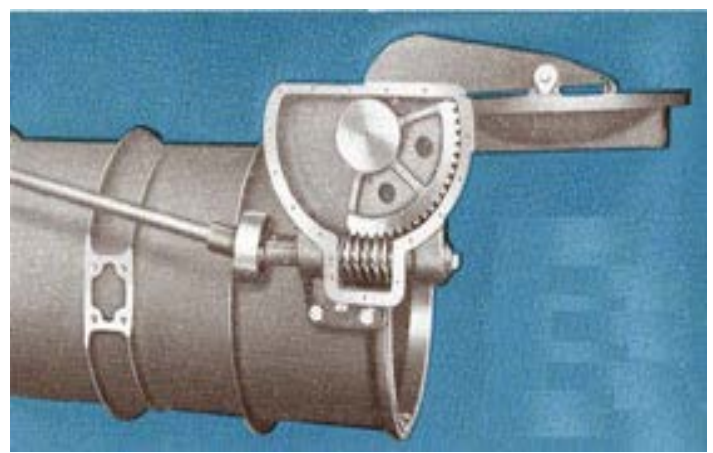

Figure 49 - Open torpedo tube

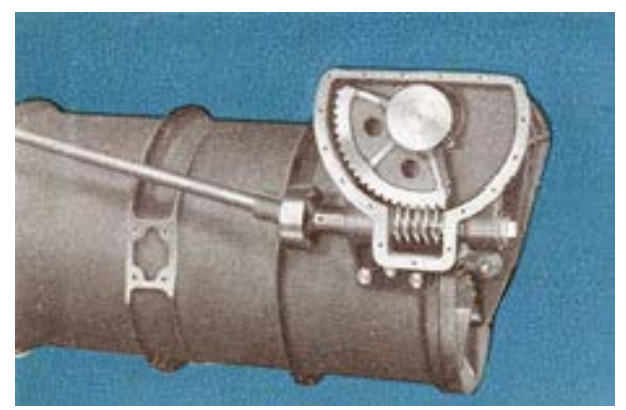

Figure 50 - Closed torpedo tube

\section{Modified sealing mechanism design for U3V}

For U3V, the shaft shown in Figure 49 and Figure 50 which rotates the worm is actuated by a motor as shown in Figure 51.

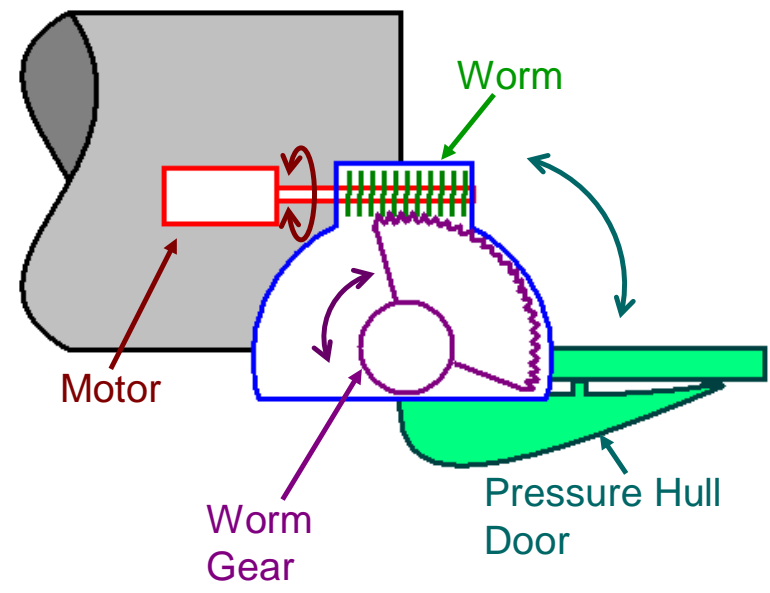

Figure 51 - Sealing mechanism for the pressure hull door

In the traditional torpedo tube design, a constant torque is maintained to ensure the door remains closed underwater. This was infeasible for U3V as this would have significantly increased the required onboard energy storage and may cause the motor to overheat creating fatal problems should the motor fail. Hence, the design was modified to include locking pins inside the door which are engaged to maintain the seal. When the jet engine is required again for air transit, the locking mechanism retracts and the door is released. Further information pertaining to motor sizing is given in Appendix I.

\section{Further work}

A simpler solution would be to adopt an air propulsion engine that did not need to be sealed from seawater. The pulse jet was analyzed as a solution to this problem, however, fuel efficiency and size increased weight to an extent making the design infeasible. In addition, submerging such an engine may cause degradation as a result of rapid heat change from operating at high temperatures to being quenched in low temperature water. One way around this, may be to use ceramics.

In the future, it is hoped that further work be done on reducing the effects of water ingestion on jet engines. This may negate the need for sealing the entire engine. Other effects that need to be addressed include the impact of salt erosion on the engine. This work may come from rotary air vehicles that work within the sea domain. 


\section{Design Assessment}

\section{Feasibility}

Most systems that form the U3V design are already in existence and can be purchased off-the-shelf. An important decision during the project was to adopt current or near current technologies for the design. The primary emphasis for this was that U3V could be designed using standard methods, tools and techniques available in the aerospace and maritime sectors. Consequently, there is a considerable amount of data in the public domain for current generation technology, reducing the number of assumptions in the vehicle design and allowing for comparisons to be drawn.

U3V includes novel systems as well. The aero-engine sealing mechanism, structural batteries and trim system are all future technologies. However, they have medium to high technology readiness levels (TRLs) allowing for relatively accurate approximations to be made for mass, volume, power and services required.

There are a number of design features and technologies that could be developed and refined further to achieve a more efficient U3V design. The selected vehicle design did balance in both mass and volume and analysis suggests that U3V can maintain neutral buoyancy sub-surface with enclosed aero systems. Optimizing vessel density was a key risk early in the design due to a desire to minimize it in flight and on the water surface while equaling that of water when submerged. The compensation system, water ballasting system, lead ballasting and large free-flood space help realize this. However, a number of issues remain outstanding. The most notable was stability and control. Little analysis could be done on the effect of sea state on take-off and landing and the control and stability of the vehicle in high sea states. It is anticipated that the current design may be difficult to control in flight, typical of flying wings. Also, only estimates were used to examine take-off run behavior. These issues will need to be addressed before the design can be taken forward.

The structural weight is a component build-up of various environments, namely air and sub-surface. Structural calculations for air-worthiness used empirical formulae and, as a result of the uniqueness of the U3V, may not deliver a wholly accurate result. Hence, further work needs to be done on properly understanding the loading conditions. In addition, the effects on the structure when U3V operates on the water surface were not considered other than a simple accounting for additional skin thickness. Of particular concern are transverse bending moments and slamming loads. Lastly, structural optimization may help refine the design which could lead to a lighter vehicle and, if utilized effectively, also lead to omission of pressure vessels.

\section{Performance}

U3V meets most of the performance targets set out at the beginning of the project. It can operate in all three environments and comes in below the mass of a fullyloaded $11 \mathrm{~m}$ RHIB ( 8 tonne). Dimensions, $5 \mathrm{~m}$ by $11 \mathrm{~m}$ by $2.4 \mathrm{~m}$, are just outside the requirements. However, without this extra length, the wing would not be capable of generating enough lift.

Final performance of the U3V was over and above the requirements for underwater operations, achieving an endurance of 3 hours at $4 \mathrm{kts}$ and up to 60 hours endurance when loitering. Aircraft performance was not met however. Cruise speed was calculated as $117 \mathrm{kts}$ (Mach 0.18 ) and an endurance at this speed of only 2 hours. 
However, with further refinement, this could be improved. Surface performance could not be evaluated without model tests.

All pressure vessels and external sensors are rated to a 50m operating depth, fulfilling this requirement. The rest of the vehicle, other than aviation fuel bladders and ballast tanks, are free flood spaces and need not be pressure rated.

There are two adaptable payload options onboard, a pressure vessel for fixed sensors and attachment points for external equipment, both of which are easily accessible by support ship's staff. There is a full suite of communications and sensory systems fitted onboard U3V for all environments. To achieve energy efficiency, systems aren't duplicated unless required. To achieve further efficiency, some systems such as the gateway buoy, wing flaps, navigation lights, computer hardware, trim rail system, chemical agent detector and cameras have uses in all three environments.

U3V adopted a "free stealth" philosophy so as not to compromise the host platform. The U3V uses faceted surfaces and is relatively small. One reason for not selecting the pulse jet was due to its excessive noise which would compromise stealth.

Largely independent, conventional propulsion systems were selected for each environment that ship's staff have prior experience with supporting. To achieve lift-off and control in flight, a number of moving parts were required. With further development, these may be refined or replaced to reduce the maintenance burden.

Lastly, while regenerative technologies were not researched, it may be possible to modify the underwater thrusters to operate as marine current turbines when the U3V is in loiter mode to extend endurance.

\section{Further work}

There are a number of issues that require further work and may pose significant risks to the design. Some of the further work has been recommended in the main body of the report where relevant. In addition to these, recommendations for further work are listed here:

Model testing - Flight and surface model testing of wing, engine and control surfaces, underwater model testing of thrusters and trim and control systems and surface model testing to determine speed and endurance performance;

Structures - assessment of over-pressurization of pressure vessel for structurally efficient design, computational analysis and model testing of landing slamming loads, 2-dimensional structural optimization including the influence of aerodynamic and hydrodynamic forces, 3-dimensional topological structural optimization of U3V wing box, detailed design of a low-weight pressure vessel end-cap sealing mechanism.

Stability and control - feasibility assessment of morphing structures for underwater control, feasibility assessment of using moveable fixed ballast for underwater stability and control, feasibility assessment of using moveable fixed ballast for control in the air, investigation of the use of fluid ballast to modify trim to assist during take-off, adaption of the trim system to use lithium batteries in addition to fixed ballast, development of a pitch control design tool in the seaplane take-off regime, investigation of yaw control surfaces for control in air;

Aero-engine - investigation of the effects of water ingestion from landing, surface operation and take-off in various sea states, development of methods to predict and manage the effects of thermal shock and pressurization when quenching the engine 
in water, research methods and materials used for deflating external aviation fuel bladders to prevent bladder tearing, investigate other methods for safely sealing an aero-engine from seawater and at submerged operating depth, and test the reliability of the aero-engine sealing mechanism for reliability;

Payload - identify dependable communications systems for long-distance and/or real time command of underwater vehicles, assess feasibility of integration of defensive weapon systems onboard U3V, develop particular modular payload mission suites to fill internal and external payload bays, investigate future payloads of unmanned underwater vehicles.

\section{Future Technologies}

To ensure that the overall design was feasible, component systems were selected for minimum risk of technological failure by assessment of the current literature. This resulted in conservatism in the down-selection of systems that eliminated some of the optimistic futurism common to system selection in some concept studies. Nonetheless, there is merit in showcasing those systems with great promise that have not been successfully demonstrated in the lab or used in the field. Table 15 identifies systems that show such potential. These are split into three categories: today, tomorrow and "Navy after Next".

\begin{tabular}{|c|c|c|c|}
\hline Technologies & Today & Tomorrow & Navy after next \\
\hline Aero propulsion & Jet engine & Next generation propeller & Rim-drive \\
\hline Aero fuel & $\begin{array}{l}\text { Conventional } \\
\text { aviation fuel }\end{array}$ & Batteries & High power efficiency fuel cell \\
\hline Control surfaces & $\begin{array}{l}\text { Single-slot } \\
\text { trailing edge } \\
\text { devices }\end{array}$ & $\begin{array}{l}\text { Mechanical actuators } \\
\text { controlling a flexible } \\
\text { membrane wing surface }\end{array}$ & $\begin{array}{l}\text { Fully morphing wing utilizing } \\
\text { shape memory alloys and } \\
\text { electrical actuators }\end{array}$ \\
\hline $\begin{array}{l}\text { Underwater } \\
\text { propulsion }\end{array}$ & $\begin{array}{l}\text { Azimuth Pod } \\
\text { Thrusters }\end{array}$ & Efficient pump jet & $\begin{array}{l}\text { Combine with aero propulsion } \\
\text { to achieve a single power and } \\
\text { propulsion plant (rim-drive) }\end{array}$ \\
\hline $\begin{array}{l}\text { Onboard and } \\
\text { underwater } \\
\text { powering }\end{array}$ & $\begin{array}{l}\text { Lithium } \\
\text { batteries }\end{array}$ & Lightweight fuel cell & High power efficiency fuel cell \\
\hline $\begin{array}{l}\text { Surface and } \\
\text { underwater } \\
\text { maneuvering }\end{array}$ & $\begin{array}{l}\text { Azimuth pod } \\
\text { thrusters and } \\
\text { trailing edge } \\
\text { devices }\end{array}$ & $\begin{array}{l}\text { Rudder (act as yaw control } \\
\text { in flight) and mechanical } \\
\text { actuation modifying the wing }\end{array}$ & $\begin{array}{l}\text { Fully morphing wing utilizing } \\
\text { shape memory alloys and } \\
\text { electrical actuators }\end{array}$ \\
\hline Payloads & $\begin{array}{c}\text { Core mission } \\
\text { package and } \\
\text { variable spaces }\end{array}$ & $\begin{array}{l}\text { CONOPS specific payload } \\
\text { packages }\end{array}$ & \\
\hline
\end{tabular}

\section{Table 15 - Future technologies}

There were two clear paths available to achieve a shared power and propulsion plant, a fully electrical vehicle with rim-driven propulsion or to use underwater fuels such as those used in some torpedoes. The former was selected as the most likely development path. This was a result of a straightforward power and electrical chain 
without a need to switch fuels between air and water operations. Also, a conventional engine may still suffer from thermal shock issues whereas a fully electric vehicle could easily circumvent this by use of the rim-drive. This would also ensure a continuous water barrier with the outside environment making transition between environments more straightforward.

\section{Conclusion}

The U3V concept design is feasible. The work began with a performance target in each of the three domains: air, surface and underwater. A wide-ranging background survey of manned and unmanned vehicles, as well as previous attempts to design manned multi-environment craft, led to the twin-hull flying wing external form. An assessment of typical operational profiles and comparison of propulsion options showed that a dedicated aero engine and battery-powered drop-down thrusters offered the best compromise between weight and volume. The onboard equipment and additional unspecified payload of up to $100 \mathrm{~kg}$ externally and $100 \mathrm{~kg}$ internally was considered sufficient for a range of non-aggressive operations.

A sizing and balancing method was adapted from the UCL submarine design course and modified to account for balancing in the air domain. This ensured that a single, balanced design was used in all analysis activities.

The key design drivers can be split into each environment. On the surface, there was concern over stability and clearance of lifting surfaces and aero engine above the water. Underwater, there was a need to maintain the correct attitude through control of center of gravity and buoyancy. In the air, the weight was to be kept low and forwards and a large lifting surface area was needed. Many of these drivers had to be carefully de-conflicted.

The design is not ready for manufacture. There are major risks associated with stability in air and performance on the water surface especially in the absence of model tests. The trim systems are largely untested. Furthermore, there are considerable assumptions regarding design of the wing-like structures and the dynamic loads experienced during landing and underwater maneuvers.

However, with further work, it is anticipated that these shortcomings are not insurmountable. In order for a U3V style system to gain traction, the advantages of such a vehicle must be well understood. As more operations look towards reducing risks to personnel in theater, unmanned vehicles will become more attractive. U3V builds on this by providing the option for spontaneous reaction to a number of scenarios in varying environments. Most importantly, it can replace a number of different vehicles onboard a host platform with a universal system. This could result in a significant reduction in logistics, manpower and training. This unique quality could make U3V a valuable addition to a future Navy.

\section{Acknowledgements}

The authors would like to thank Colen Kennell (CISD) and Andrew Tate (UK Exchange Scientist - CISD) for supervising the project and providing valuable technical expertise and critique throughout. Jack Offutt (CISD) and Robert Deon (Canadian Navy Officer - CISD) attended appraisal reviews and provided technical insight throughout. Young Hwang (Structures and Composites) and Daniel Pusey (Altair) made the work on structural optimization possible with training and support. Max 
Harper (CISD) provided valuable assistance with modeling. Tim McDonald (Naval Architecture department UCL) provided sub-system design recommendations. Gary Shields (Disruptive Technologies Lab) gave useful input on alternative energy sources and the work by the DTL group on morphing wings was appreciated. Correspondence with Mike Morabito (U.S. Naval Academy) answered many seaplane and hull design questions. John Stebe (Naval Architecture) provided insight and useful criticism on the trim system and general layout.

\section{References}

[1] Eastgate J., Goddard R., 2010. Submersible Aircraft Concept Design Study. Center for Innovation in Ship Design, MD USA.

[2] Polmar N., Moore, K., 2005. Cold War Submarines: The Design and Construction of U.S. and Soviet Submarines. Potomac Books Inc.

[3] UCL, 2011. Submarine Design Procedure. UCL Department of Naval Architecture and Marine Engineering, London UK.

[4] Raymer D., 2004. Aircraft Design: A Conceptual Approach. AIAA Education Series.

[5] Corning G., 1970. Supersonic and subsonic airplane design.

[6] Mises R.V., 1959. Theory of Flight. Dover Publications.

[7] Korvin-Kroukovsky B.V., Morabito M.. Hydrodynamic Design of Seaplanes. (course notes). Stevens Institute of Technology.

[8] Stinton D., 1987. Aero-marine design and flying qualities of floatplanes and flying-boats. Aeronautical Journal. Royal Aeronautical Society.

[9] Burcher R., Rydill L., 1995. Concepts in Submarine Design. Cambridge University Press, UK.

[10] Kota S., Osborn R., Ervin G., Maric D., Flick P., Paul, D.. Mission Adaptive Compliant Wing Design, Fabrication and Flight Test. NATO Research and Technology Organisation.

[11] Thill C., Etches J., Potter K., Weaver P., 2008. Morphing Skins. The Aeronautical Journal.

[12] Torenbeek, E., 1982. Synthesis of Subsonic Airplane Design. Springer.

[13] Buckingham J., Hodge C., Hardy T., 2008. Submarine Power and Propulsion Application of Technology to Deliver Customer Benefit. BMT Defence Services Ltd, Bath UK.

[14] Srinivasan S., 2006. Fuel Cells: From Fundamentals to Applications. Springer.

[15] Liu H., Zhang J., 2009. Electrocatalysis of Direct Methanol Fuel Cells. WileyVCH Verlag GmbH \& Co. KGaA, Weinheim.

[16] Lockwood R.M., Sargent E.R., and Lockett, J.E., 1960. Thrust Augmented Intermittent Jet Lift-Propulsion System 'Pulse Reactor'. Hiller Aircraft Corp Report no. ARD-256. 
[17] Tsien, H-S. 1946. Jet Propulsion. California Institute of Technology/Guggenheim Jet Propulsion Center

\section{Additional bibliography}

Weisshar T. Morphing Aircraft Technology - New Shapes for Aircraft Design. NATO Research and Technology Organisation, USA.

Smith J., Lock W., Payne G., 1992. Variable-Camber Systems Integration and Operational Performance of the AFTI/F-111 Mission Adaptive Wing. NASA Technical Memorandum 4370, USA.

Smith Jr K., 2009. Morphing Wing Fighter Aircraft Synthesis/Design Optimization. Blacksburg, Virginia.

Ramrkahyani D., Leiseiutre G., Frecker M., Bharti S., 2004. Aircraft Structural Morphing using Tendon Actuated Compliant Cellular Trusses. AIAA Structures Conference, California USA.

Myers J., Holm C., McAllister R., 1969. Handbook of ocean and underwater engineering. McGraw-Hill Book Company.

Coltey D., Meyer J., Roseberry T., Hicks J., Ahlgren E., 2009. Conceptual Design of a Submersible Tactical Insertion Aircraft. Auburn University, USA

Fulghum D., Sweetman B., 2009. Stealth over Afghanistan. Aviation Week: 26-27, McGraw-Hill. 


\section{Appendices}

\section{Appendix A: Background UAV survey plots}

RQ-170 Sentinel principal characteristics are given in Table 16.

\begin{tabular}{l|c|lc}
\hline Manufacturer & Lockheed & Length $(\mathrm{m})$ & 4.5 \\
\hline Model & RQ-170 & Height $(\mathrm{m})$ & 1.8 \\
Wing Type & Blended Wing & Wing span $(\mathrm{m})$ & 12 \\
Platform Description & Fixed Wing & Planform Area $\left(\mathrm{m}^{2}\right)$ & 20.4 \\
Aspect Ratio & 7.1 & Wetted Surface Area $\left(\mathrm{m}^{2}\right)$ & 43.9 \\
Wetted Aspect Ratio & 3.3 & Ceiling $(\mathrm{m})$ & 15,240 \\
Max Weight $(\mathrm{kg})$ & $>3,855$ & Suggested engine & GE TF34 \\
\hline
\end{tabular}

\section{Table 16 - RQ-170 Sentinel principal characteristics}

A standard power-law method for calculating variable weight fraction for flying boats shows that modern UAVs are able to carry a much larger payload (or fuel) for a given size. This is likely due to advancements in technology, and the fact that no human support equipment or cockpit controls are required. The result is that a typical empty weight ratio equation [4] can be modified from Equation 10 to Equation 11:

Equation 10

Equation 11

$$
\begin{aligned}
& \text { We } / \text { W0 }=1.09 \times \text { W0-0.05 x } 1.04 \\
& \text { We } / \text { W0 }=0.90 \times \text { W0-0.05 x } 1.04
\end{aligned}
$$

(flying boat, variable sweep)

(UAV parametrics)

Finally, some UAVs have specific mission payloads of fixed weight. These can be used to estimate the relationship between maximum payload and the weight of the craft. According to the data, approximately 19\% of the vehicle weight is 'payload', although the correlation is weak above $2,000 \mathrm{~kg}$. 


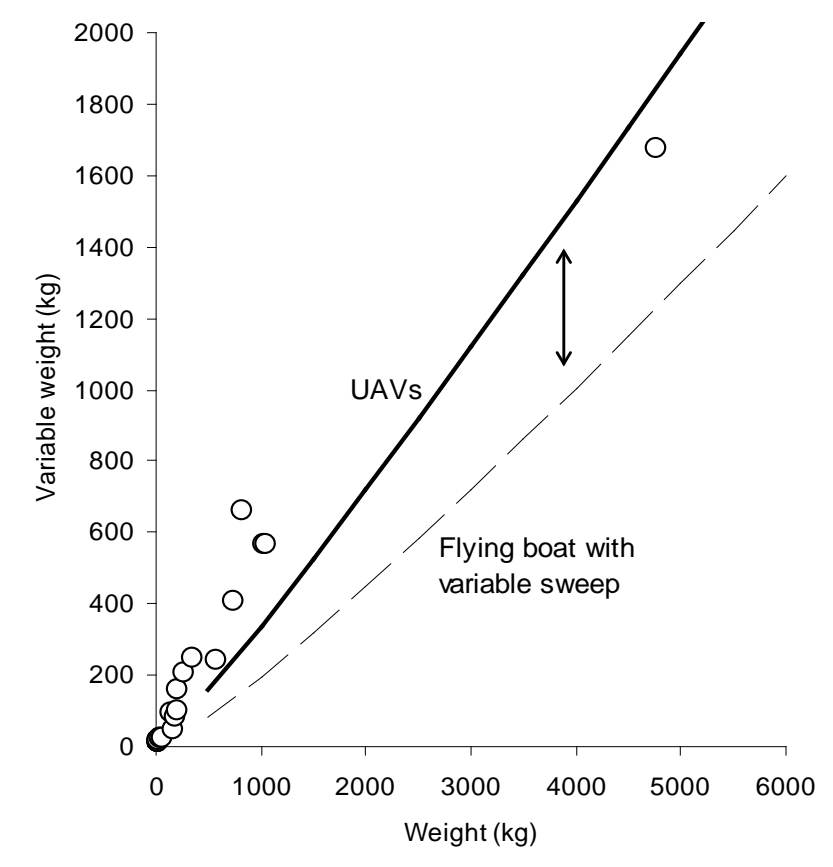

Figure 52 - UAV variable weight vs. total weight

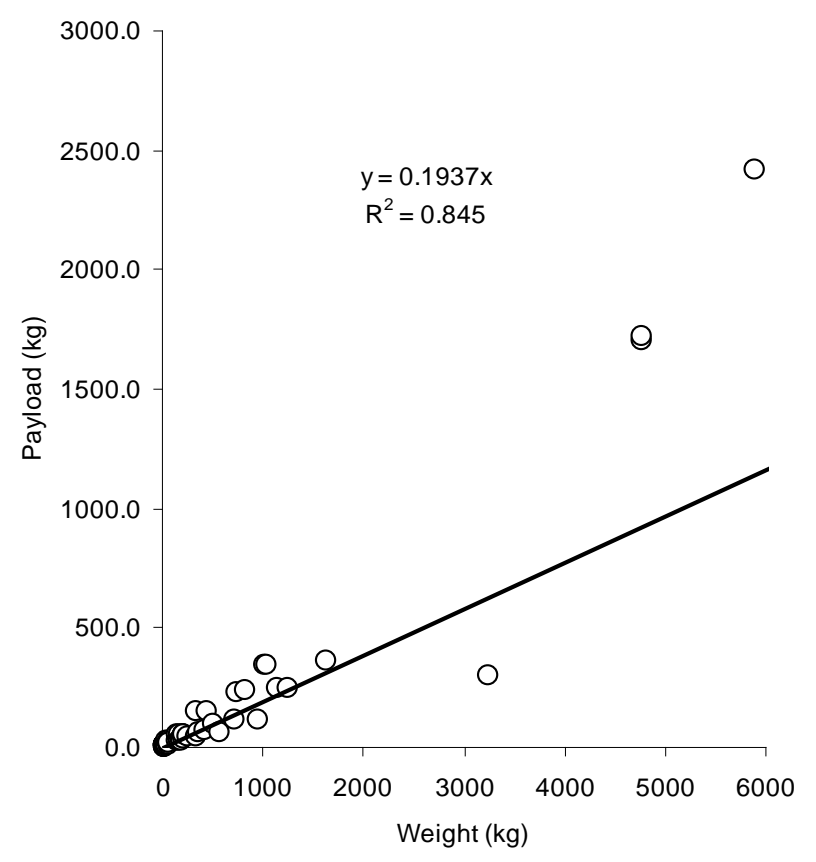

Figure 53 - UAV payload weight vs. total weight

\section{Maximum weight from wing area}

The dimensional constraint being that of an 11m RHIB and 5m DDG-1000 stern door, we can estimate the maximum useful wing area based on a flying wing design with an average $3 \mathrm{~m}$ chord. This results in a maximum wing area of $33 \mathrm{~m}^{2}$. Historical data suggest a linear relationship with reasonable correlation between MTOW and wing area. This is logical if seaplanes have similar wing loading - the spread of data points is 
the figure demonstrates that this correlation is not perfect, with the wing area requirement likely to be driven by the take-off speed, which must be as low as possible.

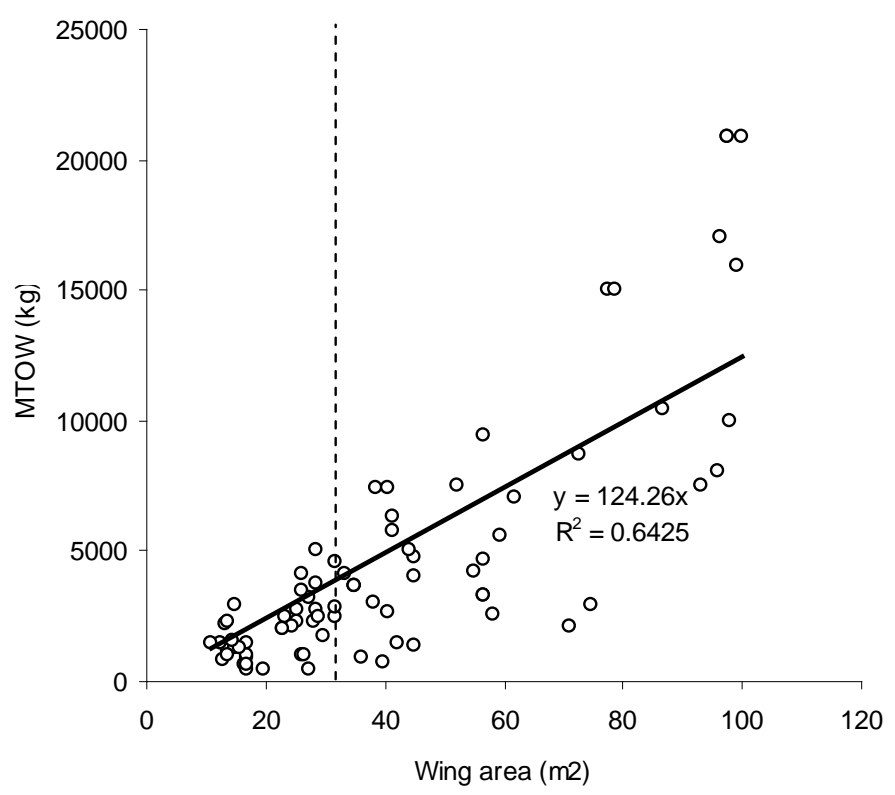

Figure 54 - Seaplane MTOW vs. wing area

It is worth noting that the final design may not resemble the most efficient flying wing design. Floats, compartments and engine integration will increase the chord, and may result in a blended-wing-body appearance. In addition, the wings will need to rise above the water surface and may be designed with substantial anhedral or dihedral. The database consists primarily of older designs, and hence does not represent the impacts of modern innovations in aircraft design. These include modern high-lift devices for take-off, lifting bodies/fuselages and novel hull forms that reduce drag. In particular, a relatively low-aspect ratio wing will have better lift-to-drag performance. In this way, modern technology may be leveraged to improve the lift characteristics of a new concept.

\section{Variable load fraction}

Having initial values for size (from requirements) and displacement (from regression), the variable load can be established. The variable load comprises everything that can be embarked or loaded, including crew, fuel, cargo and passengers. In the U3V concept, the variable load will have a very different breakdown, principally due to exclusion of personnel, but the variable load fraction should remain similar in overall proportion.

There is very good correlation of variable load fraction (variable load divided by MTOW) across all seaplane types. Figure 55 shows us that the variable load fraction is 0.37 for seaplanes below 50 tonnes, very similar to that of aircraft in general, according to Raymer [4]. 


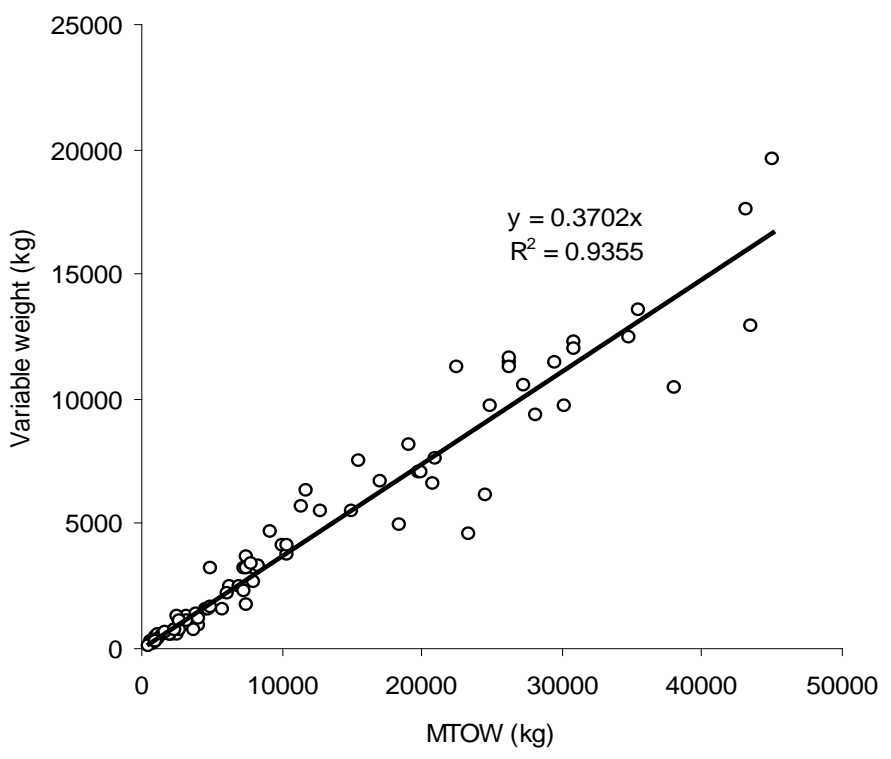

Figure 55 - Seaplane variable weight vs. MTOW

\section{Power loading and speed}

The seaplane database can yield some further useful information for the sizing process. The power loading is usually written as MTOW divided by installed horsepower, but the figure actually shows the inverse of this. Thus, a high value on yaxis means that the craft is relatively powerful for its size.

There is a good linear correlation up to about $200 \mathrm{mph}$, or Mach 0.27 at 5,000ft. Above this, the data are skewed by ultra-high-performance aircraft like the Supermarine S-6B, a past world speed record contender. Also shown in the figure with a dotted line is the standard initial sizing power-to-weight ratio of 0.1 for seaplanes. This correlates well with the data. Assuming that engines are sized for cruise speed, we can calculate the thrust of each seaplane by using engine data and Equation 12.

Equation 12 Cruise thrust $=$ Engine qty. $\times$ engine rating $(\mathrm{hp}) \times 375 /$ Cruise speed $(\mathrm{mph})$

Using this equation, the Figure 57 shows us that there is a very good correlation across all seaplanes up to 50 tonnes. Using a linear best-fit, a 4 tonne craft will require engines that generate $1,700 \mathrm{lb}$ of thrust at cruise. This value is highly dependent upon cruise speed, which will be examined through the sizing tool. 


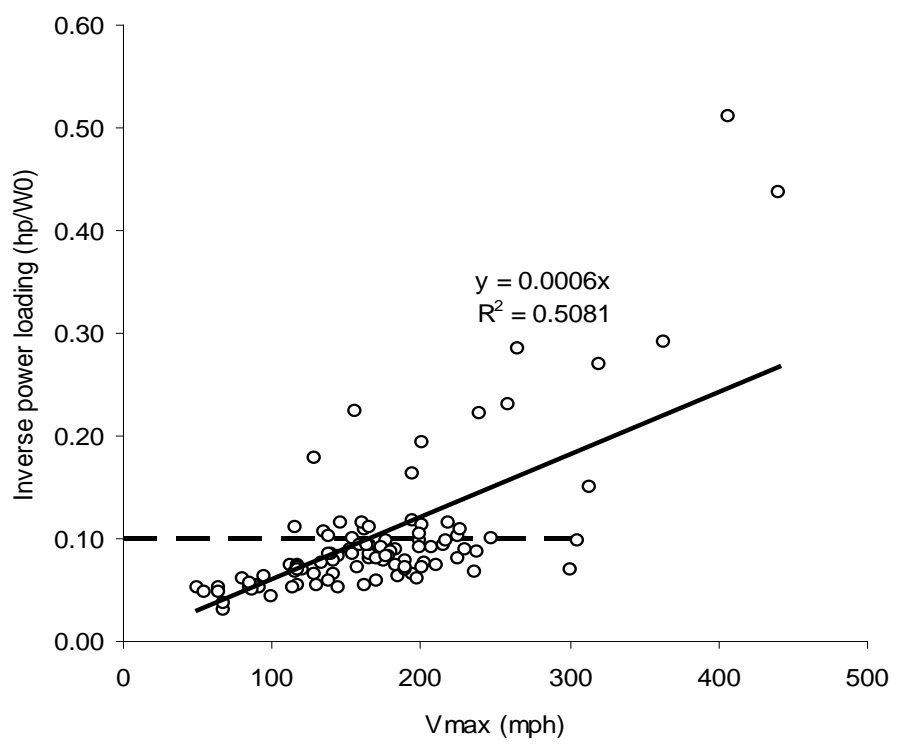

Figure 56 - Seaplane power loading vs. maximum speed

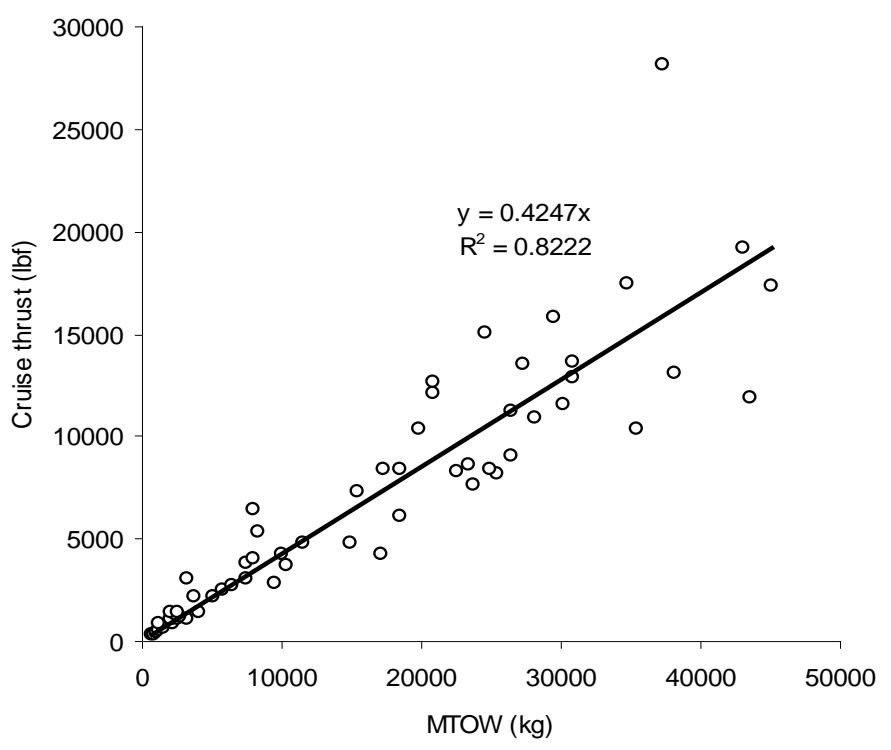

Figure 57 - Seaplane cruise thrust vs. MTOW 


\section{Appendix B: Aircraft sizing from a conceptual sketch Requirements and inputs}

With initial values for range, speed and dimensions, it was possible to conduct a basic aircraft sizing iteration using Raymer [4]. In addition to these, some further properties of the wing and lift-drag performance were assumed.

The aspect ratio of the wing can be easily calculated once the wing area has been estimated, using Equation 13. The wetted aspect ratio is a more useful determinant of drag, since it replaces the approximate wing area with total surface area exposed to the flow, as shown in Equation 14. The first estimator of $A R$ and $A R_{\text {wet }}$ for this design is the Avro Vulcan, a blended-wing-body British deterrent bomber. The maximum $L / D$ is based on the same aircraft, and cruise $L / D$ is estimate to be $86 \%$ of this.

$\begin{array}{ll}\text { Equation } 13 & A R=(\text { span })^{2} / \text { (approximate wing area) } \\ \text { Equation 14 } & A R_{\text {wet }}=(\mathrm{span})^{2} / \text { (wetted surface area) }\end{array}$

\begin{tabular}{l|lll}
\hline Category & Variable & Value & Assumption basis \\
\hline Performance & Air range $(\mathrm{nm})$ & 260 & \\
& Speed (mach) & 0.5 & \\
\multirow{4}{*}{ Wing } & Approx. wing area $\left(\mathrm{ft}^{2}\right)$ & 355 & $11 \mathrm{~m} \mathrm{x} \mathrm{3m}$ (mean chord) \\
& Aspect ratio & 3 & Avro Vulcan \\
\multirow{3}{*}{ Lift-drag } & Wetted aspect ratio & 1.1 & Avro Vulcan \\
& L/D max & 17 & Avro Vulcan \\
& $L / D$ cruise & 14.7 & Jet ratio \\
\hline
\end{tabular}

Table 17 - Example inputs to the aircraft initial sizing

Mission profile and fuel fraction

Fuel requirements can be estimated as a fraction of total weight by creating a mission profile. In this design, the aircraft must complete two full cycles of warm-up, take-off, climb, cruise, descent and landing. This is represented in Figure 58, where each cruise segment is equal to half the total range.

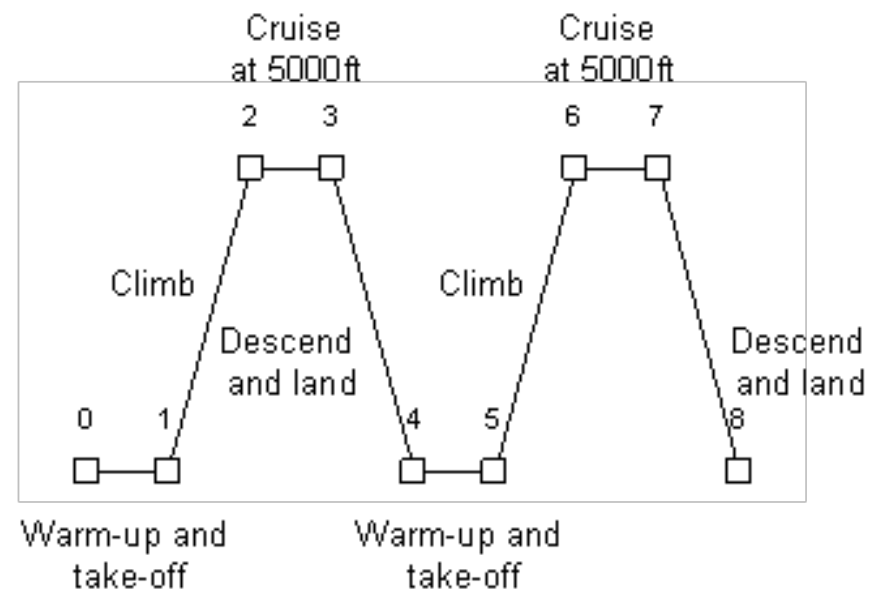

Figure 58 - Example mission profile 
Raymer provides standard values for the amount of fuel used up in each segment, represented as fractions of MTOW. For example, warm-up and take-off consume about $3 \%$ of the total aircraft weight in fuel.

To calculate this weight fraction for each cruise segment, the Breguet range equation can be used, shown in Equation 15. The only unknown is the specific fuel consumption, which can be estimated at 0.45 for initial calculations. Table 18 shows the results of these calculations for the inputs quoted above.

Equation $15 W_{\text {endcruise }} / W_{\text {startcruise }}=\exp \left[\right.$ - Range x $S F C /\left(\right.$ speed $\left.\left.\times L / D_{\text {cruise }}\right)\right]$

\begin{tabular}{l|lc}
\hline Segment & Name & Weight fraction \\
\hline 1 & Warm-up and take-off & 0.970 \\
2 & Climb & 0.985 \\
3 & Cruise & 0.987 \\
4 & Descend and land & 0.995 \\
5 & Warm-up and take-off & 0.970 \\
6 & Climb & 0.985 \\
7 & Cruise & 0.987 \\
8 & Descend and land & 0.995 \\
\hline & Total & 0.880 \\
\hline
\end{tabular}

Table 18 - Example mission segment weight calculations

\section{Iterating total weight}

The difference between empty and full weight is equal to 'non-airframe weight', which includes (for this unmanned craft) payload, fuel, and equipment/structure not related to the air flight part of the design.

Table 18 shows us that, including a standard 6\% margin, fuel weight comprises $12.7 \%$ MTOW. A first guess at the rest of non-airframe weight is $1,000 \mathrm{~kg}$ - thus, the MTOW $\left(W_{0}\right)$ is calculated in Equation 16.

Unfortunately, one variable remains unknown in this equation. The empty weight fraction can be calculated from a power-fit correlation for UAVs that depends on an initial guess for total weight Equation 17. Hence, this is an iterative process (see Table 19). The table shows us that the number chosen results in a total weight just less than four tonnes. This iterative process permits two simple trade-off studies focusing on non-airframe weight, range and fuel economy.
Equation 16
$W_{0}=W_{\text {payload }} /\left(1-W_{\text {fuel }} / W_{0}-W_{e} / W_{0}\right)$
Equation 17
$W_{e} / W_{0}=0.90 \times W_{0}^{-0.05} \times 1.04$
(Unmanned Air Vehicles)

\begin{tabular}{c|c|c}
\hline Guess $w_{0}(\mathrm{~kg})$ & Empty fraction $\left(w_{e} / w_{0}\right)$ & Calculated $w_{0}(\mathrm{~kg})$ \\
\hline 3,686 & 0.6012 & 3,627 \\
3,627 & 0.5968 & 3,633 \\
3,633 & 0.5973 & 3,633 \\
3,633 & 0.5972 & 3,633 \\
\hline
\end{tabular}

Table 19 - Example of total weight iteration

\section{Trade-offs and sensitivities}


The preceding section showed that there exists a trade-off between payload, the additional weight required for sea surface and underwater operations, and range (fuel). For example, a craft with a highly efficient hybrid structure that is only slightly heavier a pure aircraft design would permit a larger payload, or greater range.

Figure 59 shows the residual weight available for payload and the additional weight for surface/subsurface operations, with variations in range, and the effect on maximum take-off weight. A design with minimal range can carry almost $800 \mathrm{~kg}$ of additional weight, whereas a long-range variant may be able to go 500nm but with only $500 \mathrm{~kg}$ of additional weight.

It is possible that a design can be envisioned that can trade-off range and payload for a given mission. This graph, or one like it, can be applied once the structural and equipment weight of surface and subsurface operations is known. At this stage, one significant uncertainty is the fuel economy of the air propulsion. Figure 60 shows the impact of deviations of 1/3 from the initial assumed rate of consumption on the available weight.

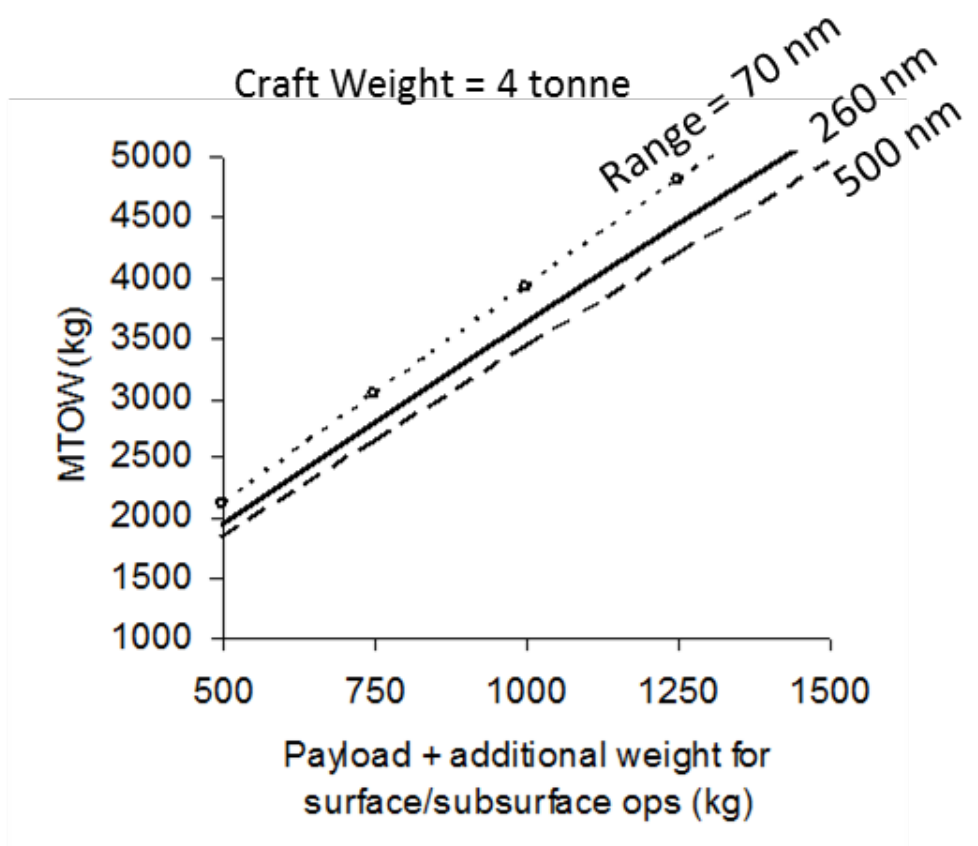

Figure 59 - Trade-off between payload, additional weight and range 


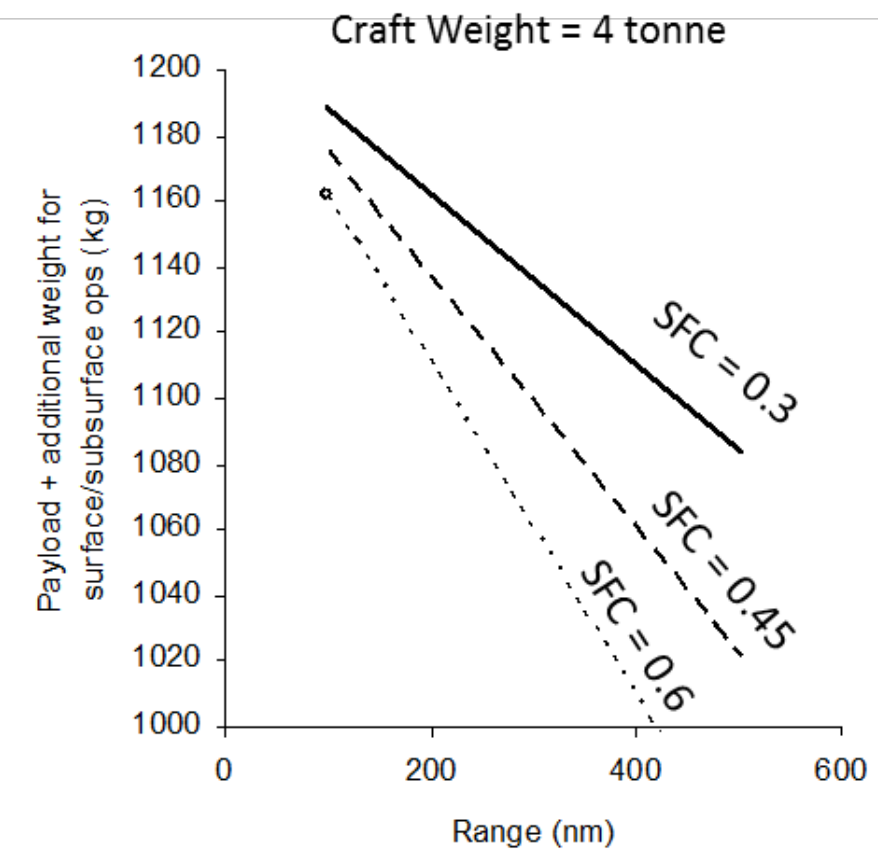

Figure 60 - Variation of weight and range with specific fuel consumption 


\section{Appendix C: Submerged power and propulsion Wing submerged resistance}

The planform area of the wing $(A), 50 \mathrm{~m}^{2}$, was used in conjunction with an estimate for drag coefficient $\left(C_{D}\right)$, to find the wing submerged resistance $(D)$ at a maximum velocity $\left(U_{\max }\right)$, of $4 \mathrm{kts}$, in seawater; shown in Equation 18.

\section{Equation 18

$$
D=1 / 2 C_{D} \rho U_{\max }^{2} A
$$

Where:

$$
\rho \text { : Fluid density }\left(1,025 \mathrm{~kg} / \mathrm{m}^{3}\right. \text { for seawater) }
$$

The section drag coefficient was based upon similar NACA airfoils to the NACA 23018; as data for this specific foil could not be well established either from reports or computational simulation. The Reynolds number used to evaluate maximum resistance was $7.1 \times 10^{6}$, found at the maximum velocity, $4 \mathrm{kts}$, and a characteristic length equal to the chord length, $4.1 \mathrm{~m}$. This was calculated at zero lift; the desirable operating condition underwater, so not to affect depth control.

At the maximum velocity, the section drag coefficient was found to be 0.006 ; delivering a hydrodynamic resistance of $651 \mathrm{~N}$ for the wing.

\section{Engine cowling submerged resistance}

The Engine cowling was assumed to be that of an airship hull. As depicted in Figure $61^{24}$, the drag coefficient was assumed constant, at 0.04 , for Reynolds numbers greater than $2 \times 10^{6}$.

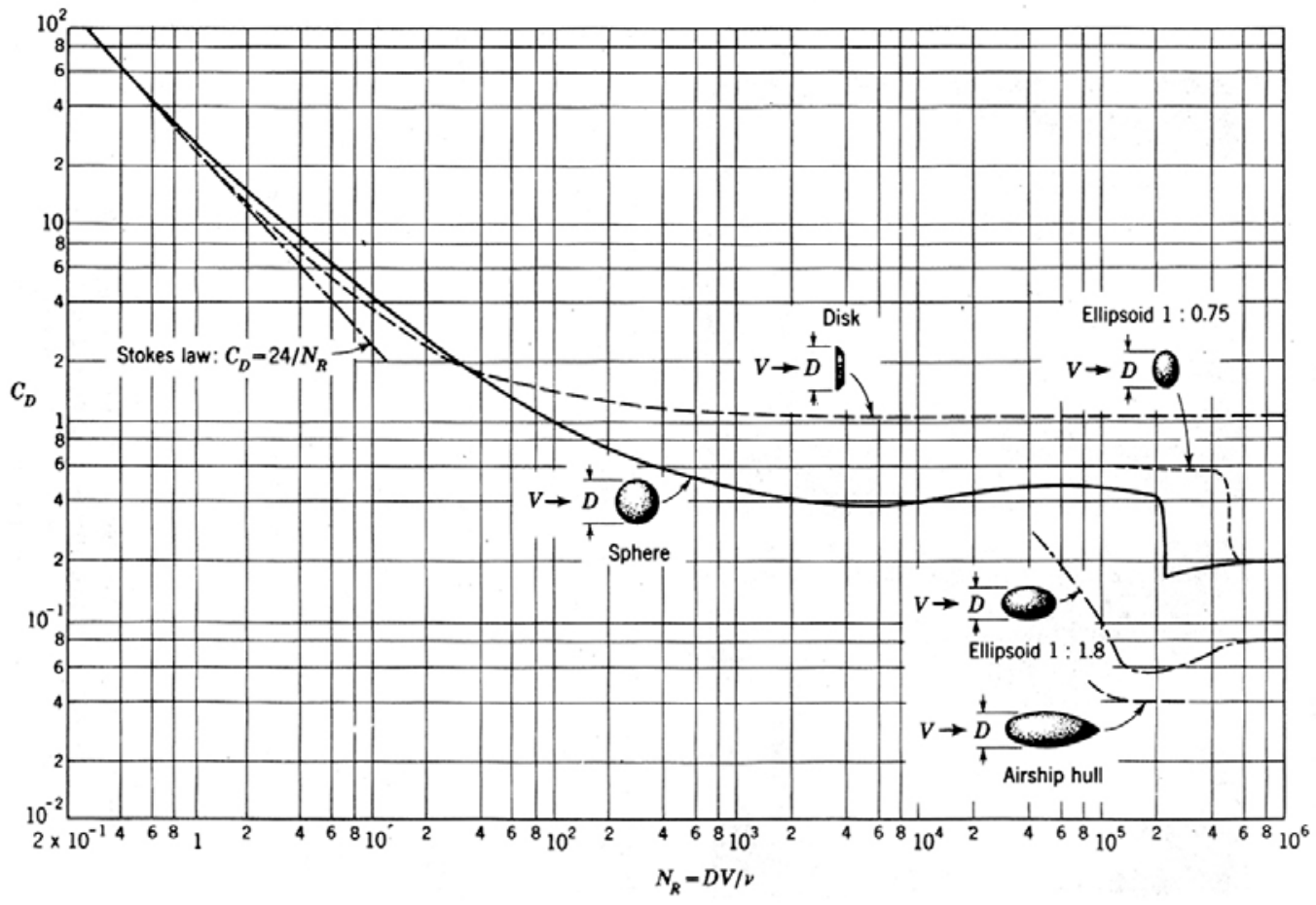

Figure 61 - Drag coefficient against Reynolds number for bluff bodies

${ }^{24}$ University of Texas at Austin. Drag Coefficient against Reynolds Number for Spherical Bodies. Available from: http://www.me.utexas.edu/ dsclab/labs/lvsimulation/sphere/Cd_v_NR.jpg [Accessed on 2nd July 2012] 
Adopting the diameter of the engine for parameter $D$ in Figure 61, produced a Reynolds number of $8.48 \times 10^{5}$; delivering a drag coefficient of 0.04 .

Using Equation 19, the total drag was calculated:

Equation $19 \quad D=1 / 2 C_{D} \rho U_{\text {max }}^{2} A$

Note; the area used for this component is based on frontal area $\left(0.06 \mathrm{~m}^{2}\right)$, not a calculated surface area of the cowling, as used for the wing section. Half the body was included in the calculation of area, due to the other half being blended with the wing. The drag found on the body was $5.2 \mathrm{~N}$.

\section{Floats submerged resistance}

The float hulls were assumed to be ellipsoid cigar style shapes; similar to a submarine hull. As a result, the equation for effective power $\left(P_{\text {eff }}\right)$ of a submarine was used [9], based upon the floats' form volume (1.0101 ${ }^{3}$ per float); given in Equation 20. Hydrodynamic resistance, if required, can be evaluated by dividing the effective power by the velocity; in this case equaling $79.2 \mathrm{~N}$ per hull at maximum velocity.

$$
\text { Equation } 20 \quad P_{E f f}=K_{P} V_{F o r m}^{0.64} U_{\max }^{2.9}
$$

\section{Hotel load requirement}

Many companies provide an endurance time at a specific speed, to illustrate usability of their UUVs. Coupled with the onboard energy requirement, an approximation for: total power; shaft power, at the stated endurance speed; and, therefore, hotel load could all be found. The constitutive parts of the total power (propulsion power and hotel load), are illustrated for a range of UUVs in Figure 62.

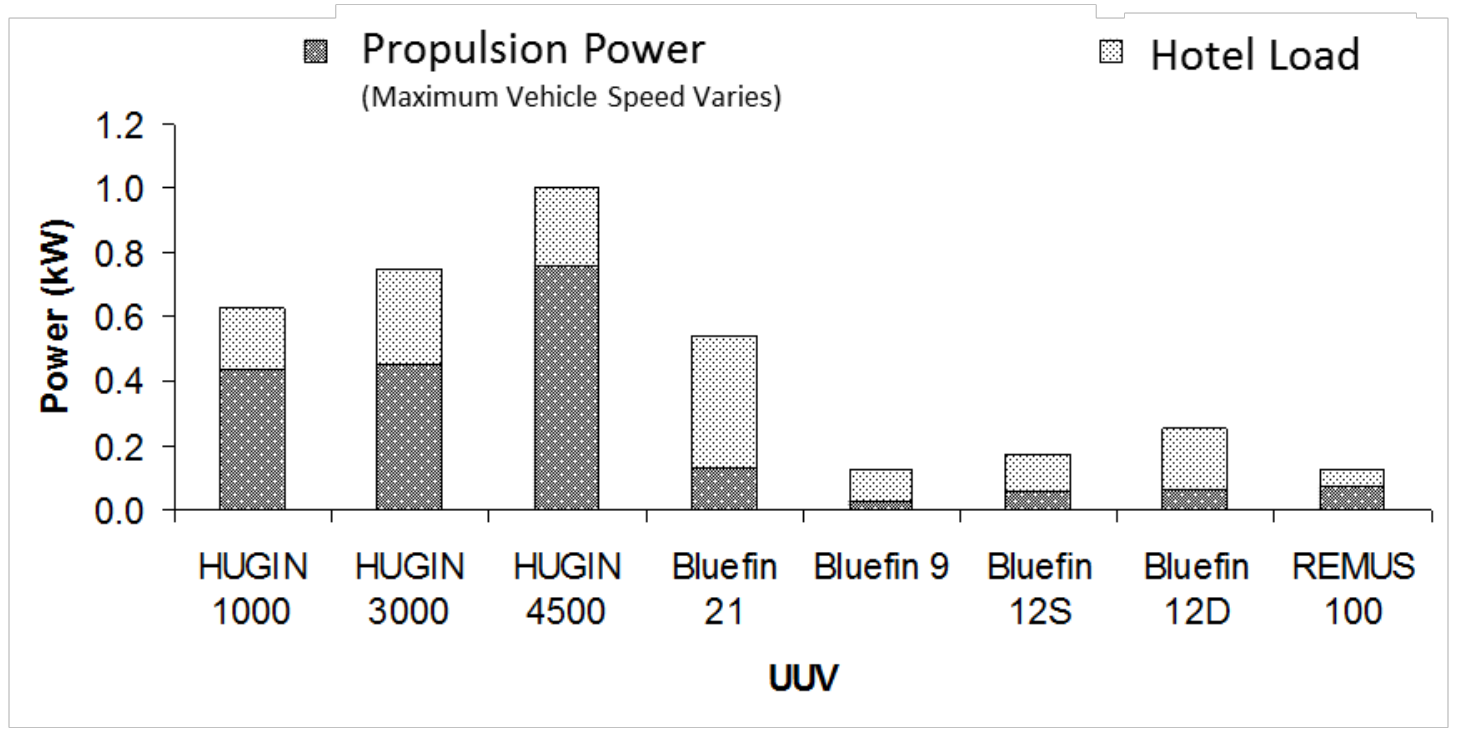

Figure 62 - Power against speed for a range of torpedo shaped UUVs

The average hotel load power requirement was calculated to be 200W. This approximation is not wholly accurate, as there will be fluctuations in hotel load as a result of mission profile and speed. However, a subject matter expert remarked that this was a sensible estimate. 


\section{Energy storage}

Battery capacity sizing adopted the process used in the UCL submarine design course [3]. This is based upon the required submerged endurance at a specific submerged speed. The following equations were used:

Equation 21

$$
D_{r}=\frac{P_{s}}{\eta_{e l}}+H_{s u b}
$$

Equation 22

$$
C=D_{r} T_{D I S}
$$

Equation 23

$$
T_{\text {DIS }}=\frac{T_{\text {sub }}}{1-x}
$$

Where:

$D_{r}$ : Battery drain

$\eta_{e l}$ : Motor efficiency $H_{\text {sub }}$ : Hotel load submerged

$C$ : Total required battery energy

$T_{\text {sub }}$ : Time submerged

$T_{D I S}$ : Total discharge time $x$ : Battery margin

A simple mission profile was established, using a maximum/transiting scenario; whereby U3V must maintain a speed of 4 kts for 3 hours. Using the resistance calculations described previously and the information above, the data in Table 20 was generated for this scenario.

\begin{tabular}{l|c}
\hline Velocity (kts) & 4 \\
Shaft Power (kW) & 3.12 \\
Motor Efficiency & 0.98 \\
Battery Drain (kW) & 2.70 \\
Submerged Time (hrs) & 8 \\
Discharge Time (hrs) & 10 \\
Required Battery Capacity (kWhr) & 27.03 \\
\hline
\end{tabular}

Table 20 - Battery sizing data

The motor was rated for maximum efficiency at maximum velocity; $4 \mathrm{kts}$. This was assumed to be $98 \%$.

Results indicate that a battery capacity of just over $15 \mathrm{kWhr}$ was required to meet the 4 kts for 3 hours scenario.

The data in Table 21 was used to calculate the volume and mass requirements needed to install the three types of battery discussed previously (lead acid, Zebra and lithium ion) [13]. 


\begin{tabular}{l|cc}
\hline Battery type & Energy Density (Wh/litre) & Specific Weight $(\mathrm{Wh} / \mathrm{kg})$ \\
\hline Lead Acid & 90 & 44 \\
Zebra & 167 & 114 \\
Lithium Ion & 270 & 120 \\
\hline
\end{tabular}

Table 21 - Energy density and specific weight for a range of batteries

By working backwards through the calculations a speed power curve can be composed. Assumptions include that the motor efficiency modifies with speed; degrading from its optimum at $98 \%$ at high speed, as speed decreases, as shown in Figure 63.

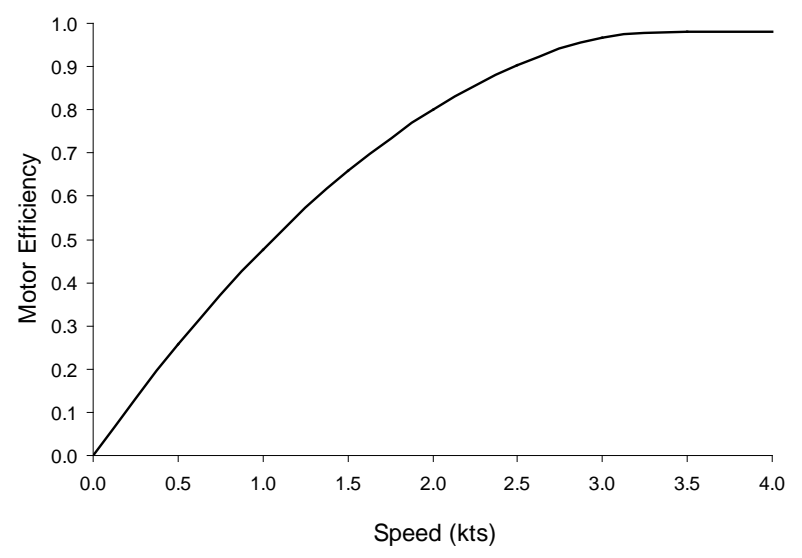

Figure 63 - Assumed relationship between motor efficiency and vehicle speed

\section{Pump jets}

The advantage pump jets have over pods is that they can remain flush with the bottom of the hull and require less moving parts; as they only need to rotate, and not move in and out from the ship surface. These pump jets work by directly sucking in water, and pumping it out in a different orientation, as depicted in Figure $64^{25}$. ${ }^{25}$ Schottel. SPJ Pump Jet. Available from: http://www.schottel.de/marine-propulsion/spj-pump-
jet/operating-principle/ [Accessed on 2nd July 2012] 


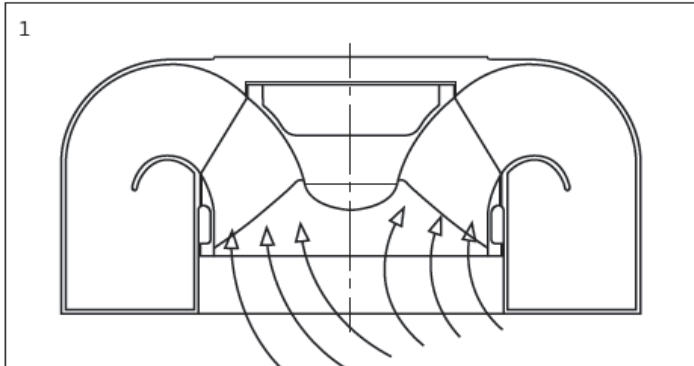

An impeller draws water into the Pump-Jet; the slow intake speed and the protective grid prevent foreign objects from entering.

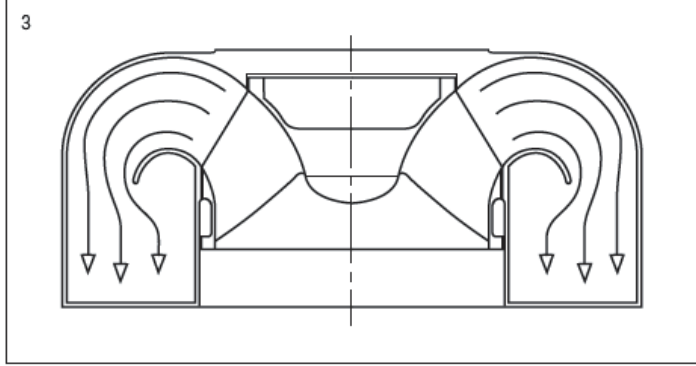

... and charged with energy by increasing static pressure.

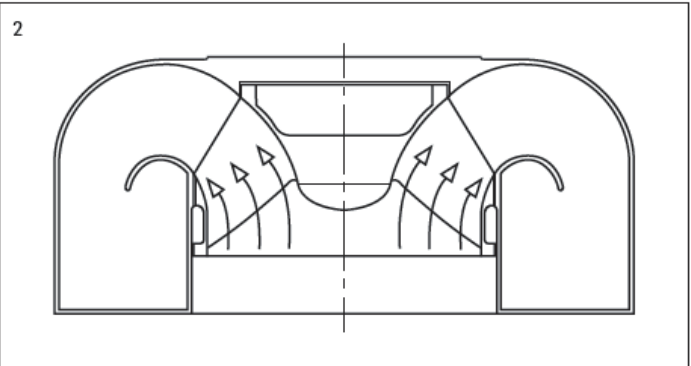

The water is then pushed into the diffuser by the impeller ...

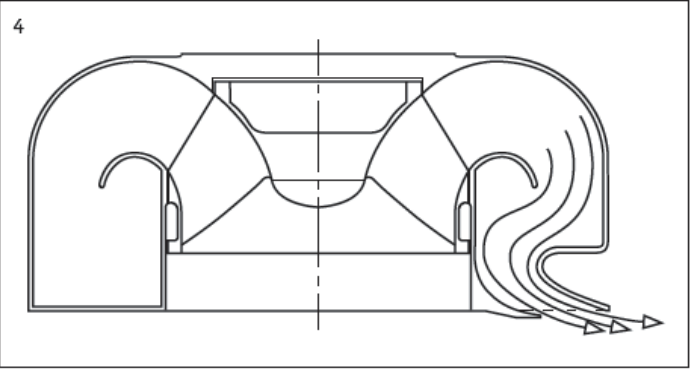

The water is ejected at very high velocity through the outlet nozzles at an output angle of approx. $15^{\circ}$.

Figure 64 - Pump jet process sketches 


\section{Appendix D: Weight and space breakdown \\ Weight and volume}

The following tables summarize the mass and volume of each sub-system within U3V. They also highlight where each are located, in terms of external to PVs

(External) or within which PV; main sensory PV (Sensory), motor PV (Motor), or gas turbine PV (Jet).

\begin{tabular}{|c|c|c|c|c|c|c|}
\hline \multirow[b]{2}{*}{ GROUP 1} & \multirow[b]{2}{*}{ Structure } & \multirow[b]{2}{*}{$\begin{array}{c}\text { Mass } \\
(\mathrm{kg})\end{array}$} & \multicolumn{4}{|c|}{ Volume } \\
\hline & & & $\begin{array}{c}\text { Sensory } \\
\qquad\left(\mathrm{m}^{3}\right)\end{array}$ & $\begin{array}{c}\text { Motor } \\
\left(\mathrm{m}^{3}\right)\end{array}$ & $\begin{array}{l}\text { Jet } \\
\left(\mathrm{m}^{3}\right)\end{array}$ & $\begin{array}{c}\text { External } \\
\left(\mathrm{m}^{3}\right)\end{array}$ \\
\hline \multirow[t]{5}{*}{10 Pressure Hull } & Main Pressure Hull Shell & 32.77 & 0.007 & & & \\
\hline & Jet Engine Hull Shell & 26.00 & & & 0.006 & \\
\hline & Propulsor Pressure Hull Shell & 4.53 & & 0.001 & & \\
\hline & Jet Engine Sealing Mechanism Fwd & 37.39 & & & 0.003 & 0.005 \\
\hline & Jet Engine Sealing Mechanism Aft & 37.39 & & & 0.003 & 0.005 \\
\hline \multirow[t]{4}{*}{11 External Structure } & Wing structure & 366.41 & & & & 0.081 \\
\hline & External Floating Hulls & 187.91 & & & & 0.042 \\
\hline & Internal Support Structure & 36.15 & & & & 0.008 \\
\hline & Totals & 729 & 0.007 & 0.001 & 0.011 & 0.141 \\
\hline
\end{tabular}

Table 22 - Group 1 Structure mass and volume breakdown

\begin{tabular}{|c|c|c|c|c|c|c|}
\hline \multirow[b]{2}{*}{ GROUP 2} & \multirow[b]{2}{*}{ Propulsion } & \multirow[b]{2}{*}{$\begin{array}{l}\text { Mass } \\
(\mathrm{kg})\end{array}$} & \multicolumn{4}{|c|}{ Volume } \\
\hline & & & $\begin{array}{c}\text { Sensory } \\
\left(\mathrm{m}^{3}\right)\end{array}$ & $\begin{array}{c}\text { Motor } \\
\left(\mathrm{m}^{3}\right)\end{array}$ & $\begin{array}{l}\text { Jet } \\
\left(\mathrm{m}^{3}\right)\end{array}$ & $\begin{array}{c}\text { External } \\
\left(\mathrm{m}^{3}\right)\end{array}$ \\
\hline $\begin{array}{l}25 \text { Insulation \& Fluids } \\
\text { in Propulsion } \\
\text { Machinery }\end{array}$ & Fuel trunking from Tanks to Engine & 19.50 & & & & 0.048 \\
\hline \multirow[t]{2}{*}{26 Main Machinery } & Jet Engine & 187.59 & & & 0.290 & \\
\hline & Jet Starter & 39.15 & & & 0.115 & \\
\hline \multirow{4}{*}{$\begin{array}{l}29 \text { Electrical } \\
\text { Propulsion Equipment } \\
\text { \& Systems }\end{array}$} & Motors (internal) & 50.78 & & 0.019 & & \\
\hline & Propeller (external) & 3.33 & & & & 0.002 \\
\hline & Main Batteries & 129.81 & 0.068 & & & \\
\hline & Totals & 430 & 0.068 & 0.019 & 0.405 & 0.050 \\
\hline
\end{tabular}

Table 23 - Group 2 Propulsion mass and volume breakdown 


\begin{tabular}{ll|ccccc}
\hline & Cabling & Mass & \multicolumn{3}{c}{ Volume } \\
GROUP 3 & & $\begin{array}{c}\text { Sensory } \\
(\mathrm{kg})\end{array}$ & $\begin{array}{c}\text { Motor } \\
\left(\mathrm{m}^{3}\right)\end{array}$ & $\begin{array}{c}\text { Jet } \\
\left(\mathrm{m}^{3}\right)\end{array}$ & $\begin{array}{c}\text { External } \\
\left(\mathrm{m}^{3}\right)\end{array}$ & $\left(\mathrm{m}^{3}\right)$ \\
\hline $\mathbf{3 0}$ Cabling & Internal Cabling & 8.70 & 0.0006 & 0.0002 & 0.0002 \\
& External Cabling & 8.70 & & & & 0.0010 \\
$\mathbf{3 1}$ Electrical & Electrical Control Power Management & 11.73 & 0.0410 & & & \\
Generating Equipment & System & $\mathbf{2 9}$ & $\mathbf{0 . 0 4 1 6}$ & $\mathbf{0 . 0 0 0 2}$ & $\mathbf{0 . 0 0 0 2}$ & $\mathbf{0 . 0 0 1 0}$ \\
\hline
\end{tabular}

Table 24 - Group 3 Electrical mass and volume breakdown

\begin{tabular}{|c|c|c|c|c|c|c|}
\hline \multirow[b]{2}{*}{ GROUP 4} & \multirow[b]{2}{*}{$\begin{array}{l}\text { Control, Communications and } \\
\text { Payload }\end{array}$} & \multirow[b]{2}{*}{$\begin{array}{c}\text { Mass } \\
(\mathrm{kg})\end{array}$} & \multicolumn{4}{|c|}{ Volume } \\
\hline & & & $\begin{array}{c}\text { Sensory } \\
\left(\mathrm{m}^{3}\right)\end{array}$ & $\begin{array}{c}\text { Motor } \\
\left(\mathrm{m}^{3}\right)\end{array}$ & $\begin{array}{c}\text { Jet } \\
\left(\mathrm{m}^{3}\right)\end{array}$ & $\begin{array}{c}\text { External } \\
\qquad\left(\mathrm{m}^{3}\right)\end{array}$ \\
\hline \multirow[t]{11}{*}{4 Core payload } & Obstacle Avoidance and Threat Sonar & 22.15 & & & & 0.005 \\
\hline & Small Tactical Radar & 30.44 & & & & 0.034 \\
\hline & Bathymetric SAS Sonar & 38.80 & & & & 0.037 \\
\hline & Acoustic Communications & 4.33 & 0.001 & & & \\
\hline & Inertial Navigation System (INS) & 8.76 & 0.013 & & & \\
\hline & Computer & 4.02 & 0.008 & & & \\
\hline & Gimballed Camera EO/IR & 20.60 & & & & 0.114 \\
\hline & Temperature/Depth Sensor & 1.30 & 0.002 & & & \\
\hline & Pressure/Speed Sensors & 4.12 & 0.007 & & & \\
\hline & Chemical Agent Detector & 44.92 & 0.059 & & & \\
\hline & Totals & 179 & 0.090 & 0.000 & 0.000 & 0.191 \\
\hline
\end{tabular}

Table 25 - Group 4 Control \& Communication mass and volume breakdown

\begin{tabular}{|c|c|c|c|c|c|c|}
\hline \multirow[b]{2}{*}{ GROUP 5} & \multirow[b]{2}{*}{ Ship Services } & \multirow[b]{2}{*}{$\begin{array}{c}\text { Mass } \\
\text { (kg) }\end{array}$} & \multicolumn{4}{|c|}{ Volume } \\
\hline & & & $\begin{array}{c}\text { Sensory } \\
\left(\mathrm{m}^{3}\right)\end{array}$ & $\begin{array}{c}\text { Motor } \\
\left(\mathrm{m}^{3}\right)\end{array}$ & $\begin{array}{l}\text { Jet } \\
\left(\mathrm{m}^{3}\right)\end{array}$ & $\begin{array}{c}\text { External } \\
\left(\mathrm{m}^{3}\right)\end{array}$ \\
\hline \multirow[t]{2}{*}{50 Miscellaneous } & MBT Vents \& Operating Gear & 0.91 & & & & 0.0021 \\
\hline & External Drains & 0.57 & & & & 0.0001 \\
\hline \multirow{4}{*}{53 Water Systems } & Trim, Bilge \& Ballast System & 5.00 & 0.0058 & & & 0.0058 \\
\hline & Comp Pumps \& Starters (2) & 0.23 & 0.0005 & & & \\
\hline & HP Ballast Pump \& Starter & 0.85 & & & & 0.0017 \\
\hline & Depth Gauges & 0.11 & 0.0003 & & & \\
\hline \multirow[t]{2}{*}{55 Air Systems } & HP Air System & 2.21 & & & & 0.0043 \\
\hline & HP Air Bottles & 26.21 & & & & 0.0631 \\
\hline 57 Trim Systems & Trim Rail System & 14.89 & 0.0063 & & & \\
\hline \multirow[t]{2}{*}{$\begin{array}{l}58 \text { Steering \& } \\
\text { Hydroplane Gear } \\
\end{array}$} & Flaps & 102.06 & & & & 0.0887 \\
\hline & Totals & 153 & 0.0129 & 0.0000 & 0.0000 & 0.1659 \\
\hline
\end{tabular}

Table 26 - Group 5 Auxiliary systems mass and volume breakdown 


\begin{tabular}{ll|ccccc}
\hline GROUP 6 & Outfit \& Furnishings & Mass & Vensory & Motor & Jet \\
& & $(\mathrm{kg})$ & $\left(\mathrm{m}^{3}\right)$ & $\begin{array}{c}\text { External } \\
\left(\mathrm{m}^{3}\right)\end{array}$ & $\left(\mathrm{m}^{3}\right)$ & $\left(\mathrm{m}^{3}\right)$ \\
\hline 62 Hull Fittings & Navigation Lights & 2.84 & & & 0.0005 \\
\hline & Totals & 3 & $\mathbf{0 . 0 0 0 0}$ & $\mathbf{0 . 0 0 0 0}$ & $\mathbf{0 . 0 0 0 0}$ & $\mathbf{0 . 0 0 0 5}$ \\
\hline
\end{tabular}

Table 27 - Group 6 Outfit \& Furnishings mass and volume breakdown

\begin{tabular}{ll|ccccc}
\hline FROUP 7 & Mass & \multicolumn{3}{c}{ Volume } \\
& Sixed Ballast & $(\mathrm{kg})$ & $\begin{array}{c}\text { Sensory } \\
\left(\mathrm{m}^{3}\right)\end{array}$ & $\begin{array}{c}\text { Motor } \\
\left(\mathrm{m}^{3}\right)\end{array}$ & $\begin{array}{c}\text { Jet } \\
\left(\mathrm{m}^{3}\right)\end{array}$ & $\begin{array}{c}\text { External } \\
\left(\mathrm{m}^{3}\right)\end{array}$ \\
\hline Fixed Ballast External & 0.00 & & & & 0.000 \\
& Fixed Ballast Internal & 50.51 & 0.152 & & & \\
\hline Totals & $\mathbf{5 1}$ & $\mathbf{0 . 1 5 2}$ & $\mathbf{0 . 0 0 0}$ & $\mathbf{0 . 0 0 0}$ & $\mathbf{0 . 0 0 0}$ \\
\hline
\end{tabular}

Table 28 - Group 7 Ballast mass and volume breakdown

\begin{tabular}{|c|c|c|c|c|c|c|}
\hline \multirow[b]{2}{*}{ GROUP 8} & \multirow[b]{2}{*}{ Variable Items } & \multirow[b]{2}{*}{$\begin{array}{c}\text { Mass } \\
\text { (kg) }\end{array}$} & \multicolumn{4}{|c|}{ Volume } \\
\hline & & & $\begin{array}{c}\text { Sensory } \\
\left(\mathrm{m}^{3}\right)\end{array}$ & $\begin{array}{c}\text { Motor } \\
\left(\mathrm{m}^{3}\right)\end{array}$ & $\begin{array}{l}\text { Jet } \\
\left(\mathrm{m}^{3}\right)\end{array}$ & $\begin{array}{c}\text { External } \\
\left(\mathrm{m}^{3}\right)\end{array}$ \\
\hline \multirow[t]{8}{*}{90 Variable Load Items } & Gateway Buoy & 18.66 & & & & 0.039 \\
\hline & Expendable Mine Neutralization & 9.37 & & & & 0.009 \\
\hline & Air in HP Air Bottles & 14.91 & & & & 0.000 \\
\hline & External Aircraft Fuel & 195.37 & & & & 0.245 \\
\hline & Internal Aircraft Fuel & 53.70 & 0.067 & & & \\
\hline & Variable Payload Internal & 103.02 & 0.055 & & & \\
\hline & Variable Payload External & 103.02 & & & & 0.099 \\
\hline & Compensation Tanks & 23.37 & 0.172 & & & \\
\hline \multirow[t]{3}{*}{$\begin{array}{l}95 \text { Water in Main } \\
\text { Ballast Tanks }\end{array}$} & Ballast Tank 1 & $1,779.75$ & & & & 1.736 \\
\hline & Ballast Tank 2 & $1,779.75$ & & & & 1.736 \\
\hline & Totals & 4081 & 0.294 & 0.000 & 0.000 & 3.865 \\
\hline
\end{tabular}

Table 29 - Group 8 Loads mass and volume breakdown 


\section{Center of gravity}

The following tables summarize the center of gravity of each sub-system within U3V.

\begin{tabular}{ll|ccc}
\hline \multirow{2}{*}{ GROUP 1 } & Structure & $\begin{array}{c}\text { LCG } \\
(\mathrm{m})\end{array}$ & $\begin{array}{c}\text { TCG } \\
(\mathrm{m})\end{array}$ & $\begin{array}{c}\text { VCG } \\
(\mathrm{m})\end{array}$ \\
\hline $\mathbf{1 0}$ Pressure Hull & Main Pressure Hull Shell & 1.58 & 0.00 & 1.13 \\
& Jet Engine Hull Shell & 1.40 & 0.00 & 2.15 \\
& Propulsor Pressure Hull Shell & 1.10 & 0.00 & 0.46 \\
& Jet Engine Sealing Mechanism Fwd & 0.70 & 0.00 & 2.02 \\
& Jet Engine Sealing Mechanism Aft & 2.10 & 0.00 & 2.02 \\
& Wing structure & 1.98 & 0.00 & 1.48 \\
& External Floating Hulls & 2.50 & 0.00 & 0.60 \\
& Internal Support Structure & 1.98 & 0.00 & 1.48 \\
\hline & Totals & $\mathbf{2 . 0 1}$ & $\mathbf{0 . 0 0}$ & $\mathbf{1 . 3 1}$ \\
\hline
\end{tabular}

Table 30 - Group 1 Structure center of gravity location

\begin{tabular}{ll|ccc}
\hline \multirow{2}{*}{ GROUP 2} & Propulsion & $\begin{array}{c}\text { LCG } \\
(\mathrm{m})\end{array}$ & $\begin{array}{c}\text { TCG } \\
(\mathrm{m})\end{array}$ & $\begin{array}{c}\text { VCG } \\
(\mathrm{m})\end{array}$ \\
\hline \multirow{2}{*}{ 25 Insulation \& Fluids in Propulsion Machinery } & Fuel Trunking from Tanks to Engine & 1.40 & 0.00 & 2.15 \\
26 Main Machinery & Jet Engine & 1.40 & 0.00 & 2.15 \\
& Jet Starter & 1.40 & 0.00 & 2.15 \\
\multirow{2}{*}{ Electrical Propulsion Equipment \& Systems } & Motors (internal) & 1.10 & 0.00 & 0.46 \\
& Propeller (external) & 1.10 & 0.00 & 0.07 \\
& Main Batteries & 1.26 & 0.00 & 1.27 \\
\hline
\end{tabular}

Table 31 - Group 2 Propulsion center of gravity location

\begin{tabular}{ll|ccc}
\hline GROUP 3 & Cabling & $\begin{array}{c}\text { LCG } \\
(\mathrm{m})\end{array}$ & $\begin{array}{c}\text { TCG } \\
(\mathrm{m})\end{array}$ & $\begin{array}{c}\text { VCG } \\
(\mathrm{m})\end{array}$ \\
\hline $\mathbf{3 0}$ Cabling & Internal Cabling & 1.40 & 0.00 & 2.15 \\
& External Cabling & 1.98 & 0.00 & 1.48 \\
$\mathbf{3 1}$ Electrical Generating Equipment & Electrical Control Power Management System & 1.26 & 0.00 & 1.27 \\
\hline & Totals & $\mathbf{1 . 5 2}$ & $\mathbf{0 . 0 0}$ & $\mathbf{1 . 6 0}$ \\
\hline
\end{tabular}

Table 32 - Group 3 Electrical center of gravity location 


\begin{tabular}{ll|ccc}
\hline \multirow{2}{*}{ GROUP 4 } & Control, Communications and Payload & $\begin{array}{r}\text { LCG } \\
(\mathrm{m})\end{array}$ & $\begin{array}{c}\text { TCG } \\
(\mathrm{m})\end{array}$ & $\begin{array}{c}\text { VCG } \\
(\mathrm{m})\end{array}$ \\
\hline \multirow{4}{*}{ (0 Core payload } & Obstacle Avoidance and Threat Sonar & 0.45 & 0.62 & 1.88 \\
& Small Tactical Radar & 0.70 & -0.80 & 1.78 \\
& Bathymetric SAS Sonar & 2.25 & 1.46 & 1.37 \\
& Acoustic Communications & 1.26 & 0.00 & 1.27 \\
& Inertial Navigation System (INS) & 1.26 & 0.00 & 1.27 \\
& Computer & 1.26 & 0.00 & 1.27 \\
& Gimballed Camera EO/IR & 1.85 & 0.00 & 2.15 \\
& Temperature/Depth Sensor & 1.26 & 0.00 & 1.27 \\
& Pressure/Speed Sensors & 1.26 & 0.00 & 1.27 \\
& Chemical Agent Detector & 1.26 & 0.00 & 1.27 \\
\hline & Totals & $\mathbf{1 . 3 5}$ & $\mathbf{0 . 2 6}$ & $\mathbf{1 . 5 5}$ \\
\hline
\end{tabular}

Table 33 - Group 4 Control \& Communications center of gravity location

\begin{tabular}{ll|ccc}
\hline \multirow{2}{*}{ GROUP 5} & Control, Communications and Payload & $\begin{array}{c}\text { LCG } \\
(\mathrm{m})\end{array}$ & $\begin{array}{c}\text { TCG } \\
(\mathrm{m})\end{array}$ & $\begin{array}{c}\text { VCG } \\
(\mathrm{m})\end{array}$ \\
\hline $\mathbf{5 0}$ Miscellaneous & MBT Vents \& Operating Gear & 2.50 & 0.00 & 0.66 \\
& External Drains & 2.50 & 0.00 & 0.66 \\
$\mathbf{5 3}$ Water Systems & Trim, Bilge \& Ballast System & 1.48 & 1.48 & 1.48 \\
& Comp Pumps \& Starters (2) & 1.48 & 1.48 & 1.48 \\
& HP Ballast Pump \& Starter & 2.50 & 0.00 & 0.66 \\
& Depth Gauges & 1.48 & 1.48 & 1.48 \\
$\mathbf{5 5}$ Air Systems & HP Air System & 2.50 & 0.00 & 0.66 \\
& HP Air Bottles & 2.50 & 0.00 & 0.66 \\
$\mathbf{5 7}$ Trim Systems & Trim Rail System & 1.26 & 0.00 & 1.27 \\
\hline $\mathbf{5 8}$ Steering \& Hydroplane Gear & Flaps & 3.94 & 0.00 & 1.66 \\
\hline
\end{tabular}

Table 34 - Group 5 Auxiliary Systems center of gravity location

\begin{tabular}{ll|ccc}
\hline GROUP 6 & Outfit \& Furnishings & $\begin{array}{c}\text { LCG } \\
(\mathrm{m})\end{array}$ & $\begin{array}{c}\text { TCG } \\
(\mathrm{m})\end{array}$ & $\begin{array}{c}\text { VCG } \\
(\mathrm{m})\end{array}$ \\
\hline 62 Hull Fittings & Navigation Lights & 1.98 & 0.00 & 1.48 \\
\hline & Totals & $\mathbf{1 . 9 8}$ & $\mathbf{0 . 0 0}$ & $\mathbf{1 . 4 8}$ \\
\hline
\end{tabular}

Table 35 - Group 6 Outfit \& Furnishings center of gravity location 


\begin{tabular}{ll|ccc}
\hline GROUP 7 & Fixed Ballast & $\begin{array}{c}\text { LCG } \\
(\mathrm{m})\end{array}$ & $\begin{array}{c}\text { TCG } \\
(\mathrm{m})\end{array}$ & $\begin{array}{c}\text { VCG } \\
(\mathrm{m})\end{array}$ \\
\hline & Fixed Ballast External & 0.00 & 0.00 & 0.00 \\
& Fixed Ballast Internal & 1.26 & 0.00 & 1.27 \\
\hline Totals & $\mathbf{1 . 2 6}$ & $\mathbf{0 . 0 0}$ & $\mathbf{1 . 2 7}$ \\
\hline
\end{tabular}

Table 36 - Group 7 Ballast center of gravity location

\begin{tabular}{ll|ccc}
\hline \multirow{2}{*}{ GROUP 8 } & Variable Items & $\begin{array}{c}\text { LCG } \\
(\mathrm{m})\end{array}$ & $\begin{array}{c}\text { TCG } \\
(\mathrm{m})\end{array}$ & $\begin{array}{c}\text { VCG } \\
(\mathrm{m})\end{array}$ \\
\hline 90 Variable Load & Gateway Buoy & 3.00 & -0.94 & 1.76 \\
& Expendable Mine Neutralization & 2.20 & 0.00 & 1.55 \\
& Air in HP Air Bottles & 2.50 & 0.00 & 0.66 \\
& External Aircraft Fuel & 1.61 & 0.00 & 1.52 \\
& Internal Aircraft Fuel & - & - & - \\
& Variable Payload Internal & 1.26 & 0.00 & 1.27 \\
& Variable Payload External & 1.40 & 0.00 & 2.15 \\
& Compensation Tanks & - & - & - \\
95 Water in Main & Ballast Tank 1 & - & - & - \\
Ballast Tanks & Ballast Tank 2 & - & - & - \\
\hline & Totals & $\mathbf{0 . 0 9}$ & $\mathbf{0 . 0 0}$ & $\mathbf{0 . 0 9}$ \\
\hline
\end{tabular}

Table 37 - Group 8 center of gravity location 


\section{Appendix E: External form - developing and refining in RHINO Introduction}

The external shape can be imagined as the extrusion of a three-dimensional surface over a number of cross-sections. These cross-sections are made of the combination of the airfoil sections at each station along the span, and any protuberances or bulges that are necessary to contain the various pressure hulls and other equipment. The initial external form comprised that which is described in section $0 \mathrm{Wing}-\mathrm{a}$ smooth continuation of the NACA 23018 airfoil profile with minor adjustments for the engine and hulls. The final external form makes adjustments to this based on a better understanding of the internal arrangement. Sections of the flying wing that contain little or no equipment are more slender, with a NACA 23010 cross-section. It is intended that this will reduce drag underwater with little negative impact on performance in the air and an overall reduction in void spaces.

\section{Geometry construction}

RHINO is a surface modeling software tool, and was used to build the external form. There are four cross-sections that must be imported into the RHINO software. They can be imported as points files with the *.txt extension. They are:

- NACA 23018: An airfoil with a thickness-to-chord ratio of $18 \%$. This section is used as a basis for the centerline and hull sections.

- Centerline section: This is the section that must accommodate the engine and its intake and exhaust. The basis airfoil section is NACA 23018

- Hull section: This section incorporates the basic hull that supports the craft on the water surface. The basis airfoil section is NACA 23018 since it must contain the payload tubes above the main ballast tanks.

- NACA 23010: A slender airfoil with a thickness-to-chord ratio of $10 \%$. This section is used where there is little of no internal equipment.

After import, the sections can be placed at the correct spanwise and longitudinal positions. Guidelines must be created to connect the leading and trailing edges of the sections so that the RHINO surface creation tools can work effectively. The surface creation tools used in this model are (in order of preference):

- EdgeSrf: Select any four connected lines or polylines. There are no options for this tool, and the surface edges are never exactly aligned to the selection.

- Sweep1 and Sweep2: Select a guide rail and two or more cross-sections. The cross-sections may be open or closed. The sweep functions offer a number of options that can reduce inaccuracy, and one can impose a tangency condition to other nearby surfaces.

- Loft: Select two or more cross-sections. Loft does not need a guide rail, but it can introduce torsion in the surface that makes it an unattractive option.

The upper and lower surfaces were produced separately. Simple surfaces, where an airfoil section extrudes onto another airfoil section, were completed with EdgeSrf. Where possible, EdgeSrf was also employed for more complex surfaces incorporating 
engine or hulls. When this was not possible (for example, the upper surface above each hull), Sweep1 or Sweep2 were used.

It was necessary to join the surfaces in a specific sequence to prevent joining failure in RHINO. The upper surfaces were linked together first, following by the lower surfaces. This resulted in a relatively simple join between the combined upper surface and lower surface. The outer end was capped with a simple Loft comprising the end section and a small polyline. After joining the cap to the combined upper and lower surfaces, the half-wing is reflected along the longitudinal axis to complete the full span. 


\section{Appendix F: Aircraft survey}

Table 38 shows some of the aircraft surveyed for the purposes of airfoil selection. Some of these aircraft are not pure flying wings, but each has been included because they share some of the properties of this concept such as form, size, speed or other performance. In particular, the Northrop N-1M (on display at the Udvar-Hazy Air and Space Museum and one of the first such flying wings) has a similar size and planform to this concept.

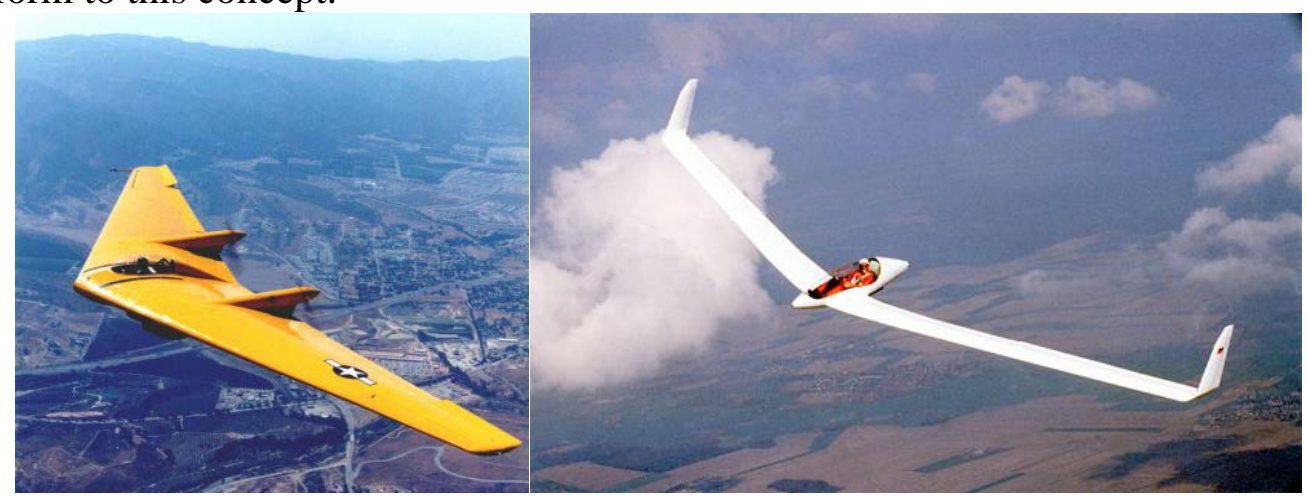

Figure 65 - The Northrop N-1M (left) and Akaflieg SB13 (right) 


\begin{tabular}{|c|c|c|c|c|}
\hline Name & $\begin{array}{c}\text { Gross } \\
\text { weight } \\
(\mathrm{kg})\end{array}$ & $\begin{array}{l}\text { Max. } \\
\text { speed } \\
(\mathrm{km} / \mathrm{h})\end{array}$ & $\begin{array}{l}\text { Wing } \\
\text { area } \\
(\mathrm{m} 2)\end{array}$ & $\begin{array}{c}\text { Wing } \\
\text { loading } \\
(\mathrm{kg} / \mathrm{m} 2)\end{array}$ \\
\hline Akaflieg SB13 & 427 & Low & 11.6 & 37 \\
\hline Armstrong Whitworth A.W.52 & 15,490 & 805 & 122 & 121 \\
\hline Baynes Bat & 437 & Low & 15 & \\
\hline \multicolumn{5}{|l|}{ Brochocki BKB-1 } \\
\hline Fauvel AV.36 & 225 & 180 & 14 & \\
\hline Arup 2 & $\begin{array}{c}354 \\
\text { (empty) }\end{array}$ & 156 & 20 & \\
\hline Hoffman 1934 flying wing & $\begin{array}{c}408 \\
\text { (empty) }\end{array}$ & 217 & 22 & \\
\hline \multicolumn{5}{|l|}{ Horten H.I - HVI } \\
\hline Horten Ho 229 & 8,100 & 977 & 50 & 138 \\
\hline Kasper Bekas & 249 & 107 & 15 & 17 \\
\hline Marske Monarch & 204 & 64 & 17 & 12 \\
\hline Marske Pioneer & 318 & 230 & 18 & 18 \\
\hline Mitchell U-2 Superwing & 249 & 42 & 13 & 20 \\
\hline \multicolumn{5}{|l|}{ Northrop B-2 Spirit } \\
\hline Northrop N-1M & 1,769 & 320 & 33 & \\
\hline Northrop N-9M & 6,326 & 415 & 46 & \\
\hline Northrop YB-49 & 87,969 & 793 & 372 & 163 \\
\hline Northrop XP-79 Flying Ram & 3,932 & 880 & 26 & 153 \\
\hline
\end{tabular}

Table 38 - Survey of flying wing aircraft for airfoil selection 


\section{Appendix G: Airfoil down selection}

Figure 66 shows typical results of an alpha sweep, with each of the airfoils overlaid. The graphs show the relationship between angle of attack, section lift coefficient (lift per unit span), section drag coefficient and section pitching moment.
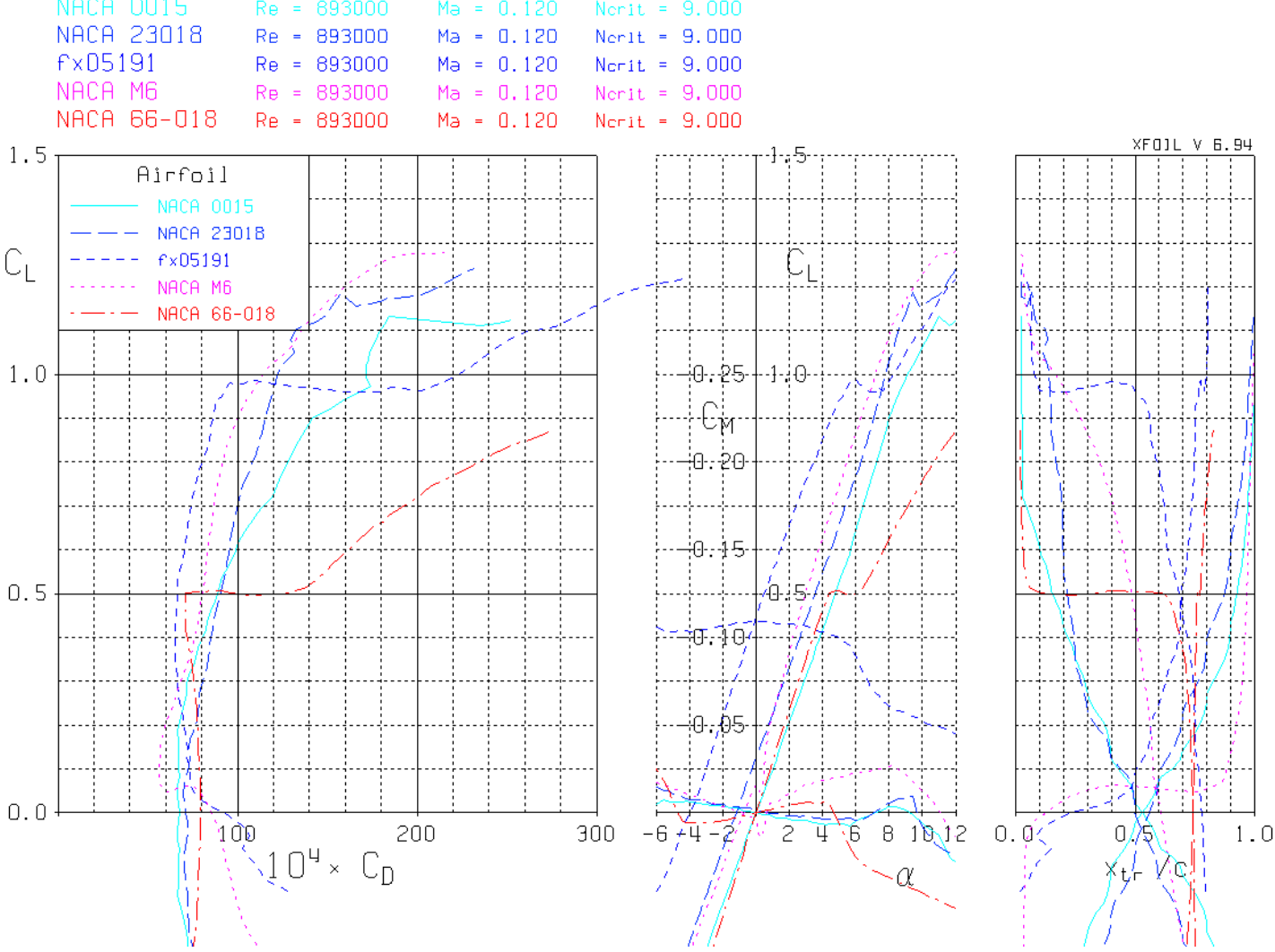

Figure 66 - Typical XFOIL alpha sweep output

Table 39 illustrates the component parts used to reach a value of merit to assist in down-selecting the airfoil.

\begin{tabular}{|c|c|c|c|c|c|c|c|}
\hline Airfoil & $\begin{array}{l}\mathrm{CL} \text { at } 2^{\circ} \\
\text { (air) }\end{array}$ & $\begin{array}{l}\mathrm{CL} \text { at } 8^{\circ} \\
\text { (air) }\end{array}$ & $\begin{array}{l}\mathrm{CD} \text { at } 8^{\circ} \\
\text { (air) }\end{array}$ & $\begin{array}{c}\text { Shape } \\
\text { suitable? } \\
(15)\end{array}$ & $\begin{array}{c}\text { Alpha @ CL=0 } \\
\text { (deg) }\end{array}$ & $\begin{array}{c}\mathrm{CM} @ \\
\mathrm{CL}=0\end{array}$ & $C D @ C L=0$ \\
\hline NACA 0015 & 0.2 & 0.9 & 0.014 & 4 & 0 & 0 & 0.006 \\
\hline NACA 23018 & 0.32 & 1.05 & 0.013 & 4 & -1.2 & 0 & 0.006 \\
\hline Wortmann FX 05-191 & 0.65 & 1.03 & 0.024 & 3 & -4 & -0.11 & 0.004 \\
\hline NACA M6 & 0.36 & 0.98 & 0.011 & 1 & -0.8 & 0 & 0.0046 \\
\hline NACA 66-018 & 0.24 & 0.62 & 0.017 & 4 & 0 & 0 & 0.0075 \\
\hline Normalizing & val/max. & vallmax. & $(1-v a l) / \max$. & val/max. & - vallmin. & - val/min. & $(1-v a l) / \max$. \\
\hline Weighting (/3) & 2 & 3 & 2 & 2 & 2 & 1 & 2 \\
\hline
\end{tabular}

Table 39 - Calculating the relative merit of five airfoils (air categories) 


\section{Appendix H: Air propulsion drag - hump resistance}

Given the wing lift coefficient, wing area and maximum take-off weight, the take-off speed can be calculated by rearranging the equation for wing lift coefficient:

Equation 24

$$
C_{L, w}=\frac{L}{\frac{1}{2} \rho U^{2} S} \rightarrow U=\sqrt{\frac{L}{\frac{1}{2} \rho S}}
$$

Knowing the getaway speed, one can estimate that hump resistance occurs at approximately a speed ratio $V / V_{G}=0.5$. The aerodynamic lift at the hump speed can be added to the hydrodynamic lift from the planing hulls. The hydrodynamic lift depends in part on the length and beam of the submerged hull. For simplicity in the sizing and balancing phase, we assume that length is half its value at rest. This means that the beam can be calculated from the block coefficient and draft to beam ratio:-

$$
\begin{array}{ll}
\text { Equation 25 } & L_{\text {hump }}=0.5 \times L_{0} \\
\text { Equation 26 } & B\left(\frac{V}{V_{g}}\right)=\frac{B_{0}}{B_{0}+T_{0}} \frac{\Delta-\text { Lift }_{\text {aero }}-\text { Lift }_{\text {hydro,assumed }}}{C_{b} L_{\text {hump }}}
\end{array}
$$

In the equations, " $L$ " refers to length and "Lift" refers to the lift generated either aero- or hydrodynamically. At this point, the hydrodynamic lift must be assumed, and can be compared to the actual result - if necessary, the assumed value is changed until it matches the calculation.

The lift of a V-shaped planing hull can be taken to be a modification of the value for a flat plate. The flat plate lift coefficient depends upon the length to beam ratio, trim, the 'speed coefficient' and deadrise. The speed coefficient is similar to the Froude number, except that the characteristic length is the beam (customary in the study of planing):

$$
\text { Equation 27 } \quad C_{v}=\frac{V}{\sqrt{g B}}
$$

The empirical expression used for flat plate lift and the modification for a planing hull of given deadrise are in Equation 28 and Equation 29. The hydrodynamic lift can be calculated from the resulting coefficient.

\section{Equation 28}

$$
C_{L o}=\tau^{1.1}\left[0.0120 \lambda^{0.5}+0.0095\left(\lambda / C_{v}\right)^{2}\right]
$$

\section{Equation $29 \quad C_{L \beta}=C_{L 0}-0.0065 \beta C_{L 0}^{0.6}$}

To summarize, the aerodynamic lift has been deducted from the take-off displacement. This displacement is modified for an assumed hydrodynamic lift, after which the actual lift is calculated using empirical relations. This is necessary to permit working out the portion of the hull that remains submerged.

Next, the combined resistance in water and air can be determined. In water, the resistance can be described as the summation of flat-plate equivalent skin friction plus an element that is a function of the lift coefficient and trim. Having already obtained the lift coefficient, the skin friction coefficient may be calculated as: 


$\begin{array}{ll}\text { Equation } 30 & C_{f}=\frac{0.455}{(\log \mathrm{Re})^{2.58}} \\ \text { Equation 31 } & C_{D}=C_{L} \tan \tau+C_{f} \sec \beta\end{array}$

A first order approximation of aerodynamic drag can be made using a wing lift-drag ratio for similar blended wing body aircraft. 


\section{Appendix I: Turbojet pressure hull sealing mechanism}

To determine the torque required at the pivot point where the end caps (doors) meet the cylindrical section of the PV; the total weight of the door and the distance from the pivot to the point of action (assumed to be the center of the door, or the radius of the pressure hull, at $0.27 \mathrm{~m}$ ) were used to find the moment. The mass of the door $(10 \mathrm{~kg})$ was calculated using flat plate bending calculations to withstand the hydrostatic pressure when submerged at U3V's operating depth (50m). A $40 \%$ mass margin was used to take account of features that would be added to form a hydrodynamic interface with the outer flow; equating to a mass of $14 \mathrm{~kg}$. This additional material required to streamline the body underwater is illustrated in Figure 67.
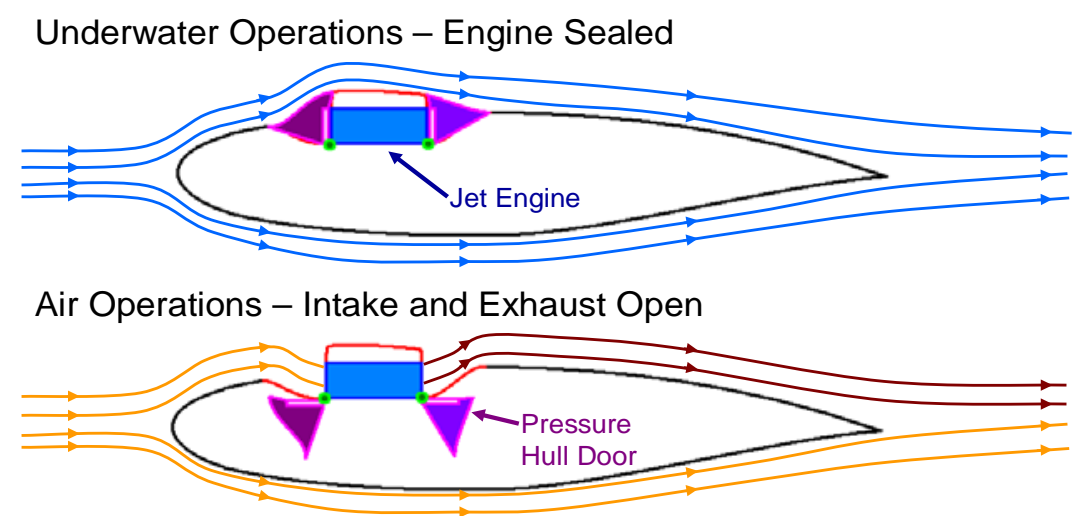

Figure 67 - Streamlining of the body using the sealing mechanism

Figure 67 is merely a sketch. Hence, it is without scale, is dimensionally inaccurate and streamlines presented are not representative of actual physical flow.

Additional mass was assumed, this included; the locking mechanism and the lever arm each at $10 \mathrm{~kg}$. This generated a torque of around $90 \mathrm{Nm}$. The speed the door would close was chosen at $9 \mathrm{deg} / \mathrm{s}$ (1.5 RPM); hence taking 10 seconds for the door to close completely.

The worm drive was selected at a 25:1 ratio, between the worm gear and worm. Hence, the motor would need to operate at $37.5 \mathrm{RPM}$, at a torque of $2.51 \mathrm{Nm}$. A worm drive from Rush Gears Inc. was selected for the selected gear ratio ${ }^{26}$. The motor chosen for this operation was a step motor provided by Stoegra ${ }^{27}$ providing significant torque benefits for its small size and power requirement, illustrated in Figure 68.

\footnotetext{
${ }^{26}$ Rush Gears inc. Worm Gears - 16 DP Quad Thread. Available from: http://www.rushgears.com/catpages/c2000rush2.pdf [Accessed on 2nd July 2012

${ }^{27}$ HepcoMotion. BSP Ballscrew Premier. Available from: http://www.hepcomotion.com/en/bspballscrew-premier-pg-14-get-26 [Accessed on 2nd July 2012]
} 


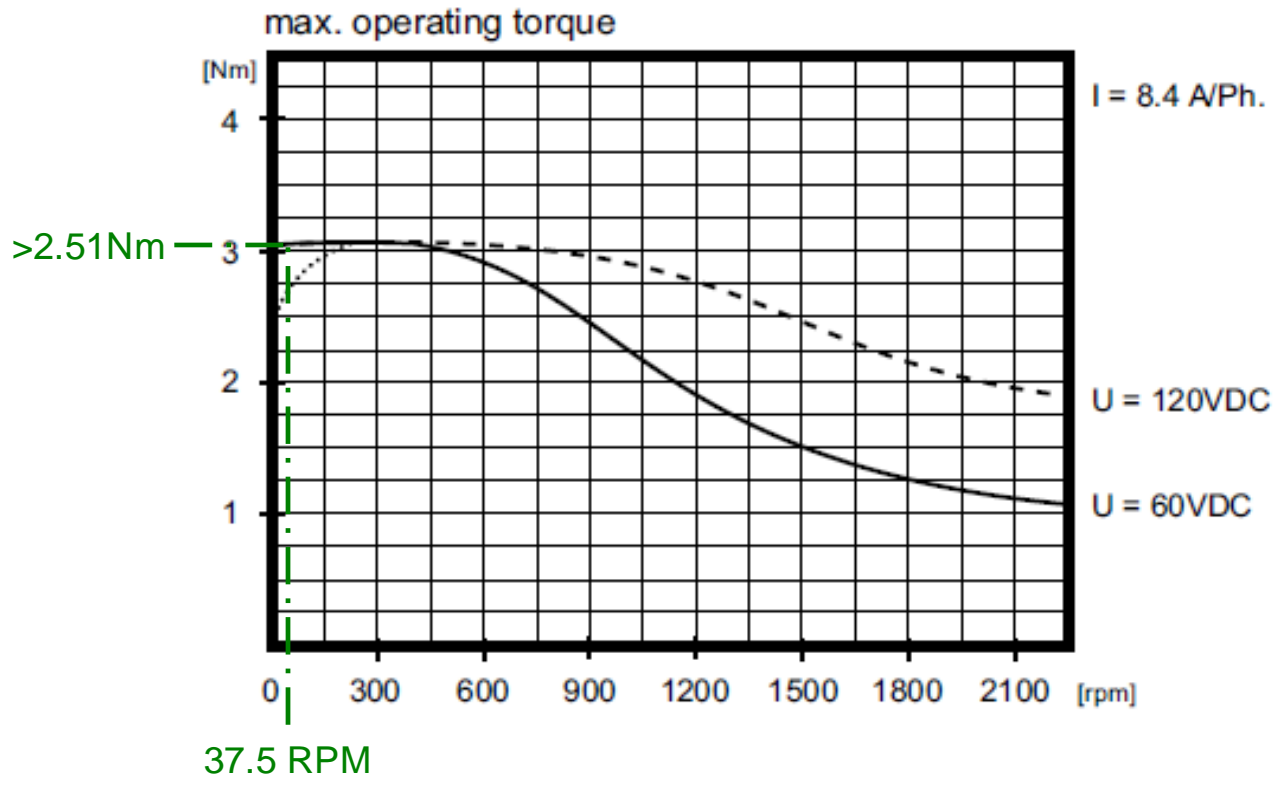

Figure 68 - Motor speed against torque for the selected step motor

The total mass per door for the sealing components, excluding the door material, was $31.88 \mathrm{~kg}$ and the volume minimal. These were integrated into the balancing model. The 12W power required for each motor, one at either end of the pressure hull, was included as part of the hotel load; used to size the batteries. 


\section{Appendix J: Fuel cell integration}

It has been voiced in recent years, that a move towards AIP methods could hold the answer for longer range and endurance for UUVs. This reduces the need for frequent launch, recharge and recovery operations; which are timely and costly. The current primary emphasis is to adopt fuel cells. Despite their advantages, a number of technical hurdles still need to be overcome; including size, safe reactant storage and heat generation.

To down select the fuel cell, what were most important to consider for the U3V was the power, ideal fuel type and operating temperature. U3V's power requirements led to only two feasible options; AFCs and DMFCs, operating at less than 10kW and $5 \mathrm{~kW}$ respectively. As can be observed, a number of the fuel cells displayed in Table 40 (including AFCs), require pure hydrogen in order to operate. For these fuel cell types, there are a number of options available for integrating this into the U3V package:

1. Store hydrogen aboard U3V and the host vessel: Common methods for achieving this include; gaseous pressurized stowage, liquid storage using cryogenics or as a metal hydride. Safety is a significant driver to not employ these features; especially in regard to gaseous and liquid storage. Not only will there be considerable risks storing hydrogen in pure form aboard the host vessel, but it would raise issues during refueling and recovery of U3V. In addition, there are a number of power and weight inefficiencies associated with these techniques.

2. Reforming traditional hydrocarbon fuels aboard the host vessel and charging U3V with pure hydrogen: Although this process improves safety aboard the host vessel, as fuels such as F-76 or bio-fuel need only be stored onboard; there remains a safety issue associated with fuelling and recovering U3V. In addition, despite not having to accommodate extra storage space and systems to manage pure hydrogen; the reformer must now be located onboard the host vessel. This may not be feasible given the power, weight and space requirements. There remains a safety issue when refueling and recovering U3V.

3. Reform traditional hydrocarbons aboard U3V: This removes the pure hydrogen storage issue completely. However, managing a reformer aboard U3V will significantly increase the weight and volume of the vehicle. The safety problems remain when recovering U3V. 


\section{Fuel cell variations}

A number of fuel cell variations exist; some of these are summarized in Table 40 [14].

\begin{tabular}{|c|c|c|c|c|c|c|c|}
\hline Property & $\begin{array}{l}\text { Alkali Fuel } \\
\text { Cells } \\
\text { (AFC) }\end{array}$ & $\begin{array}{l}\text { Polymer Exchange } \\
\text { Membrane (PEM) }\end{array}$ & $\begin{array}{l}\text { Direct Methanol } \\
\text { Fuel Cells } \\
\text { (DMFC) }\end{array}$ & $\begin{array}{c}\text { High Temperature } \\
\text { PEM } \\
\text { (HTPEM) }\end{array}$ & $\begin{array}{l}\text { Phosphoric } \\
\text { Acid (PAFC) }\end{array}$ & $\begin{array}{l}\text { Molten- } \\
\text { Carbonate } \\
\text { (MCFC) }\end{array}$ & $\begin{array}{l}\text { Solid-Oxide } \\
\text { (SOFC) }\end{array}$ \\
\hline Ideal Fuel & $\begin{array}{l}\text { Hydrogen and } \\
\text { Oxygen }\end{array}$ & Hydrogen & Methanol & Hydrogen & Hydrogen & $\begin{array}{c}\text { Hydrogen } \\
\text { and Carbon } \\
\text { Monoxide }\end{array}$ & $\begin{array}{c}\text { Hydrogen and } \\
\text { Carbon Monoxide }\end{array}$ \\
\hline $\begin{array}{c}\text { Power Range per } \\
\text { Stack }\end{array}$ & $<10 \mathrm{~kW}$ & $<250 \mathrm{~kW}$ & $<5 \mathrm{~kW}$ & $<250 \mathrm{~kW}$ & $<500 \mathrm{~kW}$ & $<500 \mathrm{MW}$ & $<500 \mathrm{~kW}$ \\
\hline $\begin{array}{c}\text { Nominal Operating } \\
\text { Temperature } \\
\text { Theoretical }\end{array}$ & $\begin{array}{c}50-250^{\circ} \mathrm{C}\left(90^{\circ} \mathrm{C}\right. \\
\text { typical })\end{array}$ & $50-100^{\circ} \mathrm{C}$ & $25-120^{\circ} \mathrm{C}$ & $150-220^{\circ} \mathrm{C}$ & $150-220^{\circ} \mathrm{C}$ & $600-700^{\circ} \mathrm{C}$ & $700-1000^{\circ} \mathrm{C}$ \\
\hline $\begin{array}{l}\text { Efficiency (Fuel cell } \\
\text { and ideal fuel only) }\end{array}$ & $45-55 \%$ & $35-50 \%$ & $30-35 \%$ & $40-55 \%$ & $36-50 \%$ & $50-55 \%$ & $45-60 \%$ \\
\hline
\end{tabular}

Table 40 - Fuel cell candidates 
DMFCs on the other hand, require only methanol as a fuel. Compared to hydrogen, methanol is far more straightforward to accommodate and operate aboard the host vessel. Refueling and recovery is also less of a safety risk. Therefore, the safety and technical challenges associated with AFCs, as well as the high operating temperatures, meant that DMFCs were the more desirable option. As a result of this short study, DMFCs were investigated further.

\section{Sizing the DMFCs}

Little data could be found on gravimetric and volumetric power densities of DMFCs. Research of existing DMFCs led to two options. The first was developed by Daimler and showcased aboard a Go-Kart style racing buggy [15] and the second was produced by Oorja and is used for powering Class 3 material handling vehicles ${ }^{28}$. Little information was publically available for the former. As a result, the study used solely information based upon the Oorja product.

The Oorja DMFC system is pictured in Figure 69 and again in Figure 70 on a Class 3 material handler to provide a sense of scale. It operates by keeping the vehicle's onboard batteries at a constant state of charge; with the primary reason to eliminate the need for battery charging or swapping out batteries. It was assumed that these units are self-contained fuel cell systems; hence they include all ancillaries required to operate, not only the fuel cell stack.

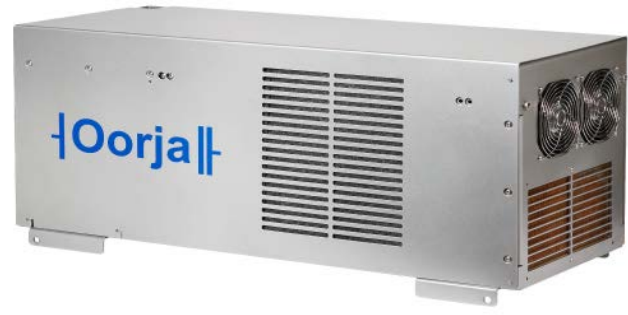

Figure 69 - DMFC by Oorja

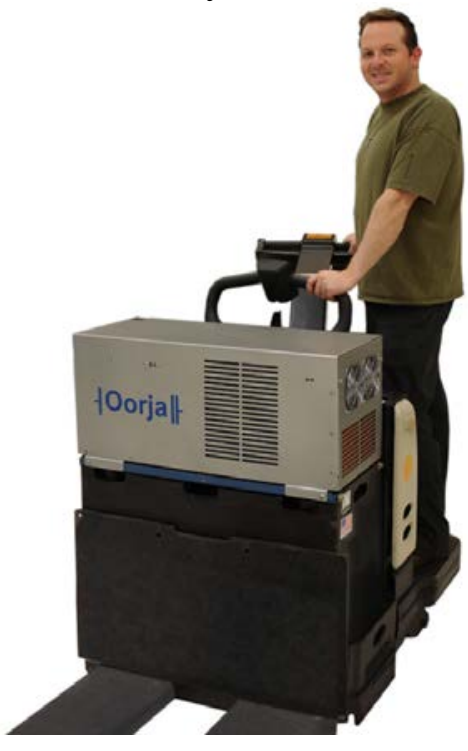

Figure 70 - Material handler powered by an Oorja DMFC

The unit provides $20 \mathrm{kWh} /$ day; at a power of $1.5 \mathrm{~kW}$. This equates to an operating time of around 13 hours. Specifications state a fuel tank capacity of 12 liters, which lasts for between 12 and 16 hours. The operating time of 13 hours (which lies between 12 and 16 hours) was used to generate a SFC using the following equation:

Equation 32

$$
S F C=\frac{V_{\text {methanol }} \rho_{\text {methanol }}}{E_{D M F C} T_{\text {drain }}}
$$

\footnotetext{
${ }^{28}$ Oorja. OorjaPac Model III. Available from:

http://www.oorjaprotonics.com/PDF/OorjaPac_Model_III_Product_Sheet.pdf [Accessed on 2nd July 2012]
} 
Where:

$V_{\text {methanol }}$ : Volume of methanol $\left(0.012 \mathrm{~m}^{3}\right)$

$\rho_{\text {methanol: }}$ Density of methanol $\left(791 \mathrm{~kg} / \mathrm{m}^{3}\right)$

$E_{D M F C}$ : Delivered energy by the fuel cell (20kWh/day)

$T_{\text {drain }}$ : Time taken to use 12 liters of methanol (0.56 days)

The SFC of the DMFC was calculated as $0.85 \mathrm{~kg} / \mathrm{kWh}$. The unit is 30.5 ” by 12.75 ” by $13.5^{\prime}\left(0.086 \mathrm{~m}^{3}\right)$ and weighs $170 \mathrm{lbs}(79 \mathrm{~kg})$. Using this information, the volumetric and gravimetric power densities were calculated as $17 \mathrm{~kW} / \mathrm{m}^{3}$ and $19 \mathrm{~W} / \mathrm{kg}$ respectively.

Using a 2.70kW power requirement, 95\% efficiency (as a result of electrical losses) and the volumetric and gravimetric power densities previously quoted, the volume and mass of the DMFC system was found to be $0.16 \mathrm{~m}^{3}$ and $150 \mathrm{~kg}$ respectively. Two of the COTS Oorja units outlined above were required.

\section{Methanol and oxidant sizing}

Methanol was sized using the following:

Equation 33

$$
M_{\text {methanol }}=S F C \times P_{\text {AIP_max }_{-}} \times \frac{\left(100+\eta_{\text {unused_margin }}\right)}{100}
$$

and

Equation 34

$$
V_{\text {methanol }}=\frac{M_{\text {methanol }}}{\rho_{\text {methanol }}}
$$

Where:

$M_{\text {methanol }}$ : Mass of methanol

$P_{\text {AIP_max }}$ : Maximum AIP power required (12kWh)

$\eta_{\text {unused_margin: }}$ Unused fuel usage margin (5\%)

Hence, the mass of methanol was $10.8 \mathrm{~kg}$ and the volume 13.6 litres.

The mass of oxygen required was calculated using the chemical reaction that takes place inside the DMFC to produce energy:

Equation 35

$$
\mathrm{CH}_{3} \mathrm{OH}+\frac{3}{2} \mathrm{O}_{2} \rightarrow 2 \mathrm{H}_{2} \mathrm{O}+\mathrm{CO}_{2}
$$

The mass ratio of oxygen to methanol is 1.5:

Equation 36

$$
\mathrm{CH}_{3} \mathrm{OH}=12+1 \times 3+16+1=32
$$

Equation 37

$$
3 / 2 \mathrm{O}_{2}=3 / 2 \times 16 \times 2=48
$$

Equation 38

$$
\frac{3 / 2 \mathrm{O}_{2}}{\mathrm{CH}_{3} \mathrm{OH}}=\frac{48}{32}=1.5
$$

Therefore, the mass of oxygen required ( $\left.M_{\text {oxygen }}\right)$ is:

$$
\text { Equation } 39 \quad M_{\text {oxygen }}=M_{\text {methanol }} \times 1.5=16.2 \mathrm{~kg}
$$

A number of storage capabilities are available for oxygen. The ones sized included liquid oxygen (LOX), compressed oxygen at 200 bar pressure and compressed air at 230 bar pressure. The volumes and calculations are summarized in Table 41. 


\begin{tabular}{|c|c|c|}
\hline Oxygen Storage Method & Calculation & $\begin{array}{l}\text { Volume (liters) } \\
\end{array}$ \\
\hline LOX & $V_{L O X}=\frac{M_{\text {oxygen }}}{\rho_{\text {LOX }}}=\frac{16.2 \mathrm{~kg}}{1.141 \mathrm{~kg} / \mathrm{l}}$ & 14.2 \\
\hline Oxygen at 200 bar & $\begin{aligned} V_{\text {oxygen_200bar }} & =\frac{M_{\text {oxygen }}}{p \rho_{\text {oxygen_as }}} \\
V_{\text {oxygen_200bar }} & =\frac{16.2 \mathrm{~kg}}{200 \mathrm{bar} \times 1.429 \mathrm{~kg} / \mathrm{m}^{3}}\end{aligned}$ & $\begin{array}{c}56.6 \\
(4 x 200 \text { bar } \\
\text { canisters, each } \\
\text { at } 15 \text { liters })\end{array}$ \\
\hline Air at $230 \mathrm{bar}$ & $\begin{aligned} V_{\text {air }} & =\frac{M_{\text {oxygen }}}{\%_{\text {oxygen_in_air }} p \rho_{\text {oxygen_gas }}} \\
V_{\text {air }} & =\frac{16.2 \mathrm{~kg}}{21 \% \times 230 \mathrm{bar} \times 1.429 \mathrm{~kg} / \mathrm{m}^{3}}\end{aligned}$ & $\begin{array}{c}235 \\
(15 x 230 \text { bar } \\
\text { canisters, each } \\
\text { at } 16 \text { liters })\end{array}$ \\
\hline
\end{tabular}

Table 41 - Sizing oxygen storage methods

LOX was disregarded from the design process, due to the added complexity of handling. Of the two methods remaining, selection was based on mass and volume. Storing oxygen as air, although simpler from a logistics viewpoint, takes up considerably more space and in terms of steel canisters alone is 3.7 times the mass of oxygen canisters. Therefore, the 200 bar oxygen canister option was selected.

\section{Final decision on DMFC}

The total mass and volume of the entire system was found to be $351 \mathrm{~kg}$ and 336 liters required respectively; this included a $10 \%$ margin for auxiliary systems. The advantages of a fuel cell did not outweigh the extra complications and issues associated with mass and volume; hence the DMFC was not used in the final design and underwater power would solely be delivered using lithium batteries. 


\section{Appendix K: Loading condition tank states}

Table 42 records hydrostatic data and loading conditions.

\begin{tabular}{l|ccc}
\hline & Trim BP (m) & Mean draft (m) & List or loll angle (deg) \\
\hline Deep & -0.258 & 0.808 & -3.161 \\
Light & -0.159 & 0.603 & -0.251 \\
& & & \\
& LCGs (m) & TCGs (m) & VCGs (m) \\
\hline Deep & 1.753 & 0.077 & 1.458 \\
Light & 1.788 & 0.091 & 1.456 \\
& & & VCB (m) \\
& LCB (m) & TCB (m) & 0.423 \\
Deep & 1.865 & 0.197 & 0.384 \\
Light & 1.865 & 0.101 & \\
& & & \\
& GMts (m) & GMls (m) & \\
\hline Deep & 4.321 & -1.139 & \\
Light & 20.577 & 1.393 & \\
\hline
\end{tabular}

Table 42 - Hydrostatic data

Compensation tanks are emptied and reduced to account for changes in onboard components. The conditions in transition are defined as:

- Deep transition: HP Air bottles full and maximum variable internal payload onboard.

- Light transition: HP Air bottles empty and no variable internal payload onboard.

For both conditions, the gateway buoy is attached to the vehicle. Deployment of the gateway buoy signifies a loss in buoyancy, hence why a residual $17 \%$ fullness in compensation tanks is preserved during deep transition.

Tank loading conditions are shown in Table 43. 


\begin{tabular}{|c|c|c|c|}
\hline & $\begin{array}{c}\text { Deep surfaced } \\
\text { (\% Tank capacity) }\end{array}$ & $\begin{array}{c}\text { Deep transition step } 1 \\
\text { (\% Tank capacity) }\end{array}$ & $\begin{array}{c}\text { Deep transition step } 2 \\
\text { (\% Tank capacity) }\end{array}$ \\
\hline Port_PV_Fwd_Port_Comp & 0 & 17 & 17 \\
\hline Port_PV_Fwd_Stbd_Comp & 0 & 17 & 17 \\
\hline Port_PV_Aft_Port_Comp & 0 & 17 & 17 \\
\hline Port_PV_Aft_Stbd_Comp & 0 & 17 & 17 \\
\hline Stbd_PV_Fwd_Port_Comp & 0 & 17 & 17 \\
\hline Stbd_PV_Fwd_Stbd_Comp & 0 & 17 & 17 \\
\hline Stbd_PV_Aft_Port_Comp & 0 & 17 & 17 \\
\hline Stbd_PV_Aft_Stbd_Comp & 0 & 17 & 17 \\
\hline Port_Ballast_1 & 0 & 100 & 100 \\
\hline Port_Ballast_2 & 0 & 0 & 70 \\
\hline Stbd_Ballast_1 & 0 & 100 & 100 \\
\hline Stbd_Ballast_2 & 0 & 0 & 70 \\
\hline Port_PV_Port_AVCAT_Comp & 100 & 100 & 100 \\
\hline Port_PV_Stbd_AVCAT_Comp & 100 & 100 & 100 \\
\hline Stbd_PV_Port_AVCAT_Comp & 100 & 100 & 100 \\
\hline Stbd_PV_Stbd_AVCAT_Comp & 100 & 100 & 100 \\
\hline Port_External_AVCAT & 100 & 100 & 100 \\
\hline \multirow[t]{2}{*}{ Stbd_External_AVCAT } & 100 & 100 & 100 \\
\hline & $\begin{array}{c}\text { Light surfaced } \\
\text { (\% Tank capacity) }\end{array}$ & $\begin{array}{l}\text { Light transition step } 1 \\
\text { (\% Tank capacity) }\end{array}$ & $\begin{array}{l}\text { Light transition step } 2 \\
\text { (\% Tank capacity) }\end{array}$ \\
\hline Port_PV_Fwd_Port_Comp & 0 & 100 & 100 \\
\hline Port_PV_Fwd_Stbd_Comp & 0 & 100 & 100 \\
\hline Port_PV_Aft_Port_Comp & 0 & 100 & 100 \\
\hline Port_PV_Aft_Stbd_Comp & 0 & 100 & 100 \\
\hline Stbd_PV_Fwd_Port_Comp & 0 & 100 & 100 \\
\hline Stbd_PV_Fwd_Stbd_Comp & 0 & 100 & 100 \\
\hline Stbd_PV_Aft_Port_Comp & 0 & 100 & 100 \\
\hline Stbd_PV_Aft_Stbd_Comp & 0 & 100 & 100 \\
\hline Port_Ballast_1 & 0 & 100 & 100 \\
\hline Port_Ballast_2 & 0 & 0 & 70 \\
\hline Stbd_Ballast_1 & 0 & 100 & 100 \\
\hline Stbd_Ballast_2 & 0 & 0 & 70 \\
\hline Port_PV_Port_AVCAT_Comp & 10 & 10 & 10 \\
\hline Port_PV_Stbd_AVCAT_Comp & 10 & 10 & 10 \\
\hline Stbd_PV_Port_AVCAT_Comp & 10 & 10 & 10 \\
\hline Stbd_PV_Stbd_AVCAT_Comp & 10 & 10 & 10 \\
\hline Port_External_AVCAT & 10 & 10 & 10 \\
\hline Stbd_External_AVCAT & 10 & 10 & 10 \\
\hline
\end{tabular}

Table 43 - Tank loading conditions 


\section{Appendix L: Wing weight fraction}

The wing weight fraction, $W_{w g} / W_{z f}$, depends upon the design limit normal maneuvering load factor through $n_{\text {ult }}=1.5 n_{\text {limit }}$. Since the wing weight is approximately $8 \%$ of the aircraft's weight it is suggested that for aircraft weights in the range where $n_{\text {limit }}$ is variable the wing weight fraction be varied with the limit normal load factor within the iteration process described previously. Torenbeek [12] offers the following equation for initially estimating the weight of the wing group:

Equation $40 \quad \frac{W_{w g}}{W_{z f}}=0.0017 n_{u l t}^{0.55} t_{r, \max }^{-0.3}\left(\frac{b}{\cos \Lambda_{c / 2}}\right)^{1.05}\left(1+\sqrt{\frac{6.25 \cos \Lambda_{c / 2}}{b}}\right)\left(\frac{W_{z f}}{S}\right)^{-0.3}$

This equation is written for lengths in feet and weights in pounds; the quantities $W_{z f}$ and $t_{r, \max }$ denote aircraft zero-fuel weight and wing root maximum thickness, respectively. A schematic diagram of the wing group and the associated notation is shown in Figure 68. This wing weight expression includes high lift devices and ailerons, but not spoilers or wing-mounted engines. These may be accounted for by increasing the wing weight given by this equation by $2 \%$ for spoilers. To account for 2 or 4 wing mounted engines reduce the wing weight by $5 \%$ or $10 \%$, respectively. The actual weight of the propulsion group, that is, the weight of the engines and associated equipment is calculated separately.

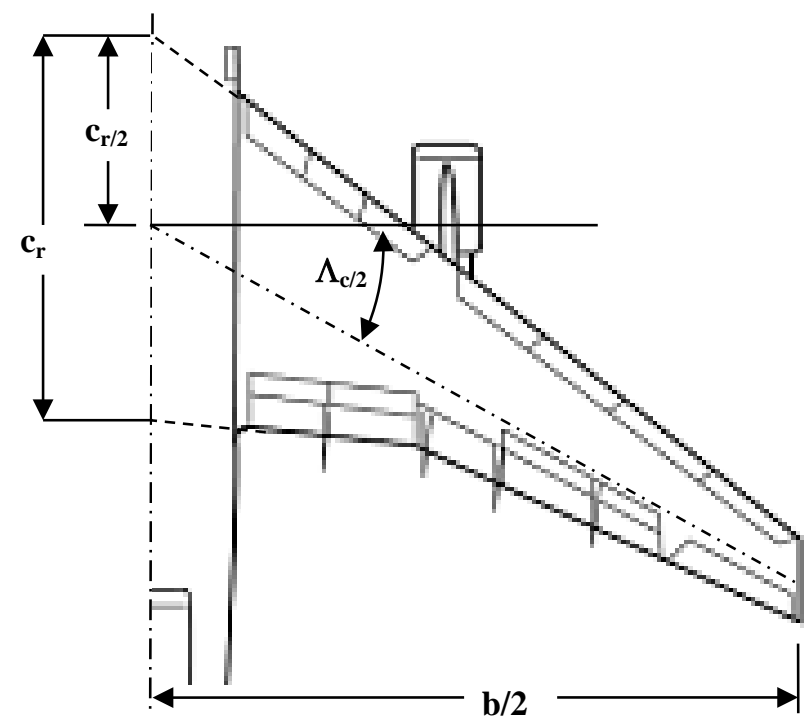

Figure 71 - Schematic diagram of the wing group and its notation 


\section{Appendix M: Water compensation system}

The required mass and volume of the ballast tanks is calculated using:

Equation 41

Equation 42

$$
M_{\text {COMP }}=\sum\left[V_{\text {VARIABLE }} \rho_{\text {SW }}-M_{\text {VARIABLE }}\right]_{\text {EXTERNAL }}
$$

$$
V_{\text {COMP }}=\left[\frac{M_{\text {VARIABLE }}}{\rho_{S W}}\right]_{\text {INTERNAL }}+\left[\frac{M_{\text {COMP }}}{\rho_{S W}}\right]
$$

Where:

$M_{\text {COMP: }}$ Compensation Mass

$V_{\text {VARIABLE }}$ : Volume of Variables

$M_{V A R I A B L E}$ : Mass of Variables

$\rho_{S W}$ : Density of Sea Water

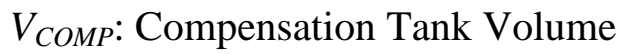

The mass of the compensation water required to be carried $\left(M_{C O M P}\right)$ is only valid for positive values of external payload. Hence, those objects are buoyant; or have a density less than that of seawater. Therefore, if these instruments are carried onboard, then water must be present in the compensation tanks to counter their buoyant effects. If these devices are deployed, then water should be pumped out of the tanks. The volumes of the tanks are sized for both the mass of this water, as well as for internal variable loads. 


\section{Appendix N: Aircraft fuel compensation system}

If the total mass of fuel ( $\left.M_{F_{-} \text {Total }}\right)$ used up has to be replaced by an equal mass of water ballast $\left(M_{F_{-} \text {Ballast }}\right)$, then:

Equation 43

$$
M_{F_{-} \text {Total }}=M_{F_{-} \text {Ballast }}
$$

If the externally stowed fuel is placed in bladders, then in the surrounding free flood space the water will displace any fuel that has been used. It can therefore be assumed; that the mass of ballast water, which equates to the total mass of fuel, is equal to the volume of the external fuel $\left(V_{F_{-} \text {External }}\right)$ multiplied by the density of seawater:

Equation 44

$$
M_{F_{-} \text {Ballast }}=M_{F_{-} \text {Total }}=V_{F_{-} \text {External }} \rho_{S_{W}}
$$

The volume and mass of external fuel $\left(M_{F_{-} E x t e r n a l}\right)$ are related by the fuel density $\left(\rho_{F}\right)$ :

Equation 45

$$
V_{F_{-} \text {External }}=\frac{M_{F_{-} \text {External }}}{\rho_{F}}
$$

Therefore:

Equation 46

$$
M_{F_{-} \text {Total }}=V_{F_{-} \text {External }} \rho_{S W}=M_{F_{-} \text {External }} \frac{\rho_{S W}}{\rho_{F}}
$$

Hence:

Equation 47

$$
M_{F_{-} \text {External }}=M_{F_{-} \text {Total }} \frac{\rho_{F}}{\rho_{S W}}
$$

Equation 48

$$
M_{F_{-} \text {Internal }}=M_{F_{-} \text {Total }}-M_{F_{-} \text {External }}
$$

Where:

$$
M_{F_{-} \text {Internal: }} \text { Mass of Internal Fuel }
$$

The total mass of fuel is known, and sized from air operation requirements. Hence, the mass, and therefore volume (using fuel density), for both the external bladder and internal tank can be sized as demonstrated above. 


\section{Appendix 0: Trim system calculations}

The solid ballast is calculated through a balancing calculation for submerged operation. Since this is insufficient in this concept to correct for the pitching moment, the volume of water required must next be calculated. In brief, the required additional water must correct for the remaining aerodynamic pitching moment. Figure 72 shows the variables that must be known to calculate the mass of water required. Note that lower case ' $m$ ' denotes masses, while upper case ' $M$ ' describes moments.

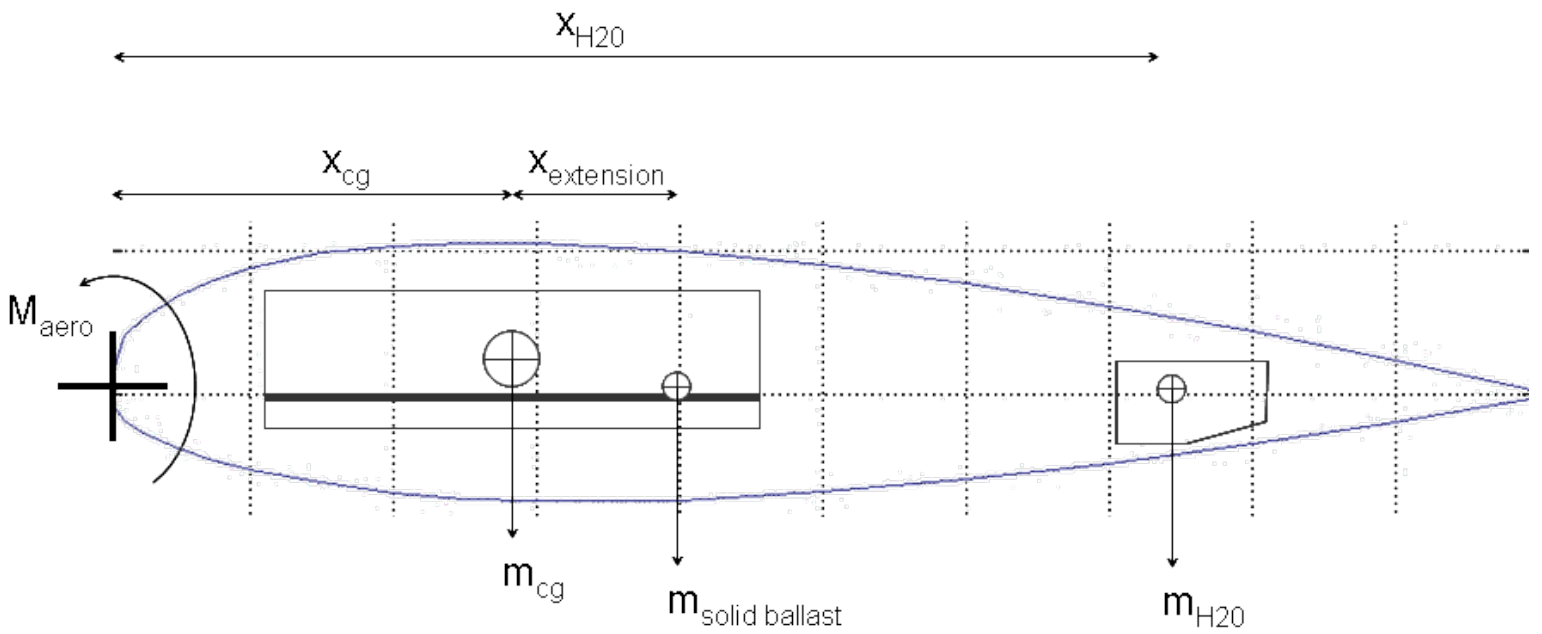

Figure 72 - Calculation of restoring forces and moments at take-off

The pitching moment curve for this state can be extracted from TORNADO. Knowing the angle of attack and flap position, the pitching moment coefficient can be extracted and redimensionalized.

Equation 49

$$
M_{\text {aero,Takeoff }}=C_{M, \text { takeoff }} \times \frac{1}{2} \rho_{\text {air }} U_{\text {takeoff }}^{2} S
$$

For zero pitching moment, the moments must sum to zero. The aerodynamic moment wishes to push the nose down, while the rest act in the opposite direction.

$$
\text { Equation } 50 \quad M_{\text {aero,Takeoff }}+M_{\text {craft }}+M_{\text {solidballast }}+M_{H 20}=0
$$

We can calculate the effect of the weight of the craft (minus moveable solid ballast and water) and the solid ballast.

Equation 51

Equation 52

$$
\begin{aligned}
& M_{\text {craft }}=m_{\text {craft }} \times X_{\text {craft }} \\
& M_{\text {solidballast }}=m_{\text {solidballast }} \times\left(x_{\text {craft }}+x_{\text {extension }}\right)
\end{aligned}
$$

Finally, the mass of water is dependent only on the center of mass of fluid, which depends on the position of the tank.

Equation 53

$$
m_{H 20}=\frac{-\left(M_{\text {aero,Takeoff }}+M_{\text {craft }}+M_{\text {solidballast }}\right)}{X_{H 2 O}}
$$

It is worth noting that there are approximations in this calculation. No correction is made for the effect of angle of attack on the moment arm. In addition, the mass of the additional water is not accounted for in the MTOW. Since the water mass is small, the result is to increase the take-off speed very slightly. 


\section{Trim in the cruise}

The center of gravity has been positioned such that no trim is required in the cruise.

However, it is expected that minor adjustments may be made by moving the solid ballast, and occasional employment of the flaperons. 


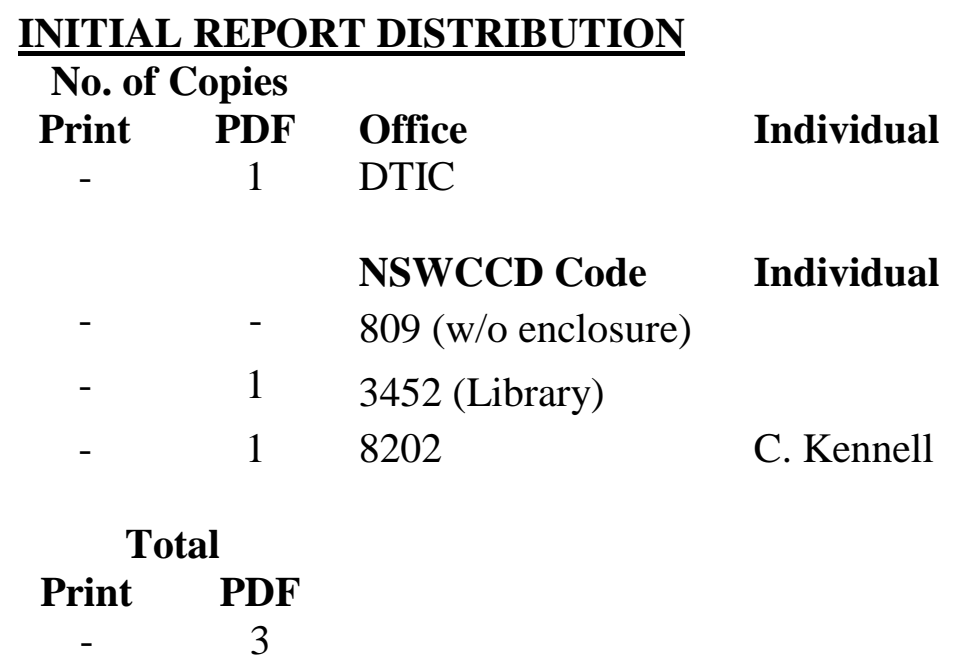



